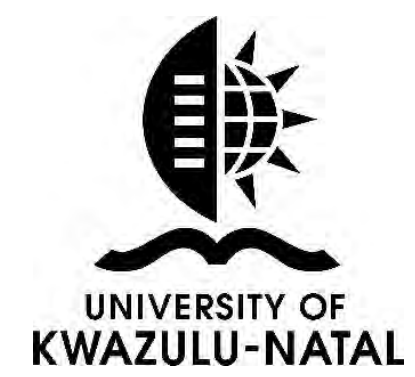

\title{
ASSESSING STUDENTS' PERCEPTIONS OF CONVERSATIONAL ISIZULU AS A \\ COMPULSORY MODULE IN A SOUTH AFRICAN UNIVERSITY
}

A dissertation submitted in partial fulfillment of the requirements of Masters in Education in the School of Education, College of Humanities, University of KwaZulu-Natal

BY

CHINEKPEBI NGOZI ANYANWU

212558676

Supervisor: Prof Ayub Sheik

December 2014 


\section{DECLARATION}

I CHINEKPEBI NGOZI ANYANWU declare that this master dissertation titled: ASSESSING STUDENTS' PERCEPTION OF CONVERSIONAL ISIZULU AS A COMPULSORY MODULE IN A SOUTH AFRICAN UNIVERSITY

(i) Is my original and independent research work, except where otherwise indicated.

(ii) This dissertation has not been submitted for any degree or examination at any other university.

(iii) This dissertation does not contain other persons' data, pictures, graphs or other information, unless specifically acknowledged as being sourced from other persons.

(iv) This dissertation does not contain other persons' writing, unless specifically acknowledged as being sourced from other researchers. Where other written sources have been quoted, then:

a) Their words have been re-written but the general information attributed to them has been referenced;

b) Where their exact words have been used, their writing has been placed inside quotation marks, and referenced.

Signed

DATE............................

\section{CHINEKPEBI NGOZI ANYANWU}

(Researcher)

I hereby declare that this dissertation has been submitted for examination with my approval

Signed.......................

DATE...................

\section{PROF AYUB SHEIK}

(Supervisor) 


\section{DEDICATION}

To

My lovely wife Adaobi, my Angelic daughter Chizitere and to my mum

Your patience and understanding help me endure the journey toward this academic achievement.

May God's blessings never leave your side! 


\section{ACKNOWLEDGEMENT}

I wish to express my sincere appreciation and gratitude to the following individuals, without whose assistance, this study would not have been possible:

- To my Mother (Lolo Kate Deca Anyanwu) whose love, motivation and belief in me got me through not only the M.Ed. program, but through rigorous life experiences. I will always be indebted to her for the support of my studies, her prayers, in-stilling discipline, her support morally and socially, and her never ending encouragement. I couldn't have done it without her.

- To my lovely Wife Adaobi and my daughter Angel, who inspired me to embark on this academic journey.

- To my supervisor, Prof Ayub Sheik for his patience and shared knowledge of linguistic concepts and scrupulous reviews of the drafts for this study. His valuable criticisms, guidance and sense of direction, support and supervision through the various stages to the completion of this thesis.

- To my siblings whom through it all showed their support.

- To Balungile Hlongwa for her clerical support which reduced the stress of working away from home. 


\section{Abstract}

This thesis is an empirical study conducted to gauge students' perceptions of conversational isiZulu module in the University of KwaZulu-Natal. Since 2014, conversational IsiZulu has become mandatory for all undergraduate students. Driven by the bilingual policy initiatives of UKZN, a total of 1287 students have registered for conversational isiZulu as a mandatory requirement for completing an undergraduate degree.

This study is an investigation in which interviews, observation and policy documents were used to gather data from students who are taking the module for the first time. Using a qualitative case study, this study investigates the learning of Conversational IsiZulu, paying attention to the classroom social context and the meanings and experiences of participants. The sample consists of 10 students from the school of Education, University of KwaZulu-Natal. Respondents were purposively selected from non-native speakers of isiZulu from the student population of 1287 who have enrolled in the module in the School of Education of UKZN. The results of the research suggests that students responded positively to learning an additional language, despite challenges experienced in the mastery of content and vocabulary amongst other aspects. This study therefore concludes that the UKZN Language Policy of eventual bilingual education is successful within the School of Education of UKZN in its initial stages of implementation. 


\section{Acronyms}

DoE: $\quad$ Department of Education

UNESCO: United Nations Educational, Scientific and Cultural Organization

LoLT: $\quad$ Language as the language of learning and teaching

UKZN: University of KwaZulu- Natal

ICELDA: The Inter-institutional Centre for Languages Development and Assessment

L1: $\quad$ First Language

L2: $\quad$ Second Language

HEI: $\quad$ Higher Education Institutions

SABC: $\quad$ South African Broadcasting Commission

LiEP: $\quad$ The Language - in- Education Policy

CALP: Cognitive Academic Language Proficiency

BICS: $\quad$ Basic Interpersonal Skills

SASA: $\quad$ South African Schools Act

UCT: $\quad$ University of Cape Town

ALRI: African Language Research Institute

PANSALB: Pan South African Language Board

NLPF: The National Language Policy Framework

NLF: $\quad$ National Language Forum 


\section{Table of Contents}

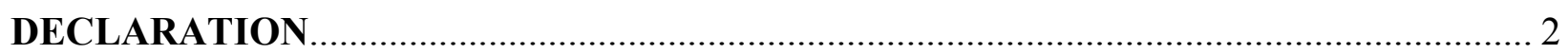

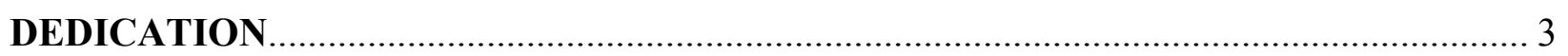

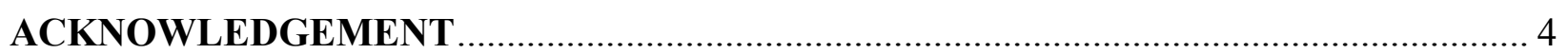

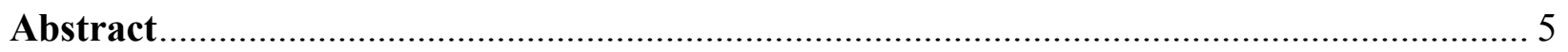

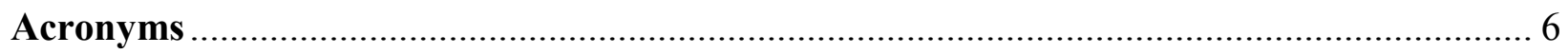

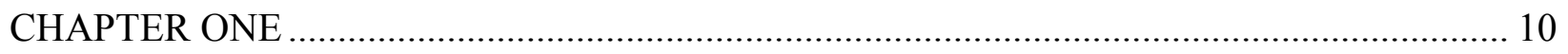

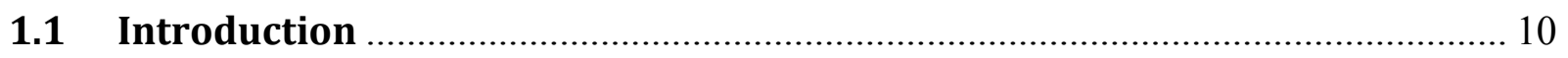

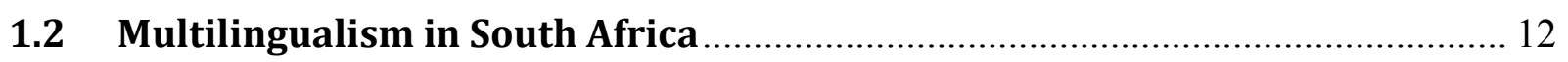

1.3 What the Language Boards are saying ......................................................... 13

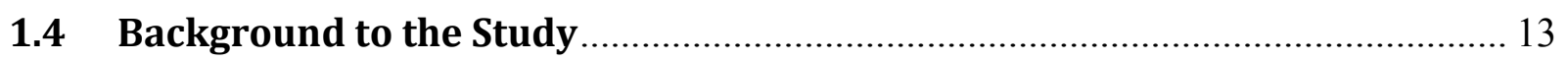

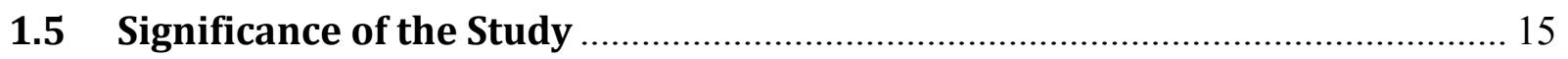

1.6 Rationale and Relevance of the Study ....................................................... 16

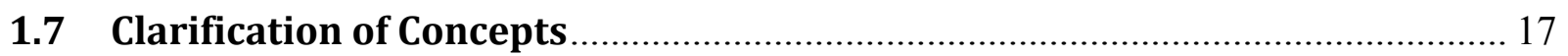

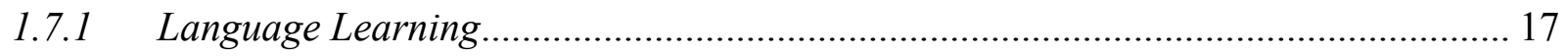

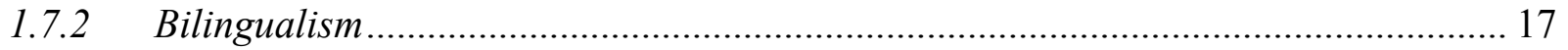

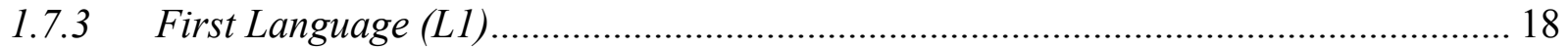

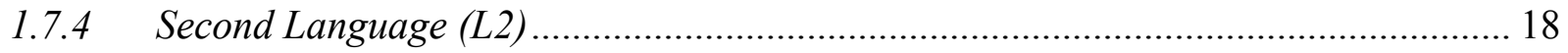

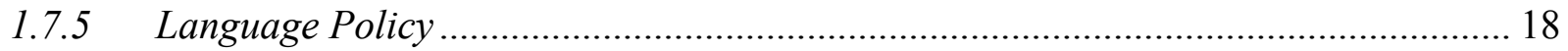

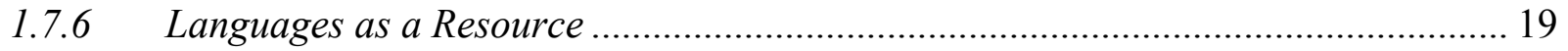

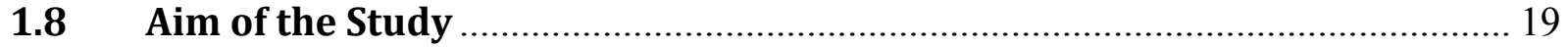

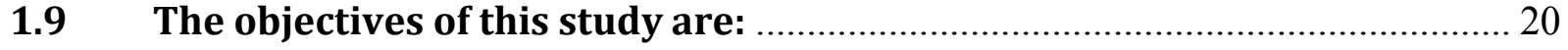

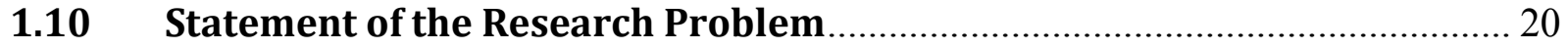

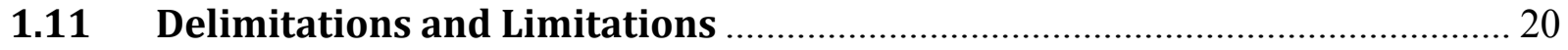

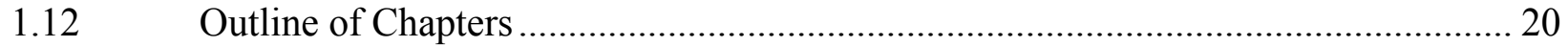

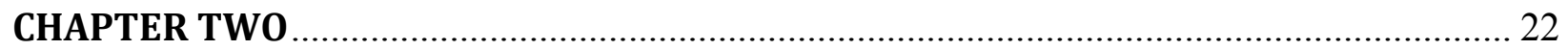

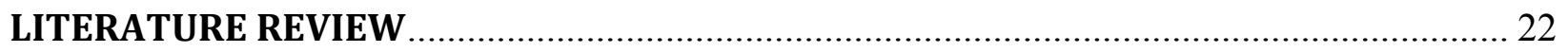

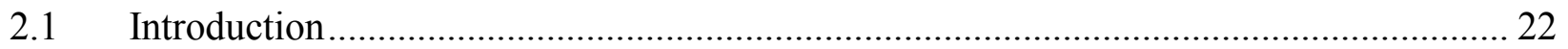

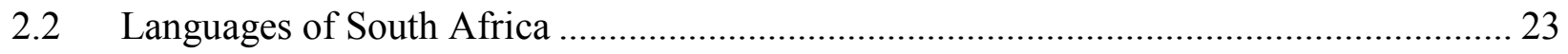

2.3 Historical Background on the use of isiZulu in South Africa...................................... 24

2.4 Marginalization of Indigenous Languages........................................................... 27

2.5 Democracy: Legitimization of Indigenous Languages .............................................. 31

2.7 Challenges faced by the Language Policy .............................................................. 46 
2.8 The Pan South African Language Board (PANSALB) and New Language Policy in South

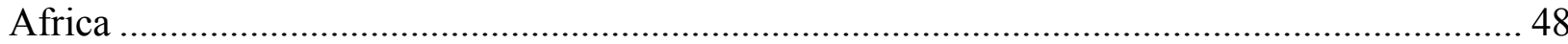

2.9 The Perception of Students towards Learning in the IsiZulu Medium............................... 52

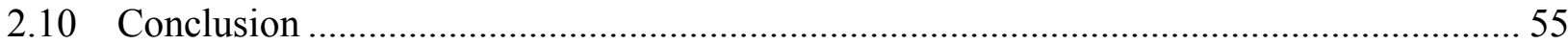

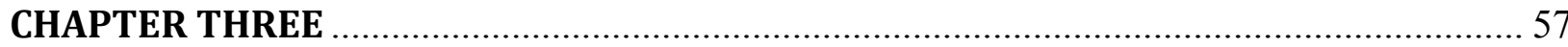

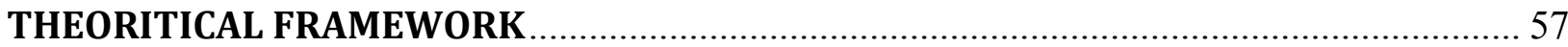

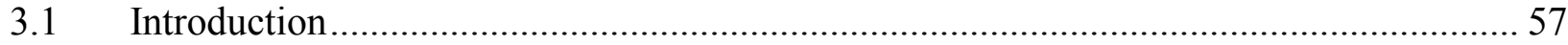

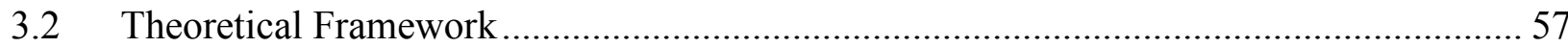

3.3 Cummins Second Language Acquisition theory .............................................................. 59

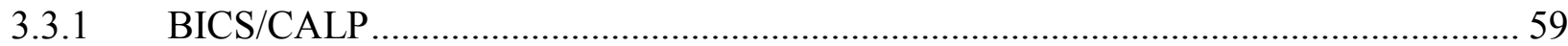

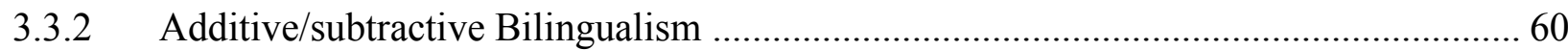

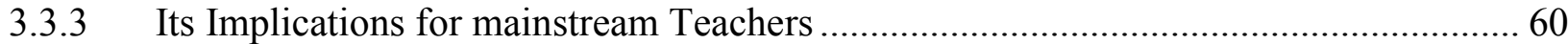

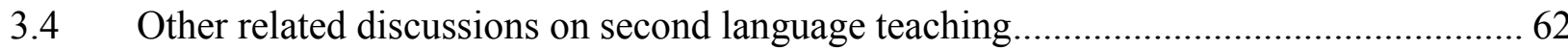

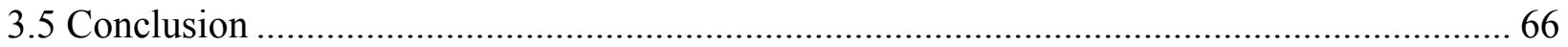

CHAPTER FOUR

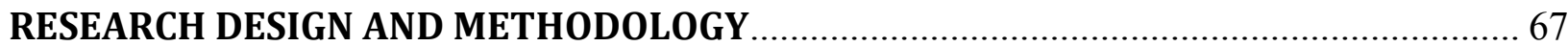

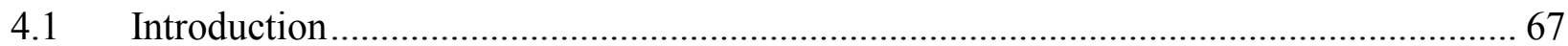

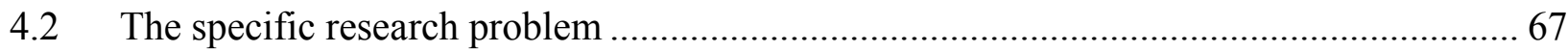

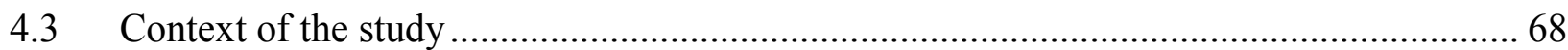

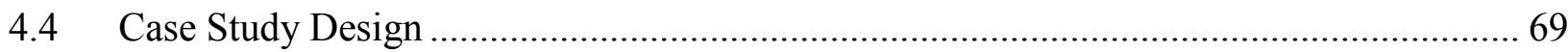

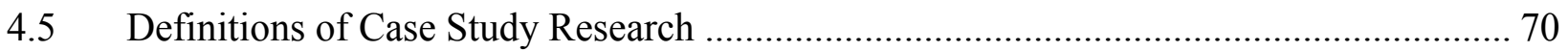

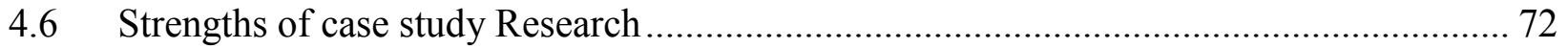

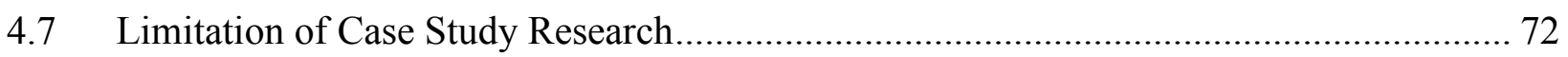

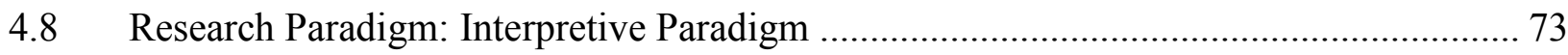

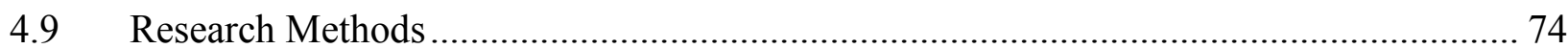

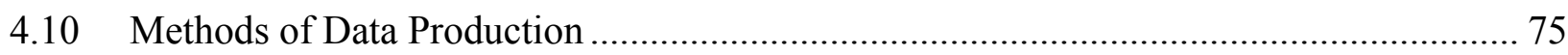

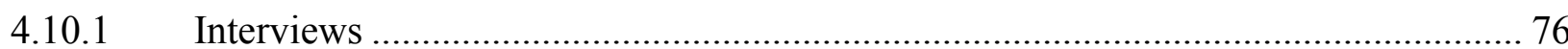

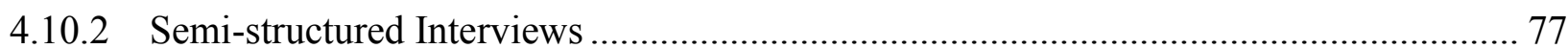

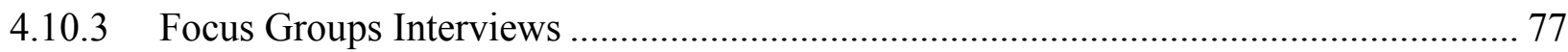

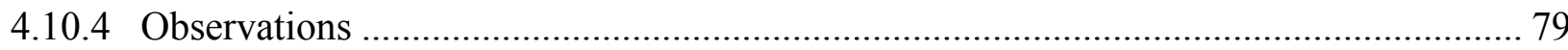

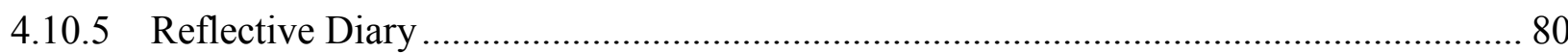

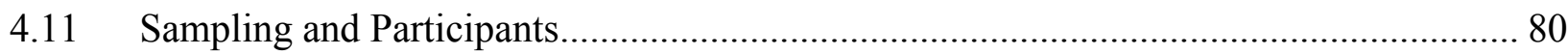

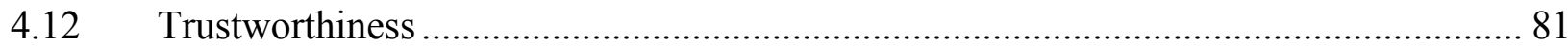

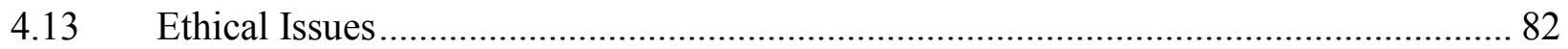




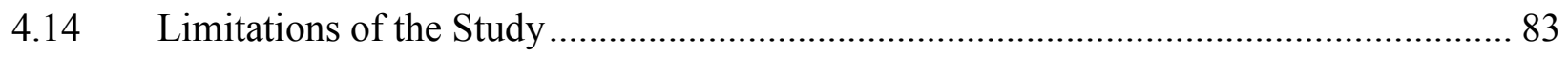

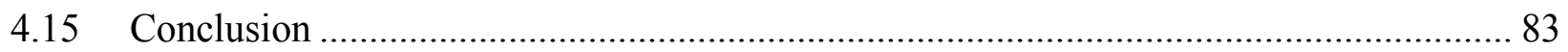

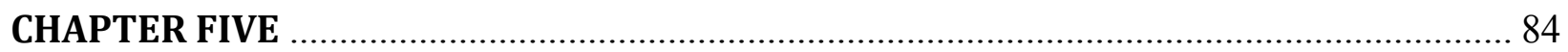

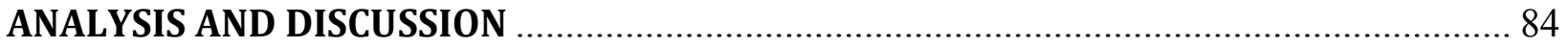

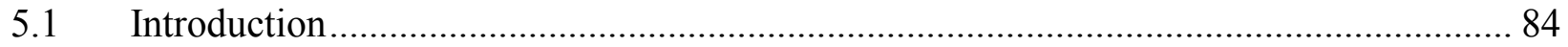

5.2 Presentation of Semi Structured Interview and focus group interview …………….......... 85

5.3 Overview of classroom observation of students .......................................................... 91

5.4 Challenges faced by the students in learning Conversational IsiZulu as observed ........... 92

5.5 General findings of Conversational IsiZulu teaching as observed ................................... 92

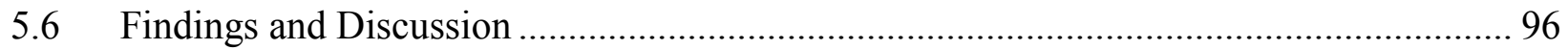

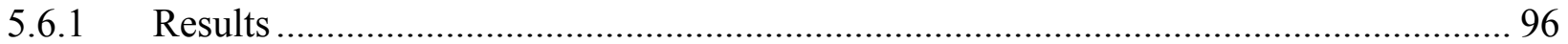

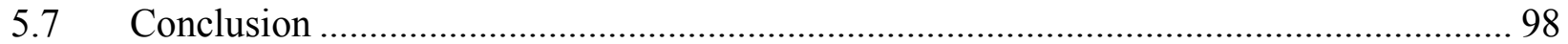

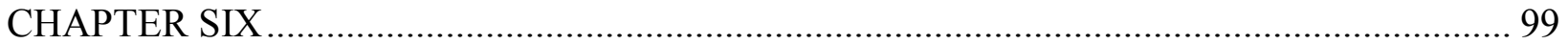

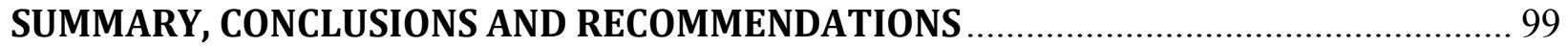

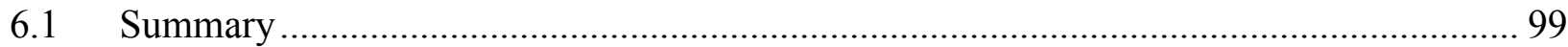

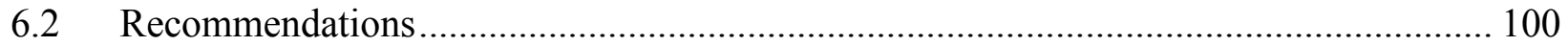

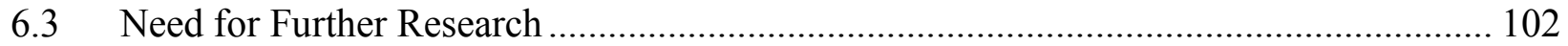

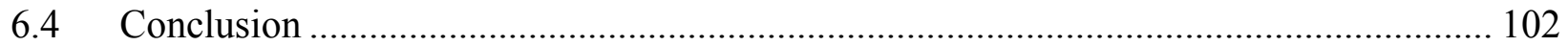

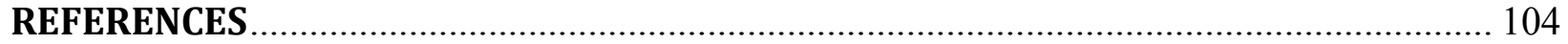

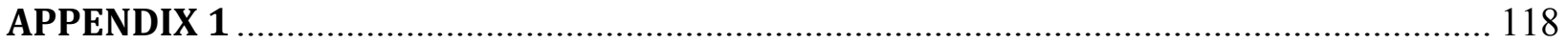

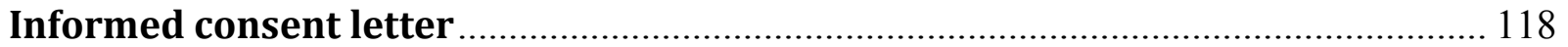

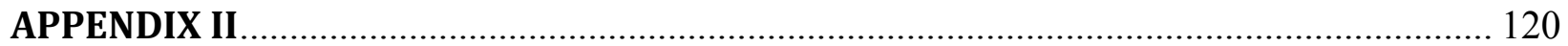

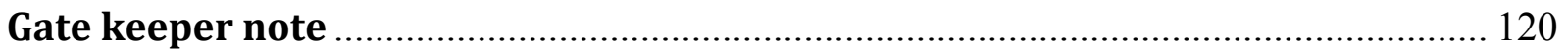

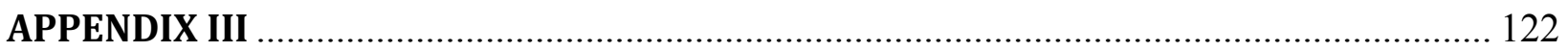

Sample of interview schedule questions for conversational isiZulu students ...... 122

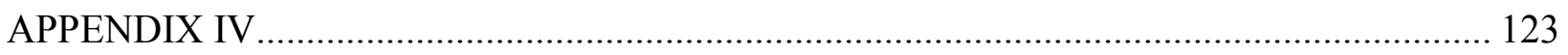

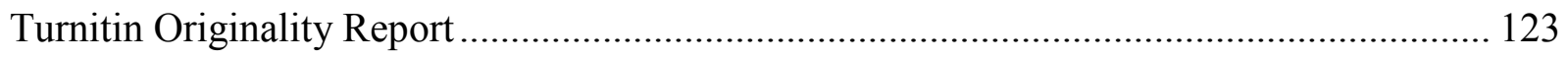




\section{CHAPTER ONE}

\subsection{Introduction}

This chapter will initially contextualize the study based on the historical background of the rich linguistic ecology of South Africa. The pre-1994 phase will describe the situation within the linguistic communities in some South African universities. A brief overview of the linguistic profile in purposefully selected South African universities will ensue. This chapter will also motivate for the use and recognition of indigenous language at the tertiary level, more specifically, the development of isiZulu in KwaZulu-Natal. Comparative analysis of the introduction of indigenous languages will also be discussed.

In the recent years there has been a strong social, economic and political call advocating for the use and the promotion of isiZulu. Dr Blade Nzimande, the Minister for Higher Education and Training, has also made a call to universities across South Africa to address the inequalities of the past by making African languages, specifically isiZulu to be used for teaching and learning. The use and the importance of indigenous African languages were understudied during the apartheid years in South Africa. Increasingly in the post-apartheid moment, more scholars such as Mhlambi (2012) are increasingly writing about the importance of African languages in the post-apartheid state. According to Rudwick (2004) languages have an important role to play in the market value and the desirability of English as the most important global language today has an effect in most Black learners in South Africa. Against this backdrop, this study assesses the perception of student towards the teaching of conversational in a South African university. By using the term perceptions, I am trying to draw attention to the actions/attitudes/thinking process and reactions that students have about being taught isiZulu at a higher institution. I want to find out what are the students beliefs and attitudes about being taught isiZulu and importantly, I want to find out what factors contribute into their thinking/reacting in the particular way towards being taught isiZulu; this is particularly more so as, isiZulu and other African languages continue to be marginalised languages in many independent universities.

According to Kamwangamalu (2003) the inadequate use of indigenous African languages as medium of instruction at primary, secondary and tertiary institutions impedes the intellectualisation of African languages. It is for this reason that Kamwangamalu (2003) believes 
that indigenous African languages should be well catered for and developed and should achieve the same recognition as English and Afrikaans in South Africa, more especially in formal settings such as schools and universities.

We live in an age of linguistic diversity increased greatly by globalization, the movement of people across borders, and the widespread acquisition of additional languages by individuals in their own countries. The social context of language learning and teaching is greatly impacted by a nation's political decision to give special status to a particular language or languages. This status can be achieved either by making the language an official language of a country or by giving special priority to the language by requiring its study as a foreign language. Today there are many countries in which English has been or continues to be an official language of the country, with many more nations requiring the study of English in public schools. Two cases in point are Nigeria and South Africa as examples. This situation provides tremendous incentives for the learning of the English language but now our focus will rather be on isiZulu a language that was sidelined during the apartheid regime in South Africa.

Historically, isiZulu, together with other indigenous languages have been marginalized and given little credence as languages to mediate scholarship and learning. This was largely due to the apartheid policies of the time, which sought to keep black communities in a perpetual state of under-development. In a broader linguistic context, I will try to give an appraisal of the evolving status of isiZulu and how it can claim legitimacy as a compulsory language for teaching and learning in the University of KwaZulu-Natal. This study therefore sets out to assess the reception of students on the use of Conversational isiZulu as a compulsory module in a university. The South African constitution, more specifically its linguistic policy recommends the use of an indigenous language as the language of learning where possible. Although much needs to be done in the development of language registers and lexicons for academic purposes, I believe, together with the UKZN language authorities, that one must start the process to initiate such scholarship and language development (Vithal, 2013).

This case at hand is centred on the University in KwaZulu-Natal located in the province of KwaZulu-Natal in South Africa where almost 80 per cent of the population speaks isiZulu as a 
home language (L1). It is one of the few tertiary institutions in the country where tangible steps have been taken toward incorporating an African language for academic purposes. This policy will introduce isiZulu as a compulsory subject for all undergraduate students starting from 2014, and aims to develop this language as the language of learning and teaching (LoLT). Against this background it seems appropriate for the research to investigate how students in the University of KwaZulu-Natal feel about the implications of this module (i.e. that it is now a compulsory module) in an institution of higher learning, and to assess its reception amongst students.

\subsection{Multilingualism in South Africa}

South Africa has been a meeting ground of speakers of several languages, but the focus of this research is isiZulu which is a Bantu language that belongs to the Nguni language cluster derived from the Niger - Kordofanian family. Until South Africa's transition to democracy in 1994, the only two languages used as a medium of instruction in the tertiary educational sphere in the country were English and Afrikaans. Since 1996, the Constitution of the Republic of South Africa (RSA 1996) has extended official status to nine African languages, recognising the multilingual character of South African society. The Language Policy in Education (found in section 29, 2 of the Constitution (RSA 1996)) provides for all South Africans 'the right to receive education in the official language or languages of their choice in public educational institutions where that education is reasonably "practicable". Since 2002, a language policy framework by the Department of Education (DoE) has aimed specifically to enhance linguistic equity and access in higher education institutions. The document states as its goal the development, in the medium to long-term, of South African languages as mediums of instruction in higher education, alongside English and Afrikaans'. Thus, the South African government has, at least on paper, taken recognition of the 'undisputable fact' (Wolff 2003, p.17) that African languages ought to be developed as languages of learning and teaching (LoLTs) in all educational institutions in order to empower African people.

Thus far, however, multilingual education is not a reality in South Africa and overall, little has changed in terms of language-in-education matters in the country. The status of the English language as the LoLT has become only further entrenched at virtually all educational levels during the post-apartheid period. While several monolingual Afrikaans tertiary institutions 
existed during apartheid, most of these transformed into bilingual models in recent years, implementing English as the other medium of instruction (Du Plessis, 2006). Nonetheless, there have been some efforts in the higher educational sphere to develop indigenous African languages as LoLT (Balfour, 2010; Deumert, 2010).

\subsection{What the Language Boards are saying}

The Council on Higher Education (CHE, 2013) is of the view that the first phase of this policy which focuses on language competency is important given the multicultural and multilingual nature of South Africa. Similarly the development of conceptual terminology and glossaries is to be welcomed as it would enable home-language isiZulu speakers to better engage with academic and intellectual discourse.

Elsewhere, the Inter-institutional Centre for Languages Development and Assessment, (ICELDA) a partnership of four multilingual universities - Pretoria, Stellenbosch, North West and Free State encourage the nurturing and development of indigenous language of teaching and learning. ICELDA designs language tests, and supports research in language testing. It is the outcome of collaboration, since 2004, among the partnering universities. This institution is a driving force in the use of indigenous language in teaching and learning.

\subsection{Background to the Study}

The success of any mother tongue instruction policy depends on people's attitudes towards the first language and English L2. And to understand how attitudes towards a language develop, it is necessary to consider the social and political history of a nation, since such historical forces play a significant role (Bamgbose, 1991; Robinson, 1996). Thus, the colonial and the post-colonial language and educational policies obviously provide a solid basis of the explanation of attitudes towards African languages, and English L2 (Ngugi wa Thiongo, 1986; Bamgbose, 1991; RoyCampbell, 1996; Adegbija, 1994; Robinson, 1996).

However, the colonial language policies either adopted the use of English from the first grade or only used indigenous languages as a medium of instruction in the lower classes of the primary school up till the tertiary level of education across Africa. Postcolonial language policies have 
maintained the status quo, thus perpetuating the existence of an elite group, which is characterized by a relatively high economic status, high educational level and high competence in English (Robinson, 1996; Granville, Janks, Joseph, Mpahlele, Ramani, Reed \& Watson, 1998). Therefore, African nations remain "prisoners of the past" since they are so overwhelmed by established practices to such as an extent that it is virtually impossible to break away from them (Bamgbose, 1991). Hence, the colonial and neo-colonial subjects tend to undermine their own language, as mentioned by Adegbija (1994, p.33) who says:

This attitude of denigration towards one's own language and the exaltation of European languages have not been easy to remove in Africa. Its scars are still very visible today, particularly in the education system-

Thus, the fact that indigenous languages are not used for education beyond the lower grades has greatly contributed towards African indigenous languages being regarded as less important. Alexander's (2003) argument is critical for the discussion of the responses towards African languages (specifically isiZulu) in this study because it highlights the need to escape the existing stereotypes about African languages through enhancing the status of African languages so that these languages can be viewed as adding value across the social, economic and political spheres. Alexander (2003) also highlights the issue of policy which will also be addressed in this study as policy has a vital role to play within the education system.

Furthermore, Mmusi (1998) argues that in South Africa the legacy of the past policies can still be felt within the education system. Mmusi's (1998) argument raises an important issue about the impact of the past policies and how these policies have influence policy regarding the use of African languages. Mmusi (1998) argues that the effects of the past policies where English and Afrikaans enjoyed a high status are still prevalent in South Africa.

Moreover, scholars such as Kamwangamalu (2003) have argued that there is a strong need for the development of an intellectualised African language discourse from primary level to tertiary level. This implies that isiZulu, like most indigenous African languages, suffers from the threat of decaying unless their use is recognized. This view is also echoed by Bourdieu (1992) who argue that languages of the elite class are chosen to be languages of power while the minority languages suffer from linguistic stagnation. In a country which has the most progressive 
Constitutions in the world, which stipulates that there is a need to "recognise the historically diminished use and status of the indigenous people and their languages, the status must take practical and positive measure to advance the use of these languages" (Constitution of South Africa, 1996, Section 6 (2), it is argued that African indigenous languages need be given an opportunity in educational institutions. It is through active engagement and through scholarly that this can be attained in this study.

Therefore, in trying to understand this study, the research questions this study tends to engage with are:

1. What attitudes do the students have towards the introduction of Conversational isiZulu as a compulsory module in the school of Education?

2. Why do they have these particular attitudes?

3. What do students perceived to be the strengths and weaknesses of the conversational isiZulu module?

4. Why do students perceive the strengths and weaknesses the way they do?

\subsection{Significance of the Study}

The University of KwaZulu Natal has become the first university in South Africa to compel all its students to complete a module in isiZulu, therefore symbolising the seriousness with which indigenous African languages are now receiving. Further, the first ever thesis written in isiZulu in education was produced at the University of KwaZulu Natal by Dr Zinhle Nkosi. Recently, a call has been made by the Education Ministry to make the teaching of African languages compulsory in all schools. This suggests an increased focus on African languages. By highlighting the role of indigenous languages in South Africa, the state is trying to equalize the field in order to also ensure that indigenous languages can be useful for economic purposes; such can be learned from countries like China, Sweden, and Finland where local languages are used for economic purposes. This view is explained in Bourdieu (1992:8), when he argues that linguistic utterances or expressions can be understood as the product of the relation between a linguistic market and it linguistic habitus. According to Bourdieu (1992) when individuals use language in particular ways, they deploy their accumulated linguistic resources and implicitly adapt their words to the demands of the social world or the market that is their audience. 
However, while the public and legalistic platform may be such that there is this assumed 'equality' among languages, the reality is that there is a challenge for African languages that are still marginalized in spite of what is stipulated by the Constitution. According to Alexander (2003) English still remains the most privileged language in South Africa to date. Given the dominance of English, I hope this study can shed light to the views of learners towards less dominating languages such as isiZulu in schooling contexts.

Personally, I was drawn to this study for two reasons: my personal experience and issues concerning the lack of research in indigenous language policy implementation. I personally want to embark on this research especially because it is a new area of study and secondly, to unpack the way students react/responds about the fact that it is now compulsory to learn Conversational isiZulu, a language that was previously considered to be inadequate for academic purposes. Naturally, one expects criticism from many students because change is something that is rejected from the onset, especially if it has to do with language. This study evokes some nostalgic feelings in me too having come from a background where my mother tongue did not enjoy the same status largely due to policy issues. It can be empowering to see a language of the majority in the society dominated by English hegemony take a center stage in language learning. This study can also provide a platform for students' voices to be heard on the issue under scrutiny by assessing their reactions, behaviour, feelings and attitudes towards this linguistic policy.

\subsection{Rationale and Relevance of the Study}

The reason this study is relevant is that firstly it is new area of study since the introduction of Conversational isiZulu as a compulsory module in the university of KwaZulu-Natal and secondly because it affects a crucial part of South African educational history. It will also look into the key developmental issues that South African higher education has been preoccupied with during the past twenty years with a combination of transformation efforts by the new government and responses to international trends in higher education. Universally, higher education systems are under pressure to be socially responsive to changes in society by addressing concerns such as equity, access, success, production and language. 


\subsection{Clarification of Concepts}

The following concepts are frequently referred to in the text and need to be clarified to avoid any misunderstanding or misinterpretation:

\subsubsection{Language Learning}

Garcia (2009, p.65) explained that "Language learning is a continuous developmental process that occurs throughout a lifetime and is recursive and circular. In that sense, we are all language learners at certain times, under certain conditions, with certain people". First Language and Second Language as Klein (2008) opines that a language is first when no other language was acquired before; otherwise it is second. Thus, the mother tongue which is acquired first and foremost by a child when his/her language cells are empty is first language (L1); and the language which is acquired / learnt in addition to the L1 is second language (L2). In this context, the term second language refers to any language that is learnt subsequent to the mother tongue. However, Genesee (1989, p.57) argued that: “...contrary to most extant interpretations, bilingual children develop differentiated language systems from the beginning and are able to use their developing languages in contextually sensitive ways. A call for more serious attention to the possible role of parental input in the form of mixed utterances is made."

\subsubsection{Bilingualism}

Bilingualism has been defined from different perspectives over the years. Bloomfield (1933, p.56) defines bilingualism as "native like control of two languages". Other scholars have rejected this definition; rather, they view bilingualism as the ability to use a second language at any level of competence (Bialystok 2001; Bialystok, McBride-Chang, \& Luk, 2005). This perspective allows researchers to accommodate different kinds of bilingualism, including balanced, partial, sequential, and simultaneous bilingualism (Cummins, 1981; Dworin, 2003; Reyes \& Costanzo, 2002). In addition, some scholars agree that any discussion of bilingualism should consider sociocultural, historical, and political contexts that influence bilingualism (Muthwii, 2004; Obondo, 2007). In this respect, bilinguals should not be viewed as two monolinguals in one person but unique beings who use their languages in different ways as called upon by diverse contexts and needs (Grosjean, 1989). This is the perspective that I adopted in this study. I considered the sociocultural, historical and political contexts that influenced and shaped the learning of the Conversational IsiZulu as a compulsory module by the students. The students 
were sequential bilinguals who had high proficiency levels in English and were learning Conversational isiZulu as a second language.

\subsubsection{First Language (L1)}

First language (L1) refers to a person's native language or mother tongue. Usually, it is the language that a child learns from birth. In this study, this concept was used interchangeably with the term home language, mainly because the South African curricular documents use home language.

\subsubsection{Second Language (L2)}

Second language (L2) commonly refers to a language that a person learns after the first language or mother tongue has been learned. However, several studies have shown that this relationship may be complex, indicating a continuum rather than a clear cut phenomenon (Bialystok, 2001, Hornberger, 2010; Hornberger \& Skilton-Sylvester, 2000). By and large, this continuum is influenced by numerous factors, including sociocultural, acquisitional, and language use (Muthwii, 2004; Obondo, 2007), resulting in different proficiency levels among L2 students. In this study, the students were acquiring IsiZulu, their L2, mainly in the school context, with limited exposure to natural contexts. Furthermore, given that they had not had much instruction in IsiZulu literacy in their previous schools, they may be viewed as emergent bilinguals. Finally, although the South African curricular documents use the term first additional language to refer to students' L2, in this study I will employ the term L2 in some cases.

\subsubsection{Language Policy}

According to De kadt (1997 cited in Kallaway et al 1997) language policy can take wide range of forms from broad statement of goals to more specific statement of intentions. She further argues that policy can be expressed in speeches, official statements, court decisions, language of teaching and learning, laws and regulations, all of which embody the authority to define goals and priorities.

However, Schiffman (1996) argues that policy is primarily a social construct and it may consists of various elements of an explicit nature such as laws and regulations, administrations, business, official languages and so on. The current policy in South Africa seems to be dichotomized into an overt and covert policy. In South Africa, the overt policy is all the eleven languages that are given equal status, and therefore one can say that the constitution of South Africa is neutral 
regarding language. English is however the dominant language in the life of so many citizens of South Africa. It is the primary language used for education, business, sports, media, courts, administration and so on (Mda 2000).

\subsubsection{Languages as a Resource}

The concept of language as a resource has been popularized in the 'planning' model of language in which choices are made on strictly economic grounds in much the same way any other resources in a nation's economy are planned and consumed. This concept always comes into play whenever a government or institution plans to change their language policy.

In this concept like any other commodity, is subject to a cost - benefit analysis, in which the cost of a language selected for a particular purpose can be measured in terms of what could have been gained from the choice of another for the same purpose.

The economic model assumes the freedom of language learners to make choices unfettered by other considerations. Although such freedom hardly exists, hence there are built-in constraints, for example in the educational system and in terms of access to socio-cultural and political contexts. However, for many learners as opined by Emenanjo (1990), the available language is not the one they need; and hence they end up learning a language they can get rather than the one they need". The fact is that language involves attitudes and behaviours which may not necessarily confirm to rational behaviour such as it is usually postulated for non-language resources.

In spite of the problems highlighted in the foregoing discussion, it is still possible to talk of a language as a resource in a dictionary sense of "a valuable asset" or "a stock that can be drawn on". And in this sense, the resource is the benefit of learning conversational isiZulu language as an additional language. Hence multilingualism will ceased to be looked at as a problem but rather as an enrichment of the socio-cultural life of a community and acquiring more than one language be seen as something to be envied and sought after rather than a necessary evil.

\subsection{Aim of the Study}

The aim of this study is assess students' perceptions of Conversational isiZulu as a compulsory module in the University of KwaZulu-Natal. 


\subsection{The objectives of this study are:}

- To understand the attitudes of students of Conversational isiZulu among first year students enrolled in the course.

- To ascertain the reason for students to perceive Conversational isiZulu the way they do.

\subsection{Statement of the Research Problem}

Much has been written on the subject of transformation in schools. However, the available literature regarding the meaning and achievement of transformation in higher education and the literature and theories around this topic is rather scanty. The paucity of the literature on the transformation of higher education language policy as well as the relatively thin context of this subject might be attributed to the infant stages of the initiative.

This study, seeks to add to the empirical data on this language policy initiative by evaluating the perceptions of students towards the introduction of isiZulu as a compulsory module in the university.

\subsection{Delimitations and Limitations}

A study of this nature is likely to have limitations and delimitations. The major limitations and delimitations are discussed below. The study undertaken by the researcher is largely involved with analysing issues in the South African higher education systems, which have played a major role in advancing capacity in research, teaching, physical and human resources. The study is also concerned with the fundamental mismatches between what polices envisage and the desired practical outcomes of efforts aimed at achieving redress, equality and social justice imbalances in language learning.

Clearly, the scope of this study, and the size of the empirical sample used, is far too small to provide sufficient evidence to justify generalizable position. However, this small scale study presents some preliminary data on students' perceptions towards the teaching of Conversational isiZulu module. This should trigger further and more substantial interrogation of the topic.

\subsection{Outline of Chapters}

This study is divided into six chapters. The division of the study into chapters is listed below: 
Chapter One: This chapter comprises the introduction and explains the background of the study, the significance of the study, the rationale and relevance of the study, the clarification of concepts, the aim of the study, and the objectives of the study, statement of the research statement and delimitation and limitation of the study. This chapter provides the background information to the assumptions and principles that frame this study.

Chapter Two: This chapter sketches existing literature on how language has evolved in South African society and the introduction of indigenous languages in the educational landscape. It will touch on the apartheid era language policy and the shift that characterise the democratic South Africa.

Chapter Three: This chapter will touch on the theoretical framework that the study is based on; it is noteworthy to say at this point that the study will make use of second language acquisition theory as its lens.

Chapter Four: This chapter discusses the research methodology. It discusses the type of research methodology, and methods used in this study, which will be described comprehensively so that the reader can understand and develop confidence in the methods used. Methodology hence refers to the steps involved in a given approach.

Chapter Five: This chapter is the data analysis and discussion. This chapter critically analyses the students $^{\text {ee }}$ responses. In this chapter the presentation, discussion and interpretation of the findings will be given. In this chapter the data gathered in the empirical study will be analysed and discussed in the light of the key research questions: This chapter presents the findings and discussion of the study in order to answer the three critical questions generated in chapter one.

Chapter Six: This chapter contains the summary, recommendations and conclusion of the study. The chapter offers recommendations and clarifies some limitations to the study. It also provides some concluding remarks. This chapter will make a summary based on all the data and evidence available and thereby proffer recommendations before concluding. 


\section{CHAPTER TWO}

\section{LITERATURE REVIEW}

\subsection{Introduction}

This chapter deals with the review of seminal literatures which will help in the understanding of the evolution of IsiZulu language development in UKZN and the province as a whole. The study purpose is to assess students' reception of conversational isiZulu as a compulsory module in a South African university.

A literature review is defined as a systematic, and reproducible method used to identify, evaluate and interpret the existing body of recorded work that has been produced by researchers and practitioners. It provides evidence to the research audience that the researcher is aware of the work that was already done on the subject, and points out what are believed to be the key issues in the research field. Furthermore, it establishes theoretical and principle-based co-ordinates for readers in terms of what was applied to shape the research design (McNabb,2002, pp. 393-394).

Given the above statement, I am going to review several works that are related to the issue in discussion. This study will further look at the policy shift in UKZN with the recent introduction of IsiZulu as a compulsory module among undergraduates, as a prerequisite for graduation. Furthermore, it is the main goal of this study to investigate the introduction of Conversational IsiZulu as a compulsory module in UKZN and the nature of language policy and planning in UKZN and subsequent student's responses.

According to Tollefson (1991, p.13) in South Africa, the issue of language has historically been a struggle which is steered by power dynamics where social groups seek to exercise power through their control of language. Those in power will use power as means of exerting power over others. Language therefore becomes a powerful tool that is use by those in power to further dominate within the social, economic and educational spheres. Kamwangamalu (2003) observes that this has been more so because decisions about language often lead to benefits for some and loss of privilege, status and rights for others. Kamwangamalu (2003) further states that the decisions that are often made relating to language in most cases they are political. By highlighting the 
demographics of languages in South Africa, I am drawing attention to the magnitude of the variations between the languages in South Africa. Furthermore, languages are linked to a particular social, economic or political context and these factors become important in understanding the language issues in this country. According Hartshorne (1995,p.306) in South Africa, decisions have to do with issues of political dominance, the protection of power structures, the preservation of privilege and the distribution of economic resources. Next I discuss the language demography and struggles between languages in South Africa in order to further gain better understanding of the phenomenon I am exploring in this study.

\subsection{Languages of South Africa}

South Africa is a nation of diversity, with nearly 52 million people (2013) and a wide variety of cultures, languages and religious beliefs. Nearly 25 languages are used in South Africa on a daily basis by more than 50 million people (Statistics South Africa 2003). The majority of South Africans, almost $80 \%$ of the population, use an African language as their home language. Distributions of Languages in South Africa are as follows: English 8\%, Afrikaans 13\%, African languages 78\%, others, 1\% (Statistics South Africa 2003). This means that South Africa is one of the multilingual societies. The government declared ' 11 ' languages as the official languages of the country to be used at all levels. This decision was influenced by the politics of compromise that led to the formation of a democratic South Africa. The policy replaced the former language policies that contributed to the uplifting and development of English and Afrikaans as the only official national languages in South Africa. These languages are: English, Afrikaans, isiZulu, isiNdebele, isiXhosa, Sepedi, Sesotho, Setswana, Siswati, Tshivendaand Xitsonga (Statistics South Africa, 2001).

Demographically, isiZulu and isiXhosa are most commonly spoken first home languages in South Africa. IsiZulu speakers are largely located in KwaZulu-Natal, though some can also be found in Gauteng and Mpumalanga. IsiXhosa speakers are mostly located in the Eastern and Western Cape. The African languages of South Africa comprise mainly the Bantu languages, of which four distinct groups can be distinguished:

- The Nguni languages (isiXhosa, isiZulu, isiNdebele and siSwati)

- The Sotho languages (Sepedi, Sesotho and Setswana) 
- Venda

- Tsonga

The Nguni languages are by far the largest group with over 20 million speakers, followed by the Sotho group with a little over 10 million speakers, the Tsonga group with almost 2 million, and the Venda group with nearly a million speakers (see Kamwangamula, 2001). There is a clear relationship between linguistic affinity and the geographic distribution of these language groups. The Nguni family includes isiZulu, isiXhosa, isiNdebele and siSwati. The Nguni languages are mainly found in the east and along the coast. The Sotho languages are found in the west and on the inland plateau. The Venda groups are found in the north and the Tsonga group in Mpumalanga. The Bantu languages of South Africa are primarily used for everyday oral communication. These different languages have been highlighted above because they provide some background to the demographics of African languages in South Africa. I believe that this background is essential to this study because it indicates that African languages in South Africa are spoken by the majority and yet post-Apartheid, many of these languages are still marginalized at schools as well as by society at large.

\subsection{Historical Background on the use of isiZulu in South Africa}

It is important to trace the development of IsiZulu to understand the changes that has taken place so far. During the apartheid era in South Africa, education was structured according to race and ethnicity. The language of instruction was mother tongue for the black learners in the primary grades. It was only at the beginning of secondary school that English and Afrikaans were introduced to learners. Sailors, Hoffman and Matthee (2007) argues that the use of these official languages of the apartheid state, had led to many black learners failing and dropping out of the education system due to their inability to succeed in these languages.

One of the most destructive apartheid ideological strategies was the official language policy that excluded all indigenous African languages and recognised only Afrikaans and English. Thus the outcomes of the non-recognition of indigenous languages were job reservations for Afrikaners in the public service and the sustained promotion of the Afrikaner people through a highly raciallystructured and segregated education system that nurtured white Afrikaners (Pelzer, 1980; 
Wilkins \& Strydom, 2009). Hence, the apartheid political ideology structured around racial inequalities and repressive social injustice was aptly categorised as a pervasive system of affirmative political framework for the white colonists, especially for white Afrikaners (Sachs, 1992; Sonn, 2004).

The plethora of apartheid regulations and legislations that created the racial classifications was not only based primarily on targeted racial group memberships. The first target of these raciallystructured segregationist regulations and legislations were the black populations, ethnic groups such as the Xhosa, Zulu and Ndebele, who were submitted to an endless cycle of oppression and humiliation to prevent unified black resistance to apartheid rule (Manby, 2005; Kotzé, 2007). The apartheid racial classification policy based upon the 1950 Population Registration Act distinguished four major racial categories - white, black/African, coloured, and Indian/Asian. To strengthen the divide, the apartheid government self-consciously created an immediate position for Coloured and Indian communities (Carrim, 2006).

It must be noted that the isiZulu language, referred to by native speakers as isiZulu, is the native tongue of more than 10 million Zulus worldwide, with the vast majority living in South Africa. One of South Africa's 11 official languages, isiZulu is the most-spoken language of the 250strong Bantu language group. Using the Latin alphabet, isiZulu is especially noted for its click consonants. (Statistics, S.A, 2009).

However, Fanakolo a variant of IsiZulu is a bridge language; used to make communication possible between people who do not share a mother tongue. Though isiZulu is the native language of just one-quarter of South Africa's population, about half the country can understand it, along with hundreds of thousands of people in the surrounding region. IsiZulu is used as a lingua franca from the KwaZulu-Natal province. IsiZulu words reflect the high value speakers place on respect. Its vocabulary and grammar are designed to show special deference, particularly toward elders. Ancestral spirits are often invoked, and feature prominently in the language.

In the past, in small trading towns and mining areas across South Africa, a pidginized form of isiZulu known as Fanakalo is used as a lingua franca, or bridge language. It is a rare example of 
a pidgin language based on an indigenous language rather than that of a colonizing power, and is thought to be spoken or understood by tens of thousands of people across sub-Saharan Africa. In the earliest phase, South African Indians learnt pidgin isiZulu - fanakalo - to communicate with Zulus and their white sugarcane plantation employers (Mesthrie \& Hromnik, 2011).

In contrast to many other languages, there are no definite or indefinite articles in isiZulu, meaning that words are not given a particular gender. Instead, nouns are classified into 15 classes that have different prefixes, often dictated by what the noun itself has to do with.

Christian missionaries who came to South Africa in the 1800s helped record isiZulu in writing, using certain letters to represent the clicking sounds. In isiZulu, a "c" represents a dental click, a "q" is an alveolar click (such as a bottle top "pop"), and an " $\mathrm{x}$ " is a lateral click on the side of one's mouth. These click consonants sounds can also be presented phonetically as follows: c [/], $\mathrm{q}[1]$ and $\mathrm{x}[/ /]$.

Culturally, ubuntu, meaning compassion or humanity, has become one of the words most representative of South African culture and is taken directly from isiZulu. The word embodies the country's spirit of oneness and compassion between individuals for one another. Standard isiZulu is taught in schools and focuses on a more pure concept of the language - meaning that new concepts are described using derivations from isiZulu words. On the other hand, urban isiZulu borrows more extensively from English, and is used more frequently by young people. For instance, the word for a cell or mobile phone in standard Zulu is "umakhalekhukhwini," while the same word in urban Zulu is "icell."

While many isiZulu words reflect an English influence, the opposite holds true as well. Many words have found their way into South African English, such as "donga," for ditch, "induna," for chief or leader, and many more. While isiZulu can be used in primary schools until second grade and studied as an elective until 10th grade, instruction in South African schools is primarily in English at higher levels of education. However, some schools including the University of KwaZulu-Natal in KwaZulu-Natal province have made learning isiZulu compulsory for all incoming undergraduate students. 
It is important to mention that since 1930, there has been a growth in many isiZulu publications, including newspapers and magazines. The South African Broadcasting Corp. (SABC) even has domestic TV and radio in isiZulu. More importantly, missionaries were involved in dictionary making: the earliest fragments of English dictionaries of IsiZulu and other African languages were created by missionaries (Mesthrie \& Hromnik, 2011). This also means that the missionaries who are non-natives have made an earliest meaningful contribution to develop the isiZulu language.

\subsection{Marginalization of Indigenous Languages}

The historical overview of apartheid rule and its subjugation of the indigenous peoples of South Africa created the chronic educational problems and challenges that plague the post-apartheid South African education landscape today. The first problem created by the colonial and apartheid legacies is the racially segregated structure of the South African education system, which was characterised by distinctive differences in state funding. The state funding was allocated according to apartheid racial classifications. The white child received R1 211.00, the Indian child received R771.00, the Coloured child received R498.00 and the black child received R146.00 (Youth Group Fact Sheet 1, 2011, p.1). The racially-structured state funding system impacted negatively upon teacher/pupil ratio, qualifications of the teachers and other quality dynamics. The studies conducted by Davenport (1991) and Dube (1985) reported that the apartheid school curriculum was also self-consciously designed along racial lines. The ideological and political purpose of the racially-structured curriculum was to ensure that different racial groups could be educated and prepared for the jobs they were meant to do.

Thus, the above - mentioned authors described Bantu Education or the education system for indigenous Africans as an educational system, which created a subordinated position in the workplace by focusing on practical subjects and inferior curriculum (Davanport, 2001, p.535; Dube, 2005, pp.93-97). This view was also presented by Christie and Collins (1979), who argued that apartheid schooling was designed and motivated to ensure that white South Africans were schooled in order to take on management positions in society and to be dominant in economic, political and social areas of South African society, whilst black South Africans were being schooled explicitly to take on menial, un/semi-skilled, inferior positions, particularly in the economy. 
The higher education sector did not escape the negative effects of the legacies of colonialism and apartheid racist rule. The higher education system was re-structured to operate as segregated system from 1959 and most of the faculties in the open universities denied African, Indian and Coloured students access and separate ethnically defined institutions of higher education were established as agencies of academic apartheid (Davenport, 2001, p.535).

Language policy has been used as an ideological instrument in enhancing the hegemonic agenda of the white rulers. Under apartheid, English and Afrikaans were the only official languages and mediums of instruction, an ideological strategy that projected African languages as inferior and ensured that both in the workplace and acquisition of education, African students' academic performance should be hampered by the need to use foreign languages. The most destructive goal of the language policy was to limit black access to employment. Henrard (2002, p.21) observes that the sudden change from mother tongue instruction to the double medium or 50/50 policy (English/Afrikaans) caused a great deal of the educational backlog among African students and caused major upheavals, for example, the Soweto Uprisings.

As a result, African languages are being neglected in education, as English is still dominant. According to Higher Education Minister, Nzimande (2010, p.16) "No one should be leaving a university or college in the country without learning an African language. He said that South African youth were showing less and less interest in their languages. The development of languages was not a "nice-to-have", but a necessity for human rights and dignity, as well as for the preservation of culture. He highlighted that an overwhelming majority of people spoke African languages, but that this was not reflected in the education system. Languages such as English acted as "political, military, cultural, symbolic powers of rule". "Many African countries have struggled to preserve African languages." He admitted funding for the teaching of African languages was a problem, but from now on this would be made a priority (Times, 22 October 2010).

With regards to language diversity issues, the first 10 years of democracy also produced several policy processes. The outcomes of these processes are captured in, among other things, South Africa's only piece of language legislation, the Pan South African Language Board Act (Act No. 59 of 1995), and the National Language Policy Framework (2003). In addition, several other language policy documents have seen the light (Du Plessis 2006, pp.43-44): 
$\checkmark$ The Language in Education Policy (Government Notice No. 383, Vol. 17997, in terms of section 3(4)(m) of the National Education Policy Act, 1996;

$\checkmark$ Norms and Standards on language policy (Government Notice No. 383, Vol. 17997, in terms of section 6(1) of the South African Schools Act, 1996), which regulates language policy in schools; and

$\checkmark$ The Language Policy for Higher Education (2002), which regulates language dispensations in higher education institutions.

Notwithstanding the above list of enabling legislation and language policies it seems as if disillusionment has set in. In an editorial to mark the celebration of a decade of democracy in South Africa the Sunday Times (25 April 2004) laments the fate of the country's indigenous languages: We find that our 10-year-old democracy has been the greatest enemy of indigenous languages. All the lofty pronouncements made in the early days of transition seem to have been discarded and the authorities have paid token attention to the issue. The work of government is conducted virtually entirely in English and the language of our culturally diverse Parliament is almost exclusively English. Many senior politicians stay away from African language radio stations, presumably because they perceive those audiences as not sophisticated enough. .... Universities are battling to keep African language departments open as student numbers dwindle ... book publishing in indigenous languages is on its deathbed, and ... the use of these languages among native speakers is becoming unfashionable (Sunday Times 25 April 2004).

It is common knowledge that language policy implementation is a matter of concern for language stakeholders and experts alike. It seems as if government lacks a commitment to its own policy, the National Language Policy Framework (NLPF), approved by Cabinet in 2003 and that language matters have been relegated to the back seat of the transformation agenda. Almost two decades after the watershed Wits conference on language planning for a future South Africa. According to Genesee (2001) "The most proficient bilinguals mix the most and in the most sophisticated ways without violating the rules of either language. It is normal for children growing up in these communities to mix their languages extensively because they are simply learning the patterns of communication that are common in their community. It can be difficult and unnatural, if not impossible, to keep the languages completely separate. If most people in the 
children's wider community use only one language, the children will eventual learn the monolingual patterns.” (p.56)

Non- English speaking countries that invest heavily in mother-tongue education - even when national language are not spoken beyond its country's boundaries (i.e. Norway, Sweden, Liechtenstein and Switzerland) - are able to compete favourably with English - dominant developed countries such as the United Kingdom, New Zealand, Australia and the United States of America (Brock-Utne, 2007 cited in Kamwendo, 2012) - proving that English is not synonymous with education, let alone quality education. It is possible to have quality education delivered through indigenous African languages, as long as the necessary investments of resources are made (Kamwendo, 2012).

A recent study by Kamwendo (2012) adds to this mix that disrespect for indigenous languages goes beyond primary education and is manifested in the thinking of many academics at university level as well. Wa Thiong'o (2005, p.17) has issued a challenge to African intellectuals: 'How many social scientists have ever written even a single document in an African language? 'African academics should show the world that it is possible to conduct academic business through African languages (Kamwendo, 2012).

Putting this study into a global context, Amano (2010) who usually looks at extinction rates in animals said that about $25 \%$ of languages around the world were under threat. "People are forced to adopt the dominant language or risk being left out in the cold - economically and politically" The researchers found that the more successful a country was economically, the more rapidly its languages were being lost. They said that in North America, languages such as Upper Tanana, were now spoken by fewer than 25 people in Alaska, and were at risk of vanishing forever.

This shows that this is an international trend, as in Europe, languages such as Ume Sami in Scandinavia or Auvergnat in France are fading fast. Amano said: "As economies develop, one language often comes to dominate a nation's political and educational spheres. "People are forced to adopt the dominant language or risk being left out in the cold - economically and politically." The team also found that languages in the Himalayas are at risk, such as Bahing in Nepal, which has an estimated eight speakers. In the tropics, too, voices are disappearing. "These 
countries are experiencing rapid economic growth, so in the near future these languages will face risk of extinction." The scientists call for conservation efforts to focus on these regions.

Amano (2010) said that work undertaken to protect languages such as Welsh in the UK was a good example a successful strategy. Commenting on the research Daniel Kaufman, executive director of the Endangered Language Alliance, said: "Environmental factors have been overshadowed by social, political and economic factors. "We are now seeing a pattern of linguistic diversity that was originally shaped by the environment give way to a pattern that is being shaped by policy and economic realities. "The environmental pattern at this point is largely historical residue. That is, we will no longer see areas of a particular environmental type attract or spawn language diversity. The economic aspect, however, cannot be overemphasized; as there are places within the language diversity 'hotspots' where whole villages are being emptied out due to out-migration. "Because much of this migration is recent and undocumented, accurate numbers are unfortunately not readily available for statistical analysis" (Amano 2010, p.45).

Garcia (2009) also contributes to this concept of multilingualism where she terms it 'bilingual education' rather than multilingual education, as the umbrella term helps to cover a wide spectrum of practice of policy. Bilingual education usually is where two or more languages are used together in instruction, but also is the case where two or more languages are used in complex combinations. Garcia (2009) further explains that 'bilingual education' does encompass what many refer to as multilingual education, which embodies mother tongue, a national or regional language and an international language. The researcher is of the opinion that this concept of bilingual education is interesting and relevant for there are many instances where South African children speak or learn in three languages, for example a learner who speak isiZulu (home language) learns in English as the National language and later may use Afrikaans as an international language.

\subsection{Democracy: Legitimization of Indigenous Languages}

Prior to the democratization of South Africa twenty years ago, there was no use of isiZulu as the language of teaching and learning in any South African University. Some of the shortcomings of the teaching of any African language in South Africa have been the failure to relate the language 
to its historical or social context. It can be said that students seldom advance beyond the homogenizing stereotype of 'the African past' or 'African culture' (Bailey, 2007, p.20).

Since the implementation of the language policy, it appears that not much progress has been made in implementing it, especially with respect to the use of mother tongue in education. The language - in- education policy ( $\mathrm{LiEP}$ ) promotes multilingualism and equal importance is placed on all the eleven official languages in our country.

Furthermore, Mazrui (1997) in an analysis of the role of the world Bank and its role in the language in education practice in Africa, argues that despite the bank public support for local language in education, its continued advice to government to cut educational expenditure on local language in favour of an international language is a sign that they are not sincere about their policies towards the promotion of indigenous languages.

Hence the western ideology is also often accompanied by linguistic racism (linguicism) which places high status on English and low status on other languages; another factor that affects the use of isiZulu is the lack of political will. For example politicians often conduct their speeches in English even though their constituency comprises uneducated masses that have very little knowledge of English. Despite having speakers of indigenous language occupying positions of power in many institutions in this region and the country as a whole, there is this mentality that English remains the key prerequisite for access to resources and employment. For example, black television presenters tend to speak more English than African languages.

According to Balfour (as cited in the Mail\&Gaurdian 2014, p.4) reports on the policy, controversial since inception, were featured in a provincial and national press. It was anticipated that it would fail; that students would find the use of isiZulu in an academic context problematic. It was also suggested that the policy would result in a brain drain, entailing the flight of top academics, international and local students to other universities. The arguments about why the policy was both inappropriate at higher education level and doomed to fail are revealing.

Commentators suggested then that the task of developing indigenous languages ought not to be artificially institutionalised in higher education institutions that had limited capacity to develop them. The well-known dwindling student numbers in African languages in South Africa was cited as evidence that the exercise was both wasteful and futile. Language development ought 
either to occur in the communities in which they were spoken or be undertaken by extrauniversity institutions such as the Pan South African language Board.

Therefore, since the introduction of democratic rule, languages in the educational policy of most African states have primarily been aimed at promoting the use of African languages as medium of teaching and learning. Although to me, it seems this is only on paper and not actually practiced. Not many African states make use of their indigenous languages as medium of learning and teaching in schools. Scholars in the field of language planning in Africa only struggle, fight and advocate for African languages as medium of instruction while the authorities and legislators are scared of passing this into law, even if they pass it into law, one may doubt if it can be practiced.

The South African Constitution (although this appears to be on paper only) provides for linguistic and cultural rights of its people and promotes the linguistic and cultural freedom of all language groups. The Constitution of the Republic of South Africa of 1996 recognizes all eleven official languages as equal. Nationalist Africans have often seen the deterministic relationship between language, culture and cognition as an important dimension in their struggle for independence (Mazrui \& Mazrui, 2008, p.53). According to Ngugi (1986, p.16) 'the domination of the people's language by the language of the colonized nations was crucial to the domination of the mental universe of the colonized'. This is why Ngugi (1986) not only regards language and culture as inseparable, but understands the two variables on the basis of a reciprocal relationship, so inextricably interwoven that one cannot exist without the other. If you talk to someone in a language he or she understands, that goes to the person's head. If you talk to somebody in his or her language that goes to the heart' (Mandela, 1994). One of the researchers to investigate this problem is Kamwangamulu (2003); he argues that the mother tongue education in Africa is undermined by 'linguicism (or linguistic racism). Furthermore, he states that "despite all efforts to make the European languages available to the African masses and thus increase literacy, these efforts have been resounding failures" (p.14).

This shows that teaching Africans or forcing them to learn in English will not enhance their understanding of the world. It will be more beneficial if African languages are promoted among African Scholars and students. 
In order to achieve a balance in language diversity in South Africa, all languages should be equally promoted and language policies should address the challenges faced by these languages in South Africa. The next section discusses the various language policies in South Africa and their implications for education.

This policy was developed and produced because it was conceived as an integral and necessary aspect of the government's strategy of building a non-racial nation in South Africa DoE (1997). It is meant to facilitate communication across the barriers of colour, language and region, and recognizes cultural diversity as a valuable national asset. It thus aims to promote multilingualism, the development of the official languages and respect for all languages used in the country. The policy also states that "being multilingual should be a defining characteristic of being South African" and that the "learning of two or more languages should be general practice" LiEP (1997). This implies that the whole nation, not just language minority students, is required to become multilingual. The policy also promotes additive bilingualism in that it aims to maintain the home languages while providing access to the effective acquisition of additional languages.

The policy has decentralized implementation by declaring that "the governing body of the school must stipulate how the school will promote multilingualism through using more than one language of learning and teaching, and/or by offering additional languages as fully-fledged subjects, and/or applying special immersion or language maintenance programmes, or through other means approved by the head of the provincial education department" LiEP (1997).

\subsection{Language Shift and Policy Implications}

There has been on-going political pressure to transform the educational landscape in South Africa by promoting African languages. The Constitution of South Africa is one of the most democratic constitutions in the world. In South Africa, the Constitution has played a significant role in social transformation especially in the promotion of languages. According to the Constitution, South Africa has chosen 11 languages in order to:

(a) To ensure and guarantee the freedom and human dignity of all South Africans under a new dispensation, 
(b) To recognise the country's linguistic diversity as well as the fact that the majority of South Africans - probably 98 per cent - use one of these languages as their home or first language, and (c) To ensure that the process of democratization is extended to language related issues as well (The Department of Education: South Africa's New Language Policy: The Facts, 1994:

In accordance with the South African Constitution all languages should receive same equal status and the South African Schools Act, the Department of Education's Language in-Education policy aims to promote multilingualism and the development of the official languages and to pursue the language policy most supportive of general conceptual growth amongst learners.

The South African Constitution (RSA, 1996) and the South African Schools Act (RSA, 1996) acknowledge the right of all learners to receive education in the official language. The Constitution is aimed at promoting multilingualism and the development of the official languages and to pursue the language policy most supportive of general conceptual growth amongst learners. While there is political pressure for transformation, this pressure is often not coherent with reactions from learners, parents and teachers responses towards African languages. The principles of Constitution therefore, I argue should be promoted in order to ensure social justice in many South African schools.

Recently, there have been calls for a policy shift generally in the language of teaching and learning under the democratic dispensation generally because of the multilingual nature of the country and for the fact that IsiZulu is the language spoken by the majority in South Africa. IsiZulu should be compulsory at all South African universities, said Nxumalo, the former speech writer for Zulu King Goodwill Zwelithini. Speaking at a seminar at the University of KwaZuluNatal on the $26^{\text {th }}$ November 2014, Nxumalo said isiZulu-speaking people cannot properly speak the language or accurately translate it into English. "You find people have the same Zulu definition for the English terms 'aim' and purpose'," he said. "Most people would say the isiZulu term is inhloso, but aim is actually inhlosojike and purpose is inhloso mfezo." These also clarify the need to put isiZulu in an exalted position as a language of teaching and learning in South African Universities. 
Therefore, on the basis of this growing demand and linguistic reality, UKZN in 2014 implemented a compulsory IsiZulu course for first-year students. Students are required to demonstrate bilingualism to earn their degrees. This was a first for South Africa, and it sparked some criticism among students and academics. Under apartheid and the implementation of Bantu education, rigid school segregation denied black students' access to speakers of English, except in the few remaining mission schools (Mesthrie, \& Hromnik, 2011). English was the dominant lingua franca in the apartheid regime, with democracy; all 11 South African indigenous languages are deemed suitable for communication and official recognition. Demographically, isiZulu is the dominant language in the Kwa Zulu- Natal province. $80 \%$ of the people in this province has isiZulu as their first language (Maartens, 2008, pp.22-23).

However, UKZN became one of the first to introduce isiZulu as a language of learning in particular programmes in health science and education, and in 2013, was recognized as achieving among the highest number of research output. Rhodes University has made isiXhosa compulsory for students in some programmes (for example in journalism), and so too has the University of Cape Town (UCT). All these three are among the most successful South African Universities. Various claims that such policy and curriculum choices would damage the universities and results in unpleasant consequences for students and staff proved to be false. Many scholars have contributed extensively on the issue of promoting indigenous languages such as isiZulu as a language of teaching and learning. One of them is Robert Balfour whose contribution deals with the conditions for effective language policy development and implementation in institution of higher education, in particular with reference to the development of academically marginalised languages.

The rationale behind the decision to introduce a compulsory African language is explained thus: "Multilingualism is an important tool for social cohesion, and for individual and social development. Community life takes place mainly in African languages. Learners proficient in African languages are thus able to participate and take leading roles in local institutions and organisations." Learners would benefit "by being able to communicate in an African language and also being able to access learning through an African language. Being multilingual is of great value for all citizens living in South Africa" (Times, 29 November 2013). All these show how important indigenous languages have become in this dispensation. 
Therefore, one can say that 2014 is a watershed year in the linguistic status of the University of KwaZulu-Natal. This is because Conversational isiZulu was introduced as a compulsory module for undergraduate degrees. It meant that the language most spoken in the province was at last given official recognition and status. This is in line with South African Constitution's intention to promote and value indigenous languages in higher education. The Constitution of the Republic of South Africa of 1996 recognizes all eleven official languages as equal. According to the University Language policy, in phase 1 of the programme -from 2014 to 2018, students and staff would develop "communicative competence" in isiZulu and English sufficient for academic interaction. Phase 2 - from 2019 to 2029 - would encourage and facilitate all academic disciplines to assist students and staff to develop writing skills in isiZulu, making each programme to determine the appropriate level and type of proficiency. This is in line with the university's language policy and plan and the UKZN transformation charter, which seeks to develop African languages as academic languages.

The university has an obligation to ensure that linguistic choices results in effective learning solution as $60 \%$ of students are isiZulu speakers. Although universities are autonomous still there is a debate about linguistic choices. Some feel it should not be imposed on students. This is an accepted practice of a democratic dispensation where human rights and linguistic choices are respected. Phase 1 is steps to address the problem were students are regularly examined in languages other than those in which they are taught, and in which they generally have low proficiency.

Furthermore, the University vice -chancellor, Prof Renuka Vithal point out that "Each programme will determine the appropriate level and the type of proficiency. This is not expected to affect the pass rate and we know this from degree programmes for students who have not taken isiZulu in school, such as health sciences degrees, who has taken the modules in isiZulu appropriate to their practice as health professionals" (Nkosi, 2014, p. 11).

Hence, with the demise of apartheid even Afrikaans universities took a stand and introduce more languages because most of South African population speaks more than two languages. 
Stellenbosch University promotes Afrikaans and Xhosa to allow its students to interact more efficiently with the communities in their chosen fields.

According to Balfour (2006) the UKZN draft language policy aims to respond to the historical legacies of its two ancestor universities (Natal and Durban-Westville), and to give further substance to the vision of the university to be the premier university of African scholarship. It attempts to describe how English and isiZulu might come to be further developed and utilised by the university to the benefit of all constituencies of the universities. This means that it is not only the language discipline of the university that benefits from this project but all the disciplines in the university because language is one issues that is linked to all issues. There is no one that does not make use of language whether you are a nurse or a doctor you will need language to communicate to your patients and if it happen that you are fluent in isiZulu and you may be white or from Indian origin, it means that it will further help you to reach to larger segments of the society who may not have English proficiency.

African languages, both as mediums of communication and tuition, have been historically disadvantaged. Language policy development in the new democratic dispensation has not been taken a pragmatist approach needed to push for the desired change.

However, policy processes in transitional societies are especially prone to producing "gaps" and "disjunctions" between policy and implementation in "the pursuit of heavily contested, ideologically loaded, transformation goals" (Pretorius 2003, p.6). In conjunction with Pressman and Wildavsky's (2003, p.23) working definition, I use the notion "policy" as "a hypothesis containing initial conditions and predicted consequences". In order to determine possible gaps in implementation, "initial conditions" (policy goals) should be scrutinised with a view to assessing whether and how "predicted consequences" (implementation) have been realised.

In this regard Pretorius (2003, p.9) offers a useful distinction between two types of "predicted consequences". The first type, which is "commonly associated with political ideologies", comprises value statements that more often than not describe "desired consequences" and connote quality such as captured in the NLPF: equity, redress, promotion, commitment, enhance. However, the very elusive nature of such value-laden terms "could itself be a source of policy 
implementation gaps" and may at best be viewed as "desired" outcomes (Pretorius 2003, p.11). Compare the aims of the NLPF, which are to -

$\checkmark$ Promote the equitable use of the 11 official languages;

$\checkmark$ Facilitate equitable access to government services, knowledge and information;

$\checkmark$ Ensure redress for the previously marginalised official indigenous languages;

$\checkmark$ Initiate and sustain a vibrant discourse on multilingualism with all language communities;

$\checkmark$ Encourage the learning of other official indigenous languages to promote national unity, and linguistic and cultural diversity;

$\checkmark$ Promote good language management for efficient public service administration to meet client expectations and needs. (DAC 2003a, p.13, my emphasis).

How such aims are to be measured empirically and normatively thus begs the question.

The second type of "predicted consequences" comprises "basic standards" that are "relatively specific and concretely stated objectives" (Pretorius 2003, p.11). Standards are quantifiable "goods" or "services" to be "delivered" to the beneficiaries of policies within specified time frames. As far as the NLPF is concerned, its Implementation Plan states that phasing in of implementation will take place "over a reasonable period" (DAC 2003b, p.7), through a range of mechanisms and structures.

In addition to existing structures such as PANSALB (including its substructures) and language offices in the national and some provincial legislatures, three new structures to support policy implementation will be established according to the NLPF:

1. Language Units in each government department and province to manage translation, editing and interpreting services with a view to the envisaged increase in the demand for these services and also for terminology development in the indigenous languages. The establishment of these units was approved by Cabinet in July 2007, four years after the publication of the NLPF. Socalled key service delivery departments will be prioritised and monitored to ensure that they set up the units responsible for the translation of all their documents. These departments are Home Affairs, Justice and Constitutional Development, Social Development, Health, Safety and 
Security, Correctional Services, Education, Housing, Provincial and Local Government, and Land Affairs.

2. A National Language Forum (NLF), a collaborating network of representatives from government and non-government structures, to monitor the implementation process, prioritise language-related projects and drive policy advocacy campaigns under the leadership of the Department of Arts and Culture. The NLF has been (partially) functional since 2004.

3. The South African Language Practitioners' Council will be a statutory body established through an Act of Parliament to manage the training, accreditation, and registration of translators and interpreters to raise the status of the language profession and improve the quality of language products. This body will set and maintain standards. The Council Act has not yet been promulgated.

The NLPF's Implementation Plan envisages a broad range of mechanisms to facilitate implementation, i.e. terminology development, translation and editing, language technology, a language code of conduct, a directory of language services, language audits and surveys, language awareness campaigns, the Telephone Interpreting Service for South Africa, an information databank, the development of Sign Language, language learning, and budgeting. In terms of the above, precious few "goods" or "services" have to date been "delivered" except for a few multilingual terminology lists in addition to translation and editing services.

Twenty years down the lane after democracy, it is evident that democratic language policy and planning has not realized its "intended purposes" but has seemingly become trapped in the "gap" or "disjunction" between policy development and lack of policy implementation.

Similarly, the development of conceptual terminologies will be welcomed, as it would enable first-language isiZulu speakers to better engage with academic and intellectual discourse.

As earlier mentioned, the University of KwaZulu-Natal (UKZN) has announced that isiZulu will be a compulsory subject for undergraduate students from 2014. Needless to say, scholars have interpreted this issue controversially. From one perspective, language policies promoting the indigenous African languages in tertiary education support what Alexander (2001) calls the 
'democratic responsibility of the post-apartheid university'. From another perspective, however, this language policy is perceived to revert to apartheid-style Bantu education practices (Harnischfeger 1999) and as fostering ethnic identities and tribalism rather than supporting a development of a broader and more inclusive South African identity (Janks, 1992, p.11).

According to the Council of Higher Education (2013) it is a step in the right direction. But the Inter-institutional centre for Language Development and Assessment (2013) is of the opinion that the move will not set a precedent to other universities since universities are autonomous. It also said it is a positive thing because it highlights the need for multilingualism in all universities.

Previously, debates in South Africa over which language to be designated as official was also based on ethnic lines in the apartheid era. However in this case the decision of whether or not to give special status to a particular language became a rallying point for social and ethnic groups. Such social attitudes obviously can affect an individual's motivation to learn or not learn a particular language. A second consequence of a language being designated as one of the official languages of the country is that in most cases the country's official language or languages are used, or at least designated to be used, as the medium of instruction in the schools. The National Educational Policy of South Africa is a case in point. In 1997, the former Minister of Education argued that South Africa's national language-in-education policy was integral to the government's strategy of redressing the discrimination of the past and building a non-racial nation in South Africa. He contended that being multilingual should be a defining characteristic of being South African (Chick \& McKay, 2001, p.23).

Kamwangamalu (2003) reports on a similar trend in South Africa, where English is "spreading like wildfire" and has infiltrated the family domain, particularly in urban black communities, who "see the language as an open sesame by means of which one can achieve unlimited upward social mobility," and prefer English- medium education over an education in their own native languages, such as Sotho, Zulu, or Xhosa. Kamwangamalu maintains that if the current trend toward monolingualism in English continues, the African languages will face attrition and death. He points to the anxiety and agony expressed in South Africa by, on the one hand, some purists "who believe that the language is being mutilated through nativization by its new users (i.e., non- 
native speakers); and, on the other hand, African language activists and community leaders, who see the spread of English into the family domain as a threat to the maintenance and a prelude to the demise of the indigenous languages" (Kamwangamalu 2003, pp. 68-69).

The seemingly people driven spread of English in South Africa reflects a growing but worrying trend observable also in other countries. So expecting isiZulu to compete with English in the tertiary domain is comparable to 'David fighting Goliath'. Although English has acquired some negative connotations as a symbol of British domination and socio-economic gatekeeper in South Africa, its pivotal status in the sciences and research both locally and internationally is virtually incontestable, as is the fact that a mastery of English is a precondition for most professional employment in South Africa (Alexander 1993, p.154; Heugh 2002 p.12; Parmegiani 2012, p.81).

From a sociological perspective, the English language has played a paradoxical role in South Africa as it was not only the language of the colonialists, but it was also the language of the independence movement that liberated Africa (Peirce 1989, p.19). From a linguistic perspective, English has enriched many indigenous African languages by being a source of loan words but at the same time it has also marginalised them (Mazrui \& Mazrui 1998, p.79). Many sociolinguistic scholars in South Africa (Heugh 2002; Kamwangamalu 2000; McLean \& McCormick 2006; Rudwick 2010) have criticised the fact that instead of the African languages being promoted and developed, the hegemony of English has become entrenched in the post-apartheid state. IsiZulu, on the other hand, as the first language (L1) of 23 per cent of the South African population, is the most widely spoken African language in the country. The majority of IsiZulu speakers reside in kwaZulu-Natal $(\mathrm{KZN})$, where almost 80 per cent of the residents are L1 speakers. Demographically, the UKZN language policy (2006), which promotes the development of IsiZulu as a LoLT, makes perfect sense. The 2011/12 UKZN Teaching and Learning Report indicated that the majority of first-year students were IsiZulu mother tongue speakers, 46 per cent in that year.

Moreover, as stated in Nkosi (2014) UKZN is perceived as one of the premier universities in South Africa that aims to spearhead transformation and change (Ndimande-Hlongwa, Balfour, 
Mhize and Engelbrecht 2010). The UKZN language policy states 'the need to achieve for Zulu the institutional and academic status of English" and promises "facilities to enable the use of Zulu as a language of learning, instruction and administration' as well as 'the need to foster research in language planning and development'. Clearly, the UKZN language policy is also a profoundly socio-political document that 'seeks to counter the damaging and hegemonic legacy [of colonization and apartheid]' (Balfour 2007). It further symbolises the Vice Chancellor's aspirations to make UKZN the 'premier University of African scholarship' (Nkosi, 2014, p.8). Nevertheless, South Africa is one of the few countries in the world, and only in Africa which has seen, during the twentieth century, the development of a language from one which has no governmental recognition, and existed largely in spoken form, to one in which substantial parts of the government, the economy, and higher education were run. South Africa set off on another unique linguistic journey. This time, in 1994, the country became the location of an effort to develop, simultaneously, nine indigenous African languages, granting all nine along with English and Afrikaans, equal status.

From a sociolinguistic perspective, the indigenous African languages have been for obvious reasons, blatantly understudied during the apartheid years in South Africa. Over 20 years after new democratic constitution and South Africa first commitment to multilingualism, large-scale empirical studies with focus on perceptions of students of higher learning is still, it seems timely to extend sociolinguistic research to the feelings and attitudes of students. Not many African universities make use of their indigenous languages as media of learning and teaching. Scholars in the field of language planning in Africa only struggle, fight and advocate for African languages as medium of instruction while the authorities and academia are scared of discussing it.

One of the researchers who agreed with Kamwangamalu is De Kadt (2006), whois of the view that the barriers that languages is presenting for already disadvantaged students are clear, as is the fact that concerted effort towards implementing mother-tongue education at higher education levels and particularly for examinations, and towards the use of bilingual or multilingual teaching methods could go a long way to resolving these problems. 
A different approach to this question looks at language problem in the policy statement. This contrary view has shown that a study that will assess the perceptions of students on the introduction of isiZulu will add to the limited number of literatures on indigenous language and will help future study in the same area. Considering that roughly $80 \%$ (2001 census) of the population in KwaZulu-Natal consists of isiZulu mother-tongue speakers, one might assume that instruction in this language would be 'reasonably practicable' in the province. After all, the Constitution proudly stipulates that 'every person shall be entitled to instruction in the language of his or her choice where this is reasonably practicable' (Constitution 1996, Section 32).Nevertheless, English has remained virtually unchallenged as a medium of instruction in KwaZulu-Natal, as in the rest of the country.

One of the troublesome language problems addressed by Nkosi (2014) is that due to the underdeveloped nature of isiZulu academic terminology, some bilingual staff members at UKZN are currently developing subject-specific terminology in cooperation with the Zulu Language Research and Development Centre (ILRDC). For example, in workshop initiatives, 1400 Zulu terms have been developed for the discipline of Nursing and Midwifery (Engelbrecht at al. 2010, p.266 cited in Nkosi 2014). The aim is to train all students to use both English and Zulu in their clinical practice sites by engaging with community members and patients in Zulu and also to apply their bilingual skills in classroom discussions (Ndimande-Hlongwa et al. 2010, p.350 as cited in Nkosi 2014).

According to Nkosi (2014, p11) "In the School of Education, an isiZulu Academic Literacy class has been offered for post-graduate students since 2008 and the course Life Skills has been taught using Zulu as LoLT in the post-graduate programme for the Certificate in Education (Mashiya 2010). Further, there is a new project piloting a Zulu-medium Bachelor of Education (BEd) Honours programme in the School of Education. The DoE has recently announced that all primary and secondary schools will introduce an African language in their curriculum, but the current KZN secondary school system is built on English as the LoLT, hence most current students at UKZN have emerged from an English-medium schooling. While it is clear, from the above brief, that the ball (UKZN language policy) is set to roll, it has not been examined in depth 
how students and staff at UKZN feel about the prospect of being able to study in Zulu". And this exactly what this research is set out to do.

If this is not done, this may mean that isiZulu will eventually become extinct because there are not enough books written in South Africa's largest official language, and because schools are increasingly teaching in English, and those are not the only problems. One of the things I soon realised as missing from isiZulu and other indigenous languages are words related to science and technology. IsiZulu is not keeping up with the language of new technologies.

Another problem to this policy approach according to Genesee (1989) is that "contrary to most extant interpretations, bilingual children develop differentiated language systems from the beginning and are able to use their developing languages in contextually sensitive ways. A call for more serious attention to the possible role of parental input in the form of mixed utterances is made. According to Genesee $(1989$, p.13) "The most proficient bilinguals mix the most and in the most sophisticated ways without violating the rules of either language. It is normal for children growing up in these communities to mix their languages extensively because they are simply learning the patterns of communication that are common in their community. It can be difficult and unnatural, if not impossible, to keep the languages completely separate. If most people in the children's wider community use only one language, the children will eventual learn the monolingual patterns."

According to Mesthrie, \& Hromnik, (2011), a crucial question with regard to bilingualism is how to achieve stable bilingualism and prevent that stability form tipping in favour of the dominant and more prestigious language. It was estimated that from the census of 2001 that over seven million blacks in South Africa (out of a total of about thirty-nine million) have some knowledge of English.

That is not the view by Mgqwashu (2014) who opines that the success of any meaningful engagement with the development of isiZulu so that it became part of the academy would depends entirely on implementing strategies to develop its academic discourse. For most students in higher education, and the isiZulu speaking students enrolled for the module discussed in this paper in particular, this is the secondary discourse after the primary discourse of the home. 
Therefore, recognition of indigenous languages in all Africa's institutions more especially educational institutions, is a critical measure that links the African Renaissance and Africa's indigenous languages (Nkuna 2012, p12).

Some applied linguists like Ngugi (1986) argue that foundations of knowledge are best built in the mother tongue and then transferred into a language with which you are less familiar, if such a language is the general language of the education system.

\subsection{Challenges faced by the Language Policy}

One of the troubling challenges facing the use of indigenous languages is the use of English and Afrikaans as mediums of instruction, a legacy of colonialism and apartheid that continues to derail black South Africans higher education objectives. The findings of the 2008 Report of the Ministerial Committee on Transformation and Social Cohesion and the Elimination of Discrimination in Public Higher Education Institutions on students ${ }^{\text {ee }}$ academic performance had also highlighted the correlation between the language of instruction and educational outcomes, one of the most difficult challenges created by the colonial and apartheid injustice and inequalities:

The Committee found that students who are not first language-speakers of English continue to face challenges in many of the institutions. It was also found that the implementation approach to the parallel-medium language policies that are in place in a number of historically Afrikaansmedium institutions discriminated against black students. The Minister was therefore urged to initiate a broad review of the obstacles facing the implementation of effective language policies and practices, including a study of the application of equitable language policies and practices found in countries with similar social differences to those of South Africa.

The findings of the 2008 Ministerial Report highlighted the enormous challenges and difficulties higher education institutions have continued to experience and their attempts to implement their transformation policies aimed at giving effect to the commitment to multilingualism. Owing to institutional failure to create programmes that incorporate African languages and enhance the development of African languages as academic languages for classroom instruction and languages of communication, the Report recommended that the Minister should request 
institutions to indicate, as part of their institutional planning processes, how they will be addressing these difficulties. Regrettably, some of the views expressed by some people in South Africa when this policy was introduced are that it will not be practicable and realizable.

The Committee also reported that the transformation of what is taught and learnt in institutions emerged as one of the most difficult challenges facing the higher education sector. Owing to the persistence of this challenge, it was recommended that institutions should initiate an overall macro review of their undergraduate and postgraduate curricula. The object of the macro curricula review was to enable HEIs to evaluate their appropriateness and relevance in terms of the social, ethical, political and technical skills and competencies embedded in them. It is important to draw attention to the Committee's ideological stance and commitment to locating curricula restructuring and redressing the current social inequalities inherent in the higher education landscape within the contemporary social context.

The Report conveys this as follows: This should be done in the context of post-apartheid South Africa and its location in Africa and the world. In short, does the curriculum prepare young people for the role in South Africa and the world in the context of the challenges peculiar to the 21st century (MoE, 2008, p.16-17). The report highlighted some of the pertinent negative factors that continue to constrain efforts to implement the higher education transformation objectives being driven by DST/NRF Research Chairs Initiative programme. One of these is the use of English and Afrikaans as mediums of instruction and the negative impact of the usage of nonAfrican languages on African studentse qualification levels, academic performance and overall quality of knowledge production offered at historically black universities.

On the other note, there are views that the use of European languages as mediums of education in South Africa and the rest of the African continent has continued to reduce the quantity and quality of knowledge production on the continent. In his keynote address at SAALA Conference, Alexander (2004) highlighted the negative effects on the usage of English and Afrikaans instead of African languages as mediums of education in South Africa as follows:

Africa is at the bottom of the world's educational league table. This realisation, deriving from the pressures for achieving Universal Primary (or Basic) Education, was the reason for what 
has turned out to be the decisive move in the sphere of language education, that is, the gradual but definite turn by an increasing number of Africa states to what I shall call mother tonguebased bilingual education. Unless the educational systems of the continent are based on the mother tongues of the people of Africa instead of on foreign languages as most of them are at present, all attempts at establishing a platform for improving the quality of education will in the final analysis, benefit only the elite and its progeny. This is not yet acknowledged even by the most courageous of our intelligentsia. It is still impossible for most African intellectuals and academics to conceive of universities where the main languages of tuition are indigenous African languages.

Research studies (Mawasha, 2006; Lao and Krashen, 1999; Mzamane et al., 2000; Crystal, 2000; Ngubane, 2003; Sepota et al., 2003; Alexander, 2004) have not only rehearsed the findings of 2008 Ministerial Report of non-use of African languages as medium of instructions, but have also endorsed the thesis that African schools and higher education institutions can only succeed in providing innovative and stimulating education, which addresses the massive failure and

dropout rates, and are capable of enhancing learner/student performance if indigenous African languages become mediums of instruction. Hence, making the "many languages and tongues" of the Rainbow Nation work together, namely using bilingualism / multilingualism that exploits a combination of indigenous African languages and European languages, have been the focus of countless South African government policy documents (DoE, 2002; DoE, 2003; DAC, 2004; DAC, 2007). It is noteworthy and ironical to state that the call for the need to research and to prepare for mother-tongue-instruction education in South Africa appears to have been answered by only traditionally white universities.

\subsection{The Pan South African Language Board (PANSALB) and New Language Policy in South Africa}

The PANSALB is charged in the constitution with the task of promoting the use of all the official languages and it is their job to implement the NLPF. Part of their mission is to enable South Africans to free themselves from all forms of linguistic discrimination, domination and division, and to enable them to exercise appropriate linguistic choices for their own well- being as well as for national development (PANSALB, 1998). PANSALB views language in South 
Africa as a right and a resource as opposed to a problem. They also acknowledge that "the best way for language development to occur is for the language to be used...for a language to survive, it must be used for a wide range of functions otherwise it begins to wither and die. Thus, were we to have allowed higher status functions to be limited to English and Afrikaans only, the other languages of the country eventually would begin to wither and die" (PANSALB 1998, p.2).

The difficulties involved in language planning decisions compelled the democratically elected government of 1994 to reach a compromise in the language issue. Then Ministry of Arts, Culture, Science and Technology formed the Language Action Task Group (LANGTAG) as a forerunner to the Pan South African Language Board (PANSALB) to bring a solution to language issues. PANSALB was granted constitutional power to ensure that all languages are developed and properly represented in the language policy (South Africa Constitution, 1996). PANSALB completed the final draft of the National Language policy Framework, and submitted it to the Minster of Arts, Culture, Science and Technology who then submitted it to parliament for the necessary legislative Act.

The National Language Policy Framework (NLPF) is the major document and binds all government structures to a "multilingual mode of operation". The other important document is the Language in Education Policy issued Ministry of Education in 1996. Ministry of Education has another document called the Language Policy of Higher Education which places power to determine language policy in higher education. Western Cape has managed to produce a document called The Western Cape Provincial Languages Act of 1998. All these documents are important in the development of South African languages.

Antia (2000) affirms that the development of a language also depends by and large on the planning of its corpus. Even if the policy can elevate the status of language, corpus development of language is a major step that will bring practical experience in the implementation process. In 1822 the British authorities issued a formal declaration based on language use in the Cape colony as part of Anglicization where English was declared as the only official language. The Dutch speaking community resisted this policy and the resistance laid the foundation of language planning in a strict sense after the formation of the Union of South Africa in 1910. The legislated language use incidentally led to the standardization of certain indigenous languages through the 
system of "divide and rule", the politics that allowed indigenous languages to be used within ethnic designed areas.

Language planning in South Africa takes into consideration an understanding that official language policies were used by the apartheid ideology to establish and consolidate Afrikaner nationalist hegemony, ethnic separation and institutionalized inequality. The language policy is objectively designed to maintain ethnic diversity and the politics of compromise.

National Constitution (1996) which states that a Pan South African Board established by national legislation must:

$\checkmark$ Promote, and create conditions for, the development and use of (a) All official language (b) The Khoi, Nama and San languages(c) Sign languages

$\checkmark$ Promote and ensure respect for: (a) All languages commonly used by communities in South Africa, including German, Greek, Gujarati, Hindi, Portuguese, Tamil, Telegu and Urdu (b) Arabic, Hebrew, Sankrit and other languages used for religious purposes in South Africa.

According to Chick (1992), the important challenge is the promotion of the notion of "language ecology in which all languages are viewed as national resources needing to be preserved so that the talents of their native speakers may be optimally utilized for the good of all.

The main challenge to the South Africa language policy is the problem of implementation. The actual content of the official language policy is determined by specific regulation of language use in interactions between the state and the subjects. The problem of implementation is the discourse used to mobilize people of various language groups behind language planning initiative in the country. The emphasis is on equality and equity, language rights versus language and other use, and practicability. The concepts of equality and equity refer primarily to the status of the official language. This is reflected in the statement: All official languages must enjoy "parity of esteem" and be treated equitably (South African Constitution, 1996).

Looking back at the history of official denigration and neglect of the indigenous languages, a need for differential and preferential treatment is important at this stage in South African 
linguistic landscape. Parity of esteem; would suggest that considerations of practicality can be put aside and a sincere effort made to ensure that no particular languages dominate to the neglect of others. These also ensure the protection of minority languages. Equitable use of the official languages is also related to the freedom to exercise language rights. Language rights, freedom of language choice, recognition, protection and promotion. African languages are positively associated with tradition and culture. Ethnicity is a symbol of individual's identity and intimate social relations. Linguistic differences are allowed to address the communication situation of particular community. For the purposes of "practicality" it may be argued that the object of the constitutional language policy is to provide protection for the diversity of languages. The language of choice only means the language that could be used in so far as that would be "reasonably practicable". Reasonably practicable refers to as the "escape clauses" (together with usage, expense, regional circumstance, etc.). As a result the South African Language Policy is politically and ideologically functional.

However, the status planning in South Africa has addressed issues of the history of apartheid and the birth of a democratic state. The language stipulations show major strength in promoting diversity, political participation and access to services. The official language policy was intended to make one or more designated, or more identifiable language official in domains of legislation, justice, public administration and education

There are certain strategies that need to be followed in ensuring a successful implementation of the language policy in South Africa. Any language can only be developed and preserved properly through corpus planning. European languages are able to serve as means for communicating specialized information and knowledge, "crucial to the pursuit of goals on the global agenda, e.g., the environment, international public health, empowerment, democratization and good governance. English language is now seen as claiming a more and more dominant status despite a policy that uplifts the status of the languages in South Africa. Socio-economic pressures, the need for international communication standards and stable geo-political relations as the contributing factors towards language death and a shift to monolingualism. The implementation of the language policy requires the development of teaching material and other applications. Corpus planning involves providing terminologies to serve socio-economic development. It also involves developing new vocabulary and discourse which will in turn help 
in the development of teaching material and other applications. This encourages people to use their languages in all domains. There is need to establish a context and innovative influence through information and motivation. The availability of learning material in all official languages in South Africa serves as means and provides an opportunity for development and motivation to use these languages. The systematic developments of these languages need to be pursued until people accept their languages as commonly used in all domains (DoE, 1997).

Language specialists should take advantage of new and technologically-based initiatives to develop and preserve each and every language in South Africa. Computers can play an essential role in corpus planning especially in development of dictionaries and localizing content. The research focused to corpus development should be encouraged. This will help in designing assessment and training material for schools and speech therapy. This will help in lifting the level of literacy in African languages in South Africa. Trying to avoid marginalizing languages will depend on the use of new and acceptable conventions and the involvement of the designated audience.

\subsection{The Perception of Students towards Learning in the IsiZulu Medium}

Gardner (1982) defines an attitude as a mental and neural state of readiness, organized through experience, exerting a directive or dynamic influence upon the individual's response to all objects and situations with which it is related. It is argued that learners' have different attitudes towards languages that they learn and speak. Liebschner and O'Cain (2009) postulates that learners' and the society as a whole vary considerably in their attitudes to the language they are learning and to the people who speak that language. Liebschner and O'Cain (2009) further illustrates that these subjective attitudes can also influence language learning in less obvious ways. What is therefore important to take note of is how language attitudes influence other kinds

of social behaviors'. These social behaviors' become necessary for this study because they can shed light on the various attitudes that students' may have towards the learning of isiZulu as a compulsory module in the university context. 
Students' perception towards learning in the English medium varies in relation to their beliefs, wants and needs. Most, if not all students attitudes are an indication of what society propagates. According to Van der Walt (2004), the international and economic prestige given to the English language is what encourages students as well as their parents to portray a positive attitude towards learning in the English medium. Van der Walt (2004) goes on to explain that this is not a phenomena that is restricted to South Africa, but it is instead a growing global trend. In the article written by Van der Walt (2004), he explains that the reason for the students' positive attitudes towards learning in the English medium stems directly from their strong belief that English is the direct link to employment, as well as global communication. In the light of the above revelation in these literatures, it has become obvious that this language policy that allow for isiZulu to become a compulsory module will be received by non-isiZulu speaking students alike because of the numerous arguments that have been put by so many author in support of an indigenous language to be used in the tertiary level of education.

Researchers in recent studies on learners' attitudes towards African languages indicate that many learners' express appreciation for their African languages (Rudwick, 2004, 2008; Kapp, 2004; McKinney, 2007; Nongogo, 2007; Ndlangamandla, 2010; Zungu \& Pillay, 2010; Turner, 2012).

In a study conducted by Rudwick (2004) among isiZulu-speaking youth at Umlazi Township in Durban, Rudwick found that most isiZulu-speaking learners' linked the speaking of isiZulu to the Zulu culture and identity. Rudwick (2004) asserts that, learners' viewed speaking isiZulu as being loyal to one's culture. Unlike learners' in De Klerk (2002) study who expressed a strong preference of English over isiXhosa. Rudwick's (2004) study indicated a positive outlook towards the use of African languages by learners'. Rudwick (2004:164) further reports that many learners' expressed being disappointed that besides African people, other citizens of South Africa were not making an effort to learn African languages, in Kwazulu Natal; the learners' were disappointed that many white people are not making an initiative to learn isiZulu. This has created the gap to assess the response of students to conversational isiZulu as a compulsory module because most of the students are Indians and their home language is English. However, Rudwick (2004) elaborates that most learners' viewed isiZulu as being a valuable language but they also recognized that isiZulu is not often given credit for its value. Learners viewed English as being a threat to isiZulu. 
A study by McKinney (2007) focusing on African learners' use of indigenous languages in ExModel C schools found that African learners in desegregated suburb of Johannesburg saw the use of African languages as necessary for their African identify. Just like in Rudwick (2004) study, learners' who were perceived as devaluing African languages by not speaking those languages or often use of English; these learners' were labelled as "coconuts". The concepts of coconuts come from the view that those labelled coconuts are "white on the inside but black on the outside". This term is used to shame others who are perceived as not valuing their own African language.

Furthermore, a study by Nongogo (2007) conducted at a private racially desegregated high school in Gauteng indicated that many African learners' were comfortable in using their African language. Nongogo's (2007) study found that depending on the space and purpose of conversation, learners' alternated between isiZulu and English.

Drawing on observations and interviews Ndlangamandla (2010) conducted a study using two desegregated independent schools in Johannesburg. The study focused on learners' language practices and their views towards the use of African languages in South Africa. The study was useful in capturing learners' views on how they negotiate between languages through codeswitching and code-mixing. However the study failed at capturing learners' perspectives on African languages use in the classroom as well as in other domains in the school. It is therefore such gaps that this study aims to address by focusing and exploring students' perceptions towards the use of isiZulu as a compulsory module in the university.

Though the above mentioned studies paint positive attitudes towards use and the teaching of African languages, studies by Barkhuizen (2001), De Klerk (2002), Kapp (2004) and Langa (2005) indicate that there are strong negative attitudes by learners' towards the use of African languages. A study by Barkhuizen (2001) indicated that learners' favoured the use of English more because they saw isiXhosa as being inferior. De Klerk (2002) also indicated that isiXhosaspeaking learners perceived English to be more interesting than their mother-tongue. They also perceive English to have economic advantages than isiXhosa. Further up in the Limpopo Province, a study by Langa (2005) conducted at Capricorn High School indicated that learners' felt that they gained more knowledge when English was used compared to Northern Sotho which the learners' felt was less valuable than English. 
These studies mention in here set the background for exploring students' perception of conversational isiZulu as a compulsory module in a South African university context. Though these recent studies captures the students' attitudes towards African languages across South Africa, my study will address the knowledge gap that needs further exploration in the south African university context where isiZulu is taught as a compulsory to many non-IsiZulu-speakers at the university in Kwazulu Natal.

Nevertheless, a crucial issue that has been addressed with the introduction of isiZulu is that it will open windows of opportunity as an answer to numerous challenges faced by several indigenous languages which has been marginalized in Africa. This policy has the capacity will position IsiZulu to become known globally through its use at the university level. It is obvious that Africa languages is in dire need for reforms and UKZN has taken the bull by the horn as an African Premier University of African scholarship coupled with the platform laid by the country's constitution unlike what is obtainable in so many African nations. I think this should go beyond rhetoric to include detailed implementation strategies and resources for its development and learning in the University.

The issues raised in the literatures as used in the language policy reflects conflicting ideologies emanating from the history of this country and illuminates the politics that led to the formation of a democratic state in South Africa where equality reigns. Subsequently, Ethnicity and group demands have had a significant role in language discussions that led to the formation of the current language policy. According to literatures, when planning to introduce a new language policy especially in the higher learning, status planning should be complemented with corpus planning to ensure that languages are properly developed.

\subsection{Conclusion}

In this chapter, I have presented the various language policies in South Africa and their implications in a South African university. I have also discussed the studies on how students' generally responds to being taught languages that are often perceived as inferior by presenting an international as well as a local perspective. The findings in the literatures on language acquisition reveal that there are still some gaps which this study will address on this new language policy shift in the University of KwaZulu-Natal. This means that if taken seriously, this language policy 
shift can contribute immensely in building a balanced society and a prosperous South Africa. This will surely help those who neglect indigenous language learning for fear that the first language negatively interferes with the learning of a second language. In the next chapter, I will discuss the theoretical framework that framed this study. 


\section{CHAPTER THREE}

\section{THEORITICAL FRAMEWORK}

\subsection{Introduction}

The previous chapter dealt with review of literature relevant to this study. It gave account of the historical development of IsiZulu as a language from the apartheid era till the democratic dispensation. This chapter is going to explain the framework with which this study is built upon. In doing this it will be important to bear in mind that the study will assess students' perception of the introduction of IsiZulu as a compulsory module in the university. So the theory it will use as its framework will be the second language acquisition learning theory.

\subsection{Theoretical Framework}

The theoretical and conceptual framework, which informed and framed this study (students' reception of conversational isiZulu as a compulsory module in a South African university) emerged first from the second language acquisition learning theory and its two forms, namely the additive and the subtractive models, and related models of second language teaching which are the transitional and immersion models.

One of the expectations and assumption of bilingual education is that the product becomes successful both linguistically and culturally, but it is only possible when the form of bilingualism is additive rather than subtractive (Hornby, 1977; Genesee, 1977). Subtractive bilingualism arises out of a situation where the second language is acquired without accommodating the linguistic skills that have already been developed in the first language (Mwamwenda, 1996). Such situations are evident in societies where one language is considered as having a more prestigious socio-economically determined status than the other, which is regarded as inferior (Jeffreys, 1996; Hornby, 1977; Roy-Campbell, 1996). In this model, the students' L1 skills are replaced by the L2, thereby placing linguistic and cultural systems in conflict instead of complementing one another (Robinson, 1996). The subtractive model thus disadvantages bilingual children (McLaughlin, 1990) since studies by Hakuta (1986) in Travers, Elliot and 
Kratochwill (1993) show that children with a high degree of bilingualism have a better level of cognitive development.

In the additive model, Lambert (1977) says that bilingualism arises out of a situation whereby society attributes positive values to both the individual's first language and second language. In other words, children will be adding a second language at no cost to the development of their first language. Borich and Tombari (1997) observe that the development of additive bilingualism does not have any negative effect on the students' academic, linguistic or intellectual development. A more additive process of bilingualism is when the student's first language and associated culture are nurtured and supported, then the second language is later introduced (Genessee, 1977). Travers, et al (1993) regard transitional bilingual programs as those that use the students' first language for the purpose of rapid development of English L2 to occur so that students can quickly move on to an English only program. The rationale behind transitional models is to use the students' first language only to compensate for their lack of proficiency in English, so as to prepare them for immersion in English as a second language (Lemlech, 1994).

Immersion programs are described by Borich and Tombari (1997) as those that place nonEnglish speaking learners in an English only classroom with a teacher who speaks the students' native language. The principle is that the second language is used as the medium of instruction and the children's mother tongue is only used when students fail to understand a concept.

Dulay, Burt and Krashen (1982) consider immersion programs as consisting of full and partial models. Full immersion happens when programs begin in kindergarten and extend to upper grades. In partial immersion, there is early immersion which includes some subjects in L2 and others in L1, while late or delayed immersion involves subject matter in L2, starting at upper elementary or high school and tetiary. The official education language policy for South Africa falls under the transitional model, and the delayed immersion program. This model of bilingualism in South Africa is also used by countries which share the same historical background of colonialism such as Kenya and Nigeria (Cleghorn, 1992). In view of the above, I will further discuss how this study is conducted under this framework. 
In view of these studies, the question raised is: does classroom language teaching help? Classroom teaching helps when it provides the necessary comprehensible input to those students who are not at a level yet which allows them to receive comprehensible input from "the real world" or who do not have access to "real world" language speakers. It can also help when it provides students communication tools to make better use of the outside world, and it can provide beneficial conscious learning for optimal Monitor users.

Various research studies have been done comparing the amount of language competence and the amount of exposure to the language either in classroom-years or length of residence, the age of the language acquirer, and the acculturation of the language acquirer. The results of these studies are consistent with the above acquisition: the more comprehensible input one receives in lowstress situations, the more language competence that one will have.

\subsection{Cummins Second Language Acquisition theory}

Cummins is one of the world's leading authorities on bilingual education and second language acquisition. Mainstream teachers who have knowledge of his theories and act on his advice will be in a much stronger position to help the students in their classes.

\subsubsection{BICS/CALP}

Cummins makes the distinction between two differing kinds of language proficiency. BICS are Basic Interpersonal Communication Skills; these are the "surface" skills of listening and speaking which are typically acquired quickly by many students; particularly by those from language backgrounds similar to English who spend a lot of their school time interacting with native speakers.

CALP is Cognitive Academic Language Proficiency, and, as the name suggests, is the basis for a child's ability to cope with the academic demands placed upon her in the various subjects. Cummins states that while many children develop native speaker fluency (i.e. BICS) within two years of immersion in the target language, it takes between 5-7 years for a child to be working on a level with native speakers as far as academic language is concerned. 


\subsubsection{Additive/subtractive Bilingualism}

Cummins draws the distinction between additive bilingualism in which the first language continues to be developed and the first culture to be valued while the second language is added; and subtractive bilingualism in which the second language is added at the expense of the first language and culture, which diminish as a consequence. Cummins (1994) quotes research which suggests students working in an additive bilingual environment succeed to a greater extent than those whose first language and culture are devalued by their schools and by the wider society.

\subsubsection{Its Implications for mainstream Teachers}

The dangers of subtractive bilingualism for the non-native speakers in our school are obvious. Nevertheless, we should do all we can to demonstrate to non-native IsiZulu speaking students that their cultures and languages are equally as valid and valued as the indigenous culture. Teachers and departments of education should explore every possibility to incorporate the different cultural backgrounds of our students into their daily teaching and curricula.

Furthermore, Cummins work has featured strongly in studies on bilingualism and his most notable contribution to the field of academic literacy is captured in his distinction between Basic interpersonal communication skills (BICS) and Cognitive Academic Language Proficiency (CALP). Cummins (1980) defines CALP as "those aspects of language proficiency which are closely related to the development of literacy skills in L1 and L2", while BICS comprise the skills that are needed for oral fluency.

Hence Cummins' theory of academic language acquisition compares strongly with Vygotsky's Zone of Proximal Development (ZPD) which argues that there is a symbolic distance between a learner's actual development level and the level of potential development under the guidance of and through collaboration with adult or expert (Jaramillo, 1996). Though Vygotsky's ZPD theory was meant as a general theory of learning, it has received much support in language learning circles, particularly in relation to the notion of scaffolding in language acquisition.

Plausible as it is, Cummins' theorisation has not been without criticism. Criticism was harsh and forthcoming. Notable criticisms have been that the distinction represent the ability to take tests 
and do not necessarily predict how well the student will do in academic contexts (since CALP is regarded as measurable in a test) and that CALP promotes a deficit theory as it attributes academic failures of bilingual minority students to a lack of CALP rather than to other aspects such as schooling (Edelsky cited in Shore and Sabatini, 2009).

However, Cummins in Otto (1997) is also of the view that language can be used in the form of Cognitive Academic Language Proficiency (CALP) which requires sound literacy skills, vocabulary that is broad to allow for subject-matter mastery, concept development and skill in formal oral and written expression. And by virtue of it being used in formal education, CALP can be viewed as a prestigious form of language usage and in the South African context; English is accorded the role of CALP (Otto, 1997). Another main form of language use is regarded as the Basic Interpersonal Communication Skills (BICS), a form of L1 which is acquired in early childhood and meant for social access due to its relatively limited vocabulary. Otto says in South Africa, the L1 is accorded the role of BICS which has contributed to negative attitudes towards the first language, because of it not being used as CALP, during the initial years of schooling. I think this language learning method is most suitable for students who are learning Conversational isiZulu as a second language in the university.

As Cummins (2000) states: "Conceptual knowledge developed in one language helps to make input in the other language comprehensible. Cummins has devised a model whereby the different tasks we expect our students to engage in can be categorized. In the case of this study tasks range in difficulty along one continuum from cognitively undemanding to cognitively demanding; and along the other continuum from context-embedded to context-reduced. A context-embedded task is one in which the student has access to a range of additional visual and oral cues; for example he can look at illustrations of what is being talked about or ask questions to confirm understanding. A context-reduced task is one such as listening to a lecture or reading dense text, where there are no other sources of help than the language itself. So, one can say that Conversational IsiZulu is a context enriched not context reduced module.

The neglect of the students' L1 is unfortunate because several studies show that not only does the use of L1 enhance the development of writing skills in bilingual and L2 students, but it also helps these students to construct their bilingual and bicultural identities (Reyes, 2001, Reyes \& Azuara, 2008). Gutierrez, Rymes, and Larson (1995) noted that this usually happens in classes where 
students and teachers express their thoughts and interests freely as they engage in different learning activities in an unrestrictive space.

\subsection{Other related discussions on second language teaching}

There are also other ways to acquire new languages. Many linguists as well as experienced and successful bilinguals argue that it is highly desirable for multi-cultural societies to support the use of a first language in the learning of young bilinguals in schools (Scarcella, 1990 in Tompkins and Hoskisson, 1995). Hence, mother tongue education in the primary years offers the best introduction to literacy that eventually becomes useful in the acquisition of English as a second language (Westley, 1992 in Mwamwenda, 1996; Hawes, 1979; Hakuta, 1986, in Travers et al, 1993).

Research on L2 acquisition shows that if a child masters the first language, then learning another language becomes less problematic in that habits of speech, listening, reading and writing which can be transferred to the learning of the second language (Cummins, 1981; Hawes, 1979; Obanya, 1985; Dawes, 1988; Krashen, 1985 in MacLaughlin, 1987). Cummins (1981) in Kroll (1990, p.95) claims that there is an "underlying cognitive/academic proficiency" common to languages and this enables transfers of literacy related skills across languages.

However, it must be noted that there are some research findings which show that transfer of skills across languages is not automatic (McLaughlin, 1987). For this reason, Sprosty (1995) is of the opinion that second language learning can be aided by effective teaching of the language arts in the first language. Sprosty goes further to say that knowledge about the transfer of skills between languages is important since teachers who are sensitive to the role played by the first language in developing second language literacy skills are in a better position to use those relationships in preparing learners to become proficient in the $\mathrm{L} 2$.

In South Africa, the view that the skills transfer from the L1 to the L2 is expressed in the language currently in use, where lecturers are strongly discouraged from introducing English reading very early in the year, since students who speak English as a first language need to first have sufficient understanding of spoken IsiZulu on which to base the early reading vocabulary, and second, an elementary reading ability in IsiZulu. Thus, some of this will transfer to English, 
and the two languages can function as separate reading media without confusing the students, but to present both codes at the same time results in uncertainty and confusion for some students.

As indicated by the conversational IsiZulu course packs, additive bilingualism allows lecturers to emphasize the acquisition of oral language which is necessary in reading and writing in Isizulu as a second language. This view is supported by experts on language teaching cited by Sharp in Ngara (2002), who generally agreed that in the early stages of second language learning, oral language development is crucial. Learning to read before the spoken word is mastered is to invite "Pseudo-literacy" which is a problem predominant in many African nations where children fail to become competent in both the L1 and the L2 (Hawes, 1979; Duminy 1975; Bamgbose, 1991).

A growing body of research also suggests that bilingualism promotes overall cognitive development (Borich and Tombari, 1997). These authors observed that studies by Hakuta, Friedman and Diaz (1987) indicate that bilingual children perform better on tests of analytical reasoning, concept formation and cognitive flexibility. Travers et al (1993), however, state that the findings that the higher the degree of bilingualism the better the level of cognitive attainment is only possible when the first language is maintained, the social climate is positive, and when the non-English speakers are not negatively judged. Experimental work carried out by Peal and Lambert (1962) in Jeffreys (1996) also suggests that those bilinguals who loved and respected both of their languages showed positive effects in the areas of creativity and mental flexibility as compared with monolinguals and those who believe that one of the languages is better than the other.

Whereas those who learn through their L1 are at an advantage, students who learn through a second language are disadvantaged (Wallwork, 1985; Ngara, 1982; Macnamara, 1973; Miti, 1995). Chaudron (1988) asserts that in a learning situation where only the L2 is used as a medium of instruction, students face problems because their task is threefold. The first is that the student has to make sense of the instructional tasks which are presented in the second language.

In light of the findings that bilingualism has positive effects and that the mother tongue is crucial in the initial phase of the students' school life, UKZN found it necessary to implement an education language policy which recognizes an indigenous language as a language of instruction. This was done through the use of the transitional or the late immersion model of bilingualism 
where students would learn in another language as a way of expanding their linguistic horizon. It was hoped that this language policy for the students would reflect some of the expectations and assumptions of bilingualism that the students understand concepts better in their world; skills would transfer from the L1 to the L2; all instruction in L2 should be delayed until initial literacy in the L1, and that some oral fluency in the L2 is achieved.

McLaughlin (1985), however, noted that the major problem of the transitional model is that there is a tendency to emphasis IsiZulu at the expense of their first language. Instead of using linguistic and cognitive development in the first language for later development in the second language, many programmes in this bilingual model give superficial attention to mother tongue instruction and sometimes students are exited into the L2 medium of instruction before they have mastered enough of the language to enable them to access the curriculum. In this study, it is expected that IsiZulu and English reading will be done at the same time before students had acquired sufficient oral language in the L2.

As explained in the above section, Cummins (2000) distinguishes between Basic Interpersonal Communication Skills (BICS) and Cognitive Academic Language Proficiency (CALP) - the registers of language that students acquire in school and which they need to use effectively if they are to progress successfully through the grades. Basic Interpersonal Communication Skills (BICS) is context embedded and used in social situations. BICS is about the development of conversational fluency. CALP describes the use of language in decontextualized academic situations, where higher order thinking skills are developed such as analysis, synthesis and evaluation.

Although students may be able to use IsiZulu competently among peers and in social settings (BICS), they may not be proficient in the type of language expected in the classroom (CALP) (Cummins, 2000). Cummins states that L2 students could take about seven years to be competent in IsiZulu and to reach the same level as their first language. Drawing on research in Cananda, Feinberg (2002) contends that it takes four to seven years to develop the ability in second language to achieve term success in the curriculum (Feinberg, 2002).

Chomsky (1965) explains that the logical problem of learning is caused by messy and fragmentary input, and by teaching abstract concepts based on limited examples. This 
inadequate language input is at times due to teachers' own limited English language proficiency. Krashen (1982) argues that the essential ingredients for L2 acquisition of good reading comprehensive input is through teacher talk. Krashen (1982) argued that second languages are best and most successfully taught in a friendly natural way, or encountered spontaneously, for example, in the playground. Such conditions allow the second language to be acquired in much the same way as L1 is acquired.

Krashan's arguments link to the method of language learning referred to as Communicative Language Teaching (CLT). British linguist, D. A. Wilkins (1972) cited in Hernández (2011) stressed the functional or communicative aspect of language learning rather than the traditional concepts of grammar and vocabulary. Wilkins emphasized the systems of meanings that lay behind the communicative uses of language. CLT emphasizes learning to communicate in the second language or target language through social interaction. Hymes (1972) explains that the key aim of language teaching is to develop communicative competence. Classroom activities used in communicative language teaching include the following role-play, pair work, group work, games. The teacher gives space for students' personal experience to be linked to classroom learning. The idea is that students gain communicative competence in an authentic, meaningful context. CLT is a learner centered approach and gives prominence to the interests and needs of the student.

In summary, the above-discussed studies suggest that lecturers need to create supportive writing environments and opportunities that encourage bilingual and L2 students to express themselves in meaningful ways. When this happens, not only will these students come to appreciate learning a second language as a meaningful and authentic learning activity, but they will also be encouraged to explore their bilingual and bicultural identities. Furthermore, supportive writing contexts will encourage bilingual and L2 students to develop as critical writers who are able to 'write the word' and 'write the world' - to paraphrase Freire and Macedo (1987). In my study, I was keen to assess students' perception of conversational IsiZulu as a compulsory module in a South African university. 


\subsection{Conclusion}

In this chapter the discussion was focused on the theories and studies that informed this study which is to assess students' perception of conversational IsiZulu as a compulsory module in the university and how they become the bedrock on which the study stands. I made use of the second language acquisition theories because all the respondents are students from L2 background and looking at this study from this lens will help us to understand the direction of the study. In the next chapter, I will discuss the methods of data gathering that I have employed in this study. 


\section{CHAPTER FOUR}

\section{RESEARCH DESIGN AND METHODOLOGY}

\subsection{Introduction}

The primary aim of this study is to assess the reception of conversational IsiZulu as a compulsory module in a university, especially in the sense that most of the participants are non native speakers of the language. The previous chapter deals with the theoretical framework that informed the study. This chapter discusses the type of research methodology, and methods used in this study. Methodology refers to the steps involved in a given approach.

In this chapter, the significance of the study, the problem statements, the research question, and limitations of the study will be described. The various qualitative research strategies, approaches, and techniques will be explained. Types of interviews conducted will be described, and the chapter will also identify and discuss the type of research method the researcher adopted for the study.

\subsection{The specific research problem}

The relationship between language and power is a complex phenomenon. This is because according to Bourdieu (1992) there is a strong relationship between language and power in privileged social contexts. Bourdieu (1992) argue that language is used as a power symbol to promote and advance the dominance of the elite societies while marginalizing others. The marginalization can take place in many forms but for this paper, the focus is on how the dominating languages are used to marginalize the languages which are perceived as inferior to dominating languages. The specific research problem to be explored is focused on understanding students' perceptions of learning isizulu as a compulsory module in a South African university. IsiZulu is one of the main African languages in South Africa, understanding learners' responses that are taught such a language in a privileged schooling context is of vital importance to this study. Using observations, semi-structure interviews and focus groups interviews, and this chapter has gathered data that gives insight to students' perceptions of isizulu as a compulsory module in a South African university context where English is prioritized while other languages are trivialized. In chapter 2, a critical look was taken to assess the factors that influence the 
students' perceptions to languages that are often perceived as inferior in university contexts. This chapter addresses the specific problem being researched in this study which is titled: Assessing students' perceptions of Conversational IsiZulu as a compulsory module in a South African university. The aims of the research (see Chapter 1), are namely to:

- To understand the attitudes of students of Conversational IsiZulu among first year students enrolled in the course.

- $\quad$ To ascertain why students perceive Conversational IsiZulu the way they do.

\section{The key research questions are:}

1. What attitude do the students have towards the introduction of conversational IsiZulu as a compulsory module in the school of Education?

2. Why do they have these particular attitudes?

3. What do students perceived to be the strengths and weaknesses of conversational IsiZulu module?

4. Why do students perceive the strengths and weaknesses the way they do?

To answer the research question, and to reach the aims, first I present the context of the study, then a qualitative research design which has been selected will be explained next.

\subsection{Context of the study}

According to Durrheim (2006:34) "the research design of a study can be better understood as a strategic framework for action that serves as a bridge between the research questions and the execution or implementation of the research". Durrheim (2006) further postulates that the importance of a research design is first to describe how a study should be conducted, then what critical aspects the study ought to focus on; this can include when, also from whom and under what conditions the data were gathered and collected, and how the data were analyzed and interpreted. Following Durrheim's approach, this study describes the main focus as being the assessing students' perception of conversational IsiZulu as a compulsory module in a South African university. This study also describes how data will be collected from the students' who are enrolled for conversational isiZulu module using observations; semi-structured interviews 
and focus groups interviews. A qualitative research design was considered appropriate in the light of the research problem. According to Creswell (2003:14), "qualitative researchers deal with socially constructed realities and qualities that are complex and indivisible into discrete variables". Furthermore, Merriam (2002:29) view the task of qualitative research as the one of attempting to describe, to understand and to interpret how various participants in a social setting construct the world around them.

Accordingly, I have based this study on a qualitative design because it employs an inductive strategy which Creswell (2003) describes as being not based on predetermined or preconceived ideas but rather based on perspectives that emerge from the data itself. Qualitative research aims at the development of perspectives and understanding, for the purpose of this study, the aim is to assess students' perception of conversational IsiZulu as a compulsory module in a South African university.

Qualitative research method was used in this thesis to gather record and analyse the data. A case study design was used to unpack the students' reception of conversational isiZulu as a compulsory module in the university. I am of the opinion that the case study design is appropriate for this project, for the aim is to obtain rich description of students view on the module. The aim is consistent with the qualitative research which is concerned with understanding the social phenomenon from the participants' perspective (Babbie, 2004, p45).

\subsection{Case Study Design}

According to Gillham (2000) a case study is founded on the basic philosophical assumption that human behaviour, thoughts and feelings are partly determined by their context and that how people behave, feel and think can only be understood if one gets to know their world and what they are trying to do in it . Yin (1994:13) describes a case study as an empirical enquiry that "investigates a contemporary phenomenon within its real-life context, especially when the boundaries between phenomenon and context are not clearly evident". It can also be said that case studies also take into consideration other contextual conditions such as the classroom, the culture of the school and other surrounding social factors. In this study the classroom, the culture

of the school and other social factors were taken in consideration because of the critical role they 
play in the everyday lives of the participants. Yin (2009) further argues that all social aspects may be highly significant to the phenomenon under study. Yin (2009) also distinguishes the three main types of case studies which are: exploratory, descriptive and explanatory. The study under investigation was predominantly a descriptive and explanatory case study in that it aims to describe the context and then answer the questions of 'how' do the students perceive the introduction of Conversational isiZulu as compulsory module in the university.

\subsection{Definitions of Case Study Research}

From some of my readings on case study research, in a broad definition, it is a process of conducting systematic, critical inquiry into a specific phenomenon of the researcher's choice to generate data to contribute to the wide knowledge of the specific knowledge. Yin (2003, p. 2) defines the case study as, "an approach allowing investigators to retain a holistic and meaningful characteristics of real-life events." However, according to Maree (2007), a case study provides the richness and depth of descriptions from the participant's point of view. Leedy and Ormrod (2005) argue that a case study allows for the pursuit of an in-depth data gathering for the purpose of learning more about an unknown or poorly understood situation over a defined period of time. Further, it is very instrumental when one wants to unearth new and deeper understanding (Lapan, Quartaroli \& Riemer, 2012).

In conducting a qualitative inquiry, a case study approach is one method that can accommodate a variety of research designs, data collection techniques, epistemological orientations and disciplinary perspectives. I used a case study approach since it "provides unique examples of real situations" (Cohen, Manion \& Morrison, and 2000, p.181). A case study enables a researcher to "penetrate situations in a way that are not always susceptible to numerical analysis" (Cohen et al. 2000, p.181).

In the light of the above concern and against the background of hegemony of English language this study examines perceptions of students towards the language policy that allows for isiZulu becoming a compulsory module. It specifically focuses on students' perception. Further, it enabled me to empirically investigate how the students received conversational isiZulu as a compulsory module in a real-life context, using multiple source of evidence (Maree, 2007). It examines a case over time, in detail using multiple sources (McMillan \& Schumacher, 2006). In 
my study the case is how students received conversational isiZulu as a compulsory module in the university.

A case study is a qualitative research method used to examine contemporary real-life situations and provide the basis for the application of ideas. Yin (1984) defines the case study research method as an empirical inquiry that investigates a contemporary phenomenon within its real-life context; when the boundaries between phenomenon and context are not clearly evident; and in which multiple sources of evidence are used (Yin, 1984, p. 23).

In the same vein according to Cohen, Manion \& Morrison (2011) case studies can establish cause and effect ('how' and 'why');indeed one of their strengths is that they observe effects in real contexts, recognizing that context is a powerful determinant of both causes and effects, and that in-depth understanding is required to do justice to the case. It is appropriate for this study because as Yin (2009) puts it, a case study can enable readers to understand how ideas and abstract principles can fit together.

A single case study was used in this research due to the following reason: it can be said that case studies emphasize detailed contextual analysis. They can penetrate situations in ways that are not always susceptible to numerical analysis. It is deemed appropriate in this study because assessing the perceptions of how and why the students feel the way they do about the introduction of Conversational isiZulu fits a case study mode of inquiry. It will give insight into a relatively new phenomenon, the reception previously marginalised at a university and as a potential medium of teaching and learning.

These are my reasons for choosing case study design for this research project. I agree with Creswell (2007) who explain that case study provides a comprehensive examination of a single example and delivers a unique illustration of real people in real situations. It involves the study of an issue, through one or more cases in a bound system, with the goal of developing a full understanding of each case as possible.

From my reading of Merriam (1998) I have learnt that a case study does not have any particular method of data collection therefore any method of data collection maybe employed to address the research question posed. Indeed case-based research leads to detailed data about phenomenon being studied, no matter what particular research methods have been employed. 


\subsection{Strengths of case study Research}

Simons (2009, p.23) outlines some of the following strengths of using a case study research design:

$\checkmark$ It can allow the researcher to document multiple perspectives, explore contested viewpoints and to explain how and why things happened.

$\checkmark$ It is useful in exploring and understanding the process and dynamics of change, through closely describing, documenting and interpreting events as they unfolds in the 'real life' setting, it can determine the factors that were critical in the implementation of programme or a policy and can help analyse pattern and link between them.

$\checkmark$ Case studies are flexible, that is, neither time dependent or constrained by method. It can be conducted in a few days, months or several years and can be written up in different forms and length appropriate to time scale.

$\checkmark$ It has the potential to engage participants in research process. By this it is meant, that there is a shift in the power base of who controls knowledge and it recognises the importance of co-constructing perceived reality through relationships between the researcher and participants.

\subsection{Limitation of Case Study Research}

It is important as a researcher to acknowledge some potential limitation that case study research present. These are highlighted by Simons (2009, p.24):

$\checkmark$ The subjectivity of the researcher is a concern for too much personal involvement in the research process can be problem.

$\checkmark$ While the reports we write cannot capture the reality as lived, there is much we can do to highlight the timing of the study and the partial nature of interpretations so the readers can make their own judgements.

$\checkmark$ The usefulness of the findings for policy determination is partly dependent upon the acceptance of different ways in which the validity is established and the findings are communicated in case study research.

$\checkmark$ It is very important to mention that a case study research form generalisation for policymaking is not the aim. But the aim is to present a rich portrayal of a single setting to 
inform practice, establish the value of the case and to add to the knowledge of a specific topic.

The question of generalisation in case study research is an on-going debate. It must be noted that some writers have claimed that case study of a single case, is limited because its findings cannot be generalised to other cases.

In a deeper sense, Thomas, (2005) explained that case studies are analyses of persons, events, decisions, periods, projects, policies, institutions, or other systems that are studied holistically by one or more methods. The case that is the subject of the inquiry will be an instance of a class of phenomena that provides an analytical frame and object within which the study is conducted and which the case illuminates and explicates.

\subsection{Research Paradigm: Interpretive Paradigm}

An interpretive paradigm provides opportunities for looking deeply into the world of participants; their experiences and actions. Such an orientation accepts the inseparability between values and facts and attempts to understand reality, especially the behaviour of people, within a particular social context (Cantrell, 1993). According to Cantrell (1993), interpretive researchers are keen to understand the meaning people make of daily occurrences and how they interpret these within the contextual social and natural setting that they find themselves. Interpretive research regards people as agents of creation of meaning in their settings and these meanings are valuable and useful for research (Janse van Rensburg, 2001 p.16). Such an approach acknowledges that people's interpretations and interactions with their situations create reality.

The epistemological assumption in this paradigm is that events are understood through the “individual's mental process of interpretation, which is influenced by and interacts with social context" (Cantell, 1993 p. 83). Cantell maintains that reality within the boundary of the perspective of interpretivism is "multiple and divergent" (Cantell, 1993 p.83). This means that reality is not only situated and contextual but also that people may experience the same phenomenon differently. Locality is based on social meaning and these meanings are not static.

According to Terre Blance and Kelly (1999) interpretive research makes sense of data within a particular context. The central endeavour in context of the interpretive paradigm is to understand the subjective world of human experience (Cohen, Manion and Morrison, 2007, p.32). 


\subsection{Research Methods}

The study was qualitative in nature. According to Maree (2012) qualitative research is based on a naturalistic approach that seeks to understand phenomena in context (real world settings). Further, in general the researcher does not attempt to manipulate the phenomena of interest. In other words, research is carried out in real-life situations and not in an experimental (test-retest) situation.

The qualitative approach enabled me to gain insights into the second language acquisition by students in the university. I was able to discover the problems that exist in the schools pertaining to learning conversational isiZulu. According to Barbour (2007, p.13) the qualitative approach, "seeks to unpack how people construct the world around them, what they are doing or what is happening to them in terms that are meaningful and which offer rich insight." Further Barbour (2007, p. xiii) states that, "the approach takes context and cases seriously for understanding an issue under study." This approach provided the study with the richness and depth of descriptions from the participants' point of view (Maree, 2007). It enabled me to describe and analyse students, individual and collective social actions, beliefs, thoughts and perceptions of students on the introduction of Conversational isiZulu in the University of KwaZulu-Natal.

In qualitative research, subjective and personal views and experiences are acknowledged. Qualitative research, therefore, is concerned with exploring people's life history or everyday behaviour in the context in which they make meaning of their lives (Silverman, 2000, p.1). This type of research allows the researcher to study selected cases (defined later in this section) in depth (Denzin \& Lincoln, 2003, p.5), and draws on a variety of methods to understand the phenomenon. To Strauss and Corbin (1990), qualitative research is best for when we want to know the experiences, attitudes, beliefs, and perspectives of the target population. It allows the research participants to speak and makes it easier to access the meaning that people have constructed (McMillian \& Schumacher, 1993). Working within a qualitative research design enables the researcher to participate in the world of the individual to understand the experiences and perspectives from the participant's points of view (Cantrell, 1993, Creswell, 1994, Fields, 1995, Savin-Baden, 2000, and Merriam, 2002).

Within qualitative research, an interpretivist approach was most relevant since it allowed me to apply reflective interpretation of the phenomenon (Gall, Borg, \& Gall, 1996). Erickson (as cited 
in Gall et al. 1996) defines interpretive research as the study of the immediate and local meanings of social activities for the actors involved in them. Kirkegaard (2001, p.27) describes the interpretive paradigm as "... a search for deep perspectives on particular events and for theoretical insights. It may offer possibilities, but no certainties as to the outcome of future events".

\subsection{Methods of Data Production}

The data production techniques that were used in the study are semi-structured interviews and observation. In the context of data generation, good research relies on strong data. In this case systematic organization of the data is important. This study collected and stored multiple sources of evidence comprehensively and systematically, in formats that can be referenced and sorted so that converging lines of inquiry and patterns were uncovered. It involved deciding what information to gather and why, and the best way to gather it: when, how and from whom. In gathering and interpreting the information, this research will make use of interviews and observations in data collection because in a case study the researcher has to engage fully with the participants to gain fully knowledge of the issue at hand.

According to Creswell (2009) data generation in a case study occur over a "sustained period of time.". Case studies bring interesting, real-world situations into the classroom study of classroom management. By discussion with students, I learned that decision making is often a confrontational activity involving people with different points of view.

Firstly, I determined and defined the research questions, and then I selected the cases and determined data gathering and analysis techniques. Furthermore, I prepared to collect the data, collect data in the field, evaluated and analyzed the data before I prepared the report. After this, I further investigated the object of the case study in depth using a variety of data gathering methods like interviews and questionnaires to produce evidence that leads to understanding of the case and answers the research questions.

Empirical data collection methods were largely based on interviews. An interview is an art of urging participants to detail answers to pertinent questions. Interviewing is the ability of the researcher to utilise his skill in asking questions, that will elicit the desired information, and intently listening to the response (Denzin \& Lincoln, 2003, pp.56-57). There is a situated 
understanding between the interviewer and participants in an interactive environment. However this method is largely influenced by the interviewer's personal attributes such as gender, class, race and ethnicity.

The interview schedule I 1 used had two sections: Participants completed the first part of the questionnaire giving their personal details. The rest of the questionnaires were directed at assessing students' perceptions towards the introduction of conversational isiZulu as a compulsory in a University of kwaZulu-Natal.

In this dissertation, qualitative information was collected by data gathering tools which included the following:

- Observation recordings

- Semi- structured Interviews

- Focus group Interview

- The keeping of reflective journals

\subsubsection{Interviews}

I used interviews as the means to generate data. An interview occurs when researchers ask participants questions and record their answers (Creswell, 2012). And according to Cohen et al. (2007) an interview is an exchange of views between two or more people on a topic of mutual interest for production of knowledge. The interview was conducted with the purpose of providing contextual information on students' perceptions of the introduction of Conversation IsiZulu as a compulsory module in the university. The interviews enabled me to get rich descriptive data and to view the world through the eyes of the participants (Maree, 2007). They allowed the participants to discuss and interpret the world in which they live, and express their own points of view regarding the situation (Cohen et al. 2011). They are very useful since they yield a great deal of useful information (Leedy \& Ormrod, 2005). I used both semi-structured and focus group interviews.

From my reading of Simons (2009, pp.43-44) these are some of the purposes of interviewing. Firstly, 'it is to find out what is in and on someone else's mind.' Secondly, it is the active 
engagement and learning it can promote in identifying and analysing issues. Thirdly, it is the flexibility it offers to change direction to pursue emergent issues, to probe a topic or to deepen a response? And lastly, it has the potential for uncovering and representing unobserved feeling and events that cannot be observed. The interview questions consisted of open-ended questions. Sarantakos (1998: 255) notes that one of the distinguishing criteria for qualitative interviews is that they use open-ended questions. Unlike closed-ended questions, open-ended questions give no possible responses. There were a total of 20 interview questions. All these interviews were tape-recorded for later analysis.

\subsubsection{Semi-structured Interviews}

I used the semi-structured interviews, because they are ideal for interviewing participants who are not hesitant to speak and who can share ideas comfortably (Creswell, 2012). I also used it because of its flexibility. They allowed for the use of probes and required the participant to answer a set of predetermined questions (Maree, 2007). The probing technique allowed for the use of standard questions that are individually tailored to get clarification or probe a person's reasoning (Leedy \& Ormrod, 2005). They are best suited for the study because they allow the use of the phrase to accommodate individual response (McMillan and Schumacher, 2006). One semistructured interview was conducted with each student. The challenge of using semi structured interviews is that it can get side tracked by issues that are not related to the study (Maree, 2007). As a researcher it was my duty to always guide the participants back to the focus of the research.

\subsubsection{Focus Groups Interviews}

Focus groups are a research technique that collects data through group interaction on a topic determined by the researcher (Morgan, 1996: 130). Focus groups interviews were used in this study to collect data through group interact where the group discussed their responses towards the teaching of isiZulu as a First Additional Language. De Vos et al. (2005:299) on the other hand describe a focus group interviews as a way of obtaining a better understanding of how people feel or think about an issue, product or service. The focus group interviews allowed the researcher to have a better understanding of the participants' feelings and thoughts about being taught isiZulu as a First Additional Language. Focus group interview also create a process of sharing and comparing among the participants, and according to De Vos et al. (2005:299) focus 
groups interviews are powerful means of exposing reality and investigating complex behaviour and motivation. Morgan (1996) suggest that the interaction among participants often consists of their efforts to understand each other, as they convey a willingness to listen without being defensive, which is uniquely beneficial in emotionally charged environment.

The focus group interview allowed for an open conversation between the interviewer and the interviewees, with the opportunity to clarify questions and answers in order to ensure accurate responses. Each participant was able to comment, ask questions and respond to comments by others. In this study, the focus groups interviews consisted of five grade 10 learners' enrolled for isiZulu First Additional Language. The group discussion was conducted for an hour.

\section{Advantages of using Focus Groups Interviews}

According to Kitzinger (1995) focus groups interviews have an advantage of providing participants with an opportunity to engage in a group discuss. Focus groups can encourage participation from those who are reluctant to be interviewed on their own. Focus groups do not discriminate against those who cannot read or write which may be challenges, participants can find when using questionnaires.

Kitzinger (1995) further argues that focus groups advantage is that they provide insight into sources of complex behavious and motivations. A comparative advantage of focus groups interviews is its ability to enable the researcher to identify quickly the full range of perspectives held by the participants. Focus groups interviews also allow participants to clarify or expand upon their contributions to the discussion in the light of points raised by other participants, thus expanding on contributions that might be left underdeveloped in an in-depth interview

\section{Disadvantages of using Focus Groups Interviews}

Focus groups interviews are less effective as an investigative tool for the disclosure of personal and sensitive information. As a researcher, going in I was aware of this shortfall, hence the questions were not personal or sensitive in nature. Focus groups interviews are not effective 
when dealing with sensitive topics. It can sometimes be difficult for participants share their real feelings towards some sensitive topics publicly. This can in turn influence the output data.

Another disadvantage of focus groups interviews is that, focus groups draw upon spontaneous rather than carefully considered responses. This in turn may influence the results of the study. A focus groups interview can also tend to become influenced by one or two dominant people in the group discussion. This can influence the results to be very biased.

\subsubsection{Observations}

Observations played an important role in gaining insight into various situations in my research context. It covered events in real time and on site of the classroom activities. Non-participants observation assisted me towards gaining understanding of the case and provides me with firsthand the opportunity to investigate the students' reception of Conversational IsiZulu as a compulsory module in the university instead of just from second-hand accounts provided via the other data collection methods for the study. I observed the lessons several times. My role here was that of non-participant observer, in that I was there present in the classroom and my role as a researcher was made known to the lecturer and the students but I did not in any way participate in the social interaction going on inside the classroom. Observation can strengthen the validity of the research (Simons, 2009).

According Jorgensen (1989) using observations is a qualitative method which is aimed at learning more about the perspectives held by the study populations. Participant observation always takes place in community settings, in locations believed to have some relevance to the research questions. The method is distinctive because the researcher approaches participants in their own environment rather than having the participants come to the researcher. Generally speaking, the researcher engaged in participant observation tries to learn what life is like for an "insider" while remaining, inevitably, an "outsider." While in these community settings, researchers make careful, objective notes about what they see, recording all accounts and observations as field notes in a field notebook. Informal conversation and interaction with members of the study population are also important components of the method and should be recorded in the field notes, in as much detail as possible. This research is therefore interested in 
observing peoples behaviors as they naturally occur in terms that appear to be meaningful to the people involved.

\section{Advantages of using observations}

Jorgensen (1989) the first advantage of using observations is that, observations are good for gaining an understanding of the physical, social, cultural and economic context in which the study participants live. A second advantage of using observations is that, observations covers events in real time, this will give the researcher an opportunity to observe live events. A third advantage of using observations is that, observations enable researchers to develop familiarity with the cultural milieu thus allowing the researcher insight into contexts, relationships and behaviors.

\section{Disadvantages of using observations}

The first disadvantage of using observations can be found in the difficulty of documenting the data. Jorgensen (1989) argue it is hard to write down everything that is important while you are in the act of participating and observing. A second disadvantage of using observations is that it is an inherently subjective exercise, whereas research requires objectivity. It is therefore important to understand the difference between reporting and describing what you observe (more objective) versus interpreting what you see (less objective).

\subsubsection{Reflective Diary}

I recorded my observations in my reflective diary and made entries after each visits to the lecture room, since the beginning until the end of the research. I made notes including any change, what needed to be done on what I had learnt in the process. During the writing of my dissertation I read and re-read my personal raw data so as not to leave out any information that maybe vital to draw up conclusions to this study.

\subsection{Sampling and Participants}

McMillan and Schumacher (2006) view subjects, sometimes referred to as participants, as the individuals who participate in the study and from whom data are collected. The sample was 
drawn from an independent school which consisted of learners' from different social backgrounds. A small sample of 10 students' was selected. In this case, I am interested in understanding the perceptions of students from diverse cultures, ages and genders and how they perceive the introduction of conversational isiZulu as a compulsory module. The research participants will be drawn from 10 students who are non-native speakers of IsiZulu. I will make use of purposive and convenient sampling method.

A purposive sampling method was used to select participants, because it allowed for the use of the pre-selected criteria relevant to the study (Maree, 2007). According to Creswell (2012) in purposive sampling the researchers intentionally select individuals and sites to learn or understand the central phenomenon. It allows for the use of people or units who are appropriate for the study (Leedy and Ormrod, 2005). It allowed me to select the information-rich participants and groups for the study (McMillan \& Schumacher, 2006). Cohen et al., (2011, p.156) state that in purposive sampling, "the researcher hand-picks the cases to be included in the sample on the basis of their judgement of their typicality or possession of the particular characteristics being sought"

The students offering this module were interviewed using semi-structured interviews. For sampling my opinion is that sample size does not matter much and is not a major consideration in case study research as "the concern is not so much for representative sample (indeed the strength of case study approach is that the case only represents itself). (Cohen et al.2011, p.294). The ease of access to this sample is an advantage in that it allowed for easier process.

\subsection{Trustworthiness}

The aim of trustworthiness in the study pursuing the qualitative approach is to support the argument that the findings of the study are very crucial to pay attention to (Lincoln \& Guba, 1985). In the study four issues of trustworthiness were attended to: that is the credibility, transferability, dependability and confirmability (Lincoln \& Guba, 1985). According to Lincoln and Guba (1985, p.296), "credibility is an evaluation of whether or not the research findings represent a credible conceptual interpretation of the data drawn from the participants original data." Transferability is the degree to which the findings can be transferred and be applied to 
other situations (Shenton, 2004). Dependability is about the quality of data collection, data analysis and theory the data collected (Lincoln \& Guba, 1985, p.34).

In addressing credibility, firstly, the data was collected from the students through observations, interview and focus group interviews and were analysed. The intention was to develop three layers of data. This technique meets the technical definition of triangulation (Lincoln \& Guba, 1985). The use of multiple sources of data confirmed the data tying up (Lapan, Quartaroli \& Riemer, 2012). Secondly, I completed member checking (Lincoln \& Guba, 1985). In the process of member checking research participants reviewed a summary of data analysis procedure and a summary of the final results of the study.

In addressing the transferability in the study I included in (Appendix D) and several of the documents used to generate data the answer to the research questions (Lincoln \& Guba, 1985). In ensuring dependability and conformability, I relied on an independent audit of my research (Lincoln \& Guba, 1985, p.34).

Data generated in this study by qualitative approach was verified as credible through triangulation. I made use of triangulation in the collection of data which means that two or more method of data collection was used in this study.

\subsection{Ethical Issues}

Ethics is a critical part of the research process from initial formulation of the research to the research issue to the interpretation and reporting of the research findings. To the best of my knowledge, ethical issues were taken care of in order to respect the rights of the participants. In conducting research the issue of confidentiality of results and findings of the study and the protection of the participant's identities is crucial (Maree, 2007). Participants were informed of the purpose of the study and the reciprocity, assessment of risk, confidentiality, informed consent; and data access as well as ownership of data was attended to (Creswell, 2012).

The ethical clearance approval from the University of KwaZulu-Natal Ethics committee was granted (see appendix V, page 124). Signed consent forms were obtained from all participants (see appendix I, page 118). Confidentiality and anonymity was consistently ensured and pseudonyms were given. Participants were kept informed of every step of the process they were 
involved in. Informed consent was obtained. Participants were informed that they could withdraw whenever they wish to

\subsection{Limitations of the Study}

The limitations of the study are acknowledged. The major limitation of this study was the rarity in coming across the relevant literatures to review in relation to the topic. This study is concentrated on the realities of students in their respective context; therefore generalizations cannot go beyond these cases since the data is limited to what is collected from the participants. It is for this reason that the findings from this study cannot be generalized (Leedy \& Ormrod, 2005).

\subsection{Conclusion}

The chapter opened with an introduction. The research paradigm was presented, covering the issues of ontology, epistemology and methodology. The discussion of the methodology using the qualitative approach moving on to explain why I chose to adopt a case study design was covered. The methods of data production that covered semi-structured and focus group interviews were clearly presented. Further, the sampling, participants and piloting were put forward. It gave detailed briefing of data analysis, trustworthiness, and ethical issues and touched on the limitations of the study and the chapter summary. The next chapter deals with the data presentation and discussion. 


\section{CHAPTER FIVE}

\section{ANALYSIS AND DISCUSSION}

\subsection{Introduction}

In this chapter the presentation, discussion and interpretation of the findings will be given. The previous chapter dealt with research methodology. In this chapter the data gathered will be analysed and discussed in the light of the research questions. This chapter will presents the findings and discussion of the study in order to answer the three critical questions generated in chapter one.

According to Cohen et al (2007:461) the data analysis can be described as a process of "making sense of data in terms of the participants' definition of the situation". The data presented in this chapter was generated from Grade 10 learners, who are taught isiZulu as a First Additional Language at a private school in Durban (KwaZulu-Natal). The data is drawn from classroom observations, focus groups interviews and individual interviews.

As indicated in Chapter 4, Cohen (2007) explains that qualitative researchers analyze data by organizing it into categories on the bases of themes. In this chapter I present the themes which were drawn from patterns that emerged from raw data, which was categorized into themes. Using the mentioned research instruments, the responses from the learners are presented and some references to the relevant literature are made in order to support the points being put forward. In order to respect the confidentiality of the participants, the participants were given pseudonyms.

I will now discuss and analyse this data bearing in mind that the objectives of the study which are:

- To understand the attitudes of students of Conversational IsiZulu among first year students enrolled in the course.

- To ascertain the reason for students to perceive Conversational IsiZulu the way they do. 
As previously said, in presenting the data, the key research questions are used as a framework to present and discuss the data. A discussion of the data within the framework of the theoretical and conceptual tools as well as relevant literature is also presented.

As a matter of fact, specific questions addressed in this research are:

1. What attitudes do the students have towards the introduction of Conversational isiZulu as a compulsory module in the school of Education?

2. Why do they have these particular attitudes?

3. What do students perceive to be the strengths and weaknesses of Conversational isiZulu module?

4. Why do students perceive the strengths and weaknesses the way they do?

\subsection{Presentation of Semi Structured Interview and focus group interview}

This section presented in summary from the data of the semi-structured interviews relating to students views on the introduction of conversational isiZulu as a compulsory module in the university. The findings for each area are given. See Appendix for the questions in detail. In the entire interview, 10 students were interviewed in total. During the interview schedule questions, the researcher asked the students about their names which were not be disclosed in this study due to ethical reasons.

The intention of this study was to look at students' perception towards being taught isiZulu as a compulsory module. As indicated in Chapter 1, by perceptions I wanted to understand students' attitudes, actions, their thinking and their reaction towards being taught isiZulu as a First Additional Language. In addition, I wanted to look at how isiZulu is perceived in the university as a compulsory module. This study has been framed using second language acquisition theory. I found that, generally, the students' perceptions were positively towards the teaching and learning of isiZulu as a compulsory module. I also found that students' appeared to appreciate isiZulu because they claimed it reinforced their African identities. Though the students' responded positively towards the teaching of isiZulu, they also presented their concerns about the usefulness of English in the global employment context. 
I attempted to answer the targeted research questions through the review of the literature, and by conducting interviews with 10 students out 1287 students actively involved in the learning the module in the University of KwaZulu-Natal. The data presented in this chapter is an analysis of responses to interview questions I administered.

Using qualitative methods approach enabled the researcher to explore the experiences of students through a series of closed-ended, and open-ended qualitative questions. I examined the perceptions of students through open-ended, qualitative interview questions. The data analysis and report of findings will prove beneficial in the process of validating the overall research study.

\section{Research Question 1: What attitude do the students have towards the introduction of conversational IsiZulu as a compulsory module in the school of Education?}

The data indicates that there are several reasons why students choose to enroll in the learning of isiZulu as compulsory module. Question 1 in the research was an attempt to get a first-hand response from the students. Students indicated several reasons to enroll in the module apart from the fact that it is compulsory. Italicized responses (depicted in Chapter 5) summarize the students' comments. One of the major reasons the students enrolled in the module was because it is compulsory and because they wanted to experience the sense of integration and support the program offered. The learning of conversational isiZulu provided the students with a family-like structure, support, comfortable, and safe environment - which are the factors that students were looking for. The students were interested in an isiZulu learning, which was provided by the university. They did not state any objection whatsoever. Some of the students stated that they will enroll in the learning of Conversational isiZulu module seemed a good idea because of the benefit it offers and closer relationships they have built with the other students and faculty members.

Another major reason for students to have a positive attitude in the learning of Conversational isiZulu was because of the academic support and resources and the opportunity that abound in learning a new language. Students wanted an extra language and help the learning isiZulu provided such as in class tutoring and in their social circle. For example, students' works closely 
with their isiZulu tutor and mentor to prepare to them for the learning experience in the university.

Another stated reason for the positive attitude in the learning of Conversational isiZulu was that the desired or required classes were linked together, providing a block schedule for the students. This has proven beneficial for most first-time students who want to take basic skills classes and learning Conversational isiZulu offer these classes as part of their program. This helps the students ease into the university life, enroll in the desired classes and take advantage of the community structure and support of the program.

Students also stated that they enrolled in the learning of Conversational isizulu because they know that the IsiZulu language is now an important language. Other students emphasize their attitudes for the module emanate from the fact that it is now compulsory. While other talk of the support and guidance offered in the program by their lecturers, others mentioned that it would help them continue their learning and increase their persistence towards learning isiZulu. They said by being involved in the module and creating support groups, students' motivation towards isiZulu increased.

The findings suggest that, in general, students have a positive view towards the teaching of isiZulu. There were a number of reasons that contributed to the participants' positive view towards the teaching of isiZulu. It was clear from the responses that participants valued being taught isiZulu. The majority of the students argued that studying isiZulu allowed them an opportunity to learn more about other South African culture and heritage. The participants' responses revealed that being taught isiZulu gave them a sense of pride in being among the Zulus. Many of the participants noted that isiZulu as a FAL gave them skills that allowed them to be able to communicate with others not only at school but also within their communities, particularly also at home, where they were expected to speak only in English. Crystal (2009) argues that language expresses identity and is always present in identity formation and identity display. Crystal's (2009) argument is relevant for this study because the participants also viewed the identity of an individual as being interlinked with one's language. The study also found that the participants also felt strongly about the maintenance and preservation of one's language because, as they argued, if one loses track with their language then a part of their identity is also lost. 
These findings resonate with Scheffler's (2007) argument which highlights the importance of preserving African languages. Scheffler (2007) further argues that when a language dies, so does the culture, identity and knowledge that were passed down through that language. The findings of the study revealed that the participants felt strongly about their heritage and the role that being taught isiZulu played in reinforcing who they are.

\section{Research Question 2: What do students perceived to be the strengths and weaknesses of conversational IsiZulu module?}

An effective learning environment along with other factors can make learning conversational isiZulu successful according to the participants. I define success as increase in students acceptance rates, positive student learning outcomes, and overall, student that like the module. I feel that the data collected was not sufficient enough to adequately answer this research question thoroughly. The administrator and the lecturers were not included in this research and this could have provided some significant insight to answer this question theoretically, but no quantitative data was gathered to illustrate the comparison of strengths and weaknesses. However, the interviews with the students revealed some common factors that they believe is necessary for the learning to be successful, and some of these factors also have been revealed through the literature review by the researcher. The factors mentioned in the data collections are: The data indicates that lecturer's involvement and commitment is one of the most important factors that need to be present to make the learning of conversational isiZulu successful. This was also indicated by the student data when they stated that one of the things that they liked the best about the learning of conversational isiZulu was the lecturer's attitude towards them. I think the lecturers' motivation and dedication makes a huge difference in the success of the learning conversational isiZulu. When the lecturers are not dedicated or motivated enough, the success of the learning is affected and so is students' morale, as is apparent through some of the students' comments about one of the lecturer not being as committed and/or motivated compared to the rest.

A thorough planning of the curriculum and instructions is also very important to the success of the learning of conversational isiZulu. This can be accomplished through collaboration of the lecturers, especially when they are team-teaching. Proper planning and aligning of courses are 
important because they enhance students learning outcomes by reducing the instruction material complexities and student confusions.

Another important factor revealed by the data was that lecturers support is essential for the success of the learning of conversational isiZulu. University support is important to boost tutors morale as well as the students. Just by knowing the university is there to support them, students feel appreciated and wanted, and this may result in positive learning outcomes.

Notwithstanding, the students interviewed made mention of the size of the classrooms and that large numbers of student are in the same room at the same time as one of the weaknesses. One of the students suggested that it will be nice if there are more lecturers so that they will be able to see the students on one - on - one basis. Some say there is no enough campaign and awareness on the importance of the module by the school management.

One of the students says: I don't think so because after all it is a language that you are speaking and two periods a week is not enough to learn a complete language. This was when they were asked if enough time was allocated for the class. Some say that more lecturers should be employed to cater for all students.

\section{Research Question 3: Why do they have these particular attitudes?}

The discussions from the observations, focus groups and the interviews presented an eyeopening account for me because it gave me the opportunity to have a better understanding of the various factors that have played a role in informing the students' perceptions towards the teaching of isizulu in the university. The study found that there were three main factors that contributed in informing the learners' responses. The first one was policy; the study found that the language policy at the school where this study took place was the motivation for the students' perceptions. Social factor is another reason given by the learning students based on the factors such as improvement in their ability to interact with others, and contribution to group discussions in academic and social settings. These are the factors behind the attitudes that these students exhibited in the response to the interview questions. 
The interview included many questions that prompted the students to express their satisfaction of the language policy. After going through the participants responses, I concluded that this is a good indicator of the effectiveness of the teaching and learning of Conversational isiZulu. Most of the students felt that the learning of Conversational isiZulu helped them develop the interpersonal skills such as group communication, teamwork, helped them develop academically and personally, and improved their education persistence. And this might be the reason why they have this positive attitude. They all felt so free doing this module. There is no sign of coercion in this doing this module and I feel that the classroom environment created this positive attitude that most of the participants exhibited. They said learning isiZulu will give them an edge and increase their flexibility as school teachers and when they become teachers.

\section{Research question 4: Why do students perceive the strengths and weaknesses the way they do?}

The students' perception of what they might see as strengths and the weaknesses of this module may be informed by the fact that this being a new introduction and everything seems to be in embryonic stage at this moment, so it will be too early to draw a conclusion.

Although some of the students interviewed complained about the small classrooms, they also complained that there were not enough campaigns about the introduction in the campus. Some even said that there are too many students in one class, so they suggested that smaller groups can be created in order to allow them see one on one with their lecturers.

A student pointed out that: Yes, as I said it will help you to adapt yourself in a different situation, as a teacher you go into a classroom, you won't get everybody speaking the same language or they won't be able to understand us effectively. So I think if you have basic understanding of an additional language you will be able to be better, more flexible and will be able to teach belter.

Another student suggests that he wish they were asked to do this from the primary school. This statement can be linked to the theoretical framework that hence, mother tongue education in the primary years offers the best introduction to literacy that eventually becomes useful in the acquisition of a second language (Westley, 1992 in Mwamwenda, 1996; Hawes, 1979; Hakuta, 1986, in Travers et al, 1993). 
Therefore, from the data collected, one could say that the students' positive perception on the introduction of isiZulu as a compulsory module overshadows the negative feelings and this may be borne out of the fact that isiZulu was not their mother tongue. They see it through the eyes of a second language learner which includes mixed feelings of joy in learning something new and challenging at the same time in the reality of the learning process.

It is evident that the students interviewed in this study are effective and successful to a major extent.

\subsection{Overview of classroom observation of students}

This section will describe the observation of the lectures, the use of instructional techniques and the socio awareness being created in the classroom environment. The researcher used key aspects to categorize important information into themes.

There was a creative vibe in the classroom that was observed. The lecturers facilitate their work in a structured way. They interacted with students in a very relaxed manner, and were aware of their particular learning needs. The lecturers encouraged the students to get the support of their peers as they checked each other's work and offered suggestions. The learning environment was conducive and students were stimulated as they engaged in interesting and relevant classroom activities pertaining to the aspects that were taught during the lectures. The class consist of students with majority of the students being Indian. All the students are learning Conversational isiZulu as a compulsory module. The lecturer as observed is aware of the class composition and she seems to know the students very well.

The lecturers under observation made use of many resources to deliver the lecture such a chalkboard, poster and the course packs. The lecture was mainly based on pronunciation of some isiZulu word since majority of the students are non-native speakers of the language. The lecturers displayed excellent explanation skills and were very thorough in their instructions. They used a lot of repetition because there were many IsiZulu second language speakers in the class. During my observation, I noticed that, the lecturer associate new words with simple explanation to reinforce vocabulary skills in students learning Conversational isiZulu. 
Sometimes, the lecturers taught with a lot of demonstration which the students found interesting. The lecturers were also very comfortable with code-switching and from time to time they made use of English in their class and they also allows the students to code switch too. Most of the new words students learnt were linked to their daily experience such as visit to shopping mall, safety at home and school.

Most times vocabulary was extended when new words are taught and the students are guided and scaffold throughout the lectures. There is a lot of space for questioning and there is sufficient evidence of subtractive and additive bilingualism taking place in the classroom. In this observation, the researcher noted that key Cummins second language acquisition theories were used in the main teaching and learning activities. This was also noted by the researcher in my reflective journal.

\subsection{Challenges faced by the students in learning Conversational IsiZulu as observed \\ $\checkmark$ Too many students in one class \\ $\checkmark$ Many English speaking students who experience difficulties in learning the concept of IsiZulu language. \\ $\checkmark$ Communication is a problem because of language barrier. \\ $\checkmark$ Students need plenty of repetitions of instructions. \\ $\checkmark$ This is time consuming.}

\subsection{General findings of Conversational IsiZulu teaching as observed}

As observed, two Conversational isiZulu lectures that were observed were influenced by the fact that the lecturers are skilled in the teaching approach which is mainly interaction as supported by the theory. The researcher uses the ideas from Tyobeka (2006) that may be regarded as critical for second language learning development.

- Phonemic awareness (which is understanding of sound in spoken words)

- Vocabulary (learning and using new words)

- Fluency (reading with speed, accuracy and understanding)

- Comprehension (understanding the meaning of what they read) 
In keeping up with the above statement, the lecturers also make use other language teaching approaches like direct translation, questioning techniques, etc. Larry Vandergrift (2003) explains that "learners instructed in a second language often uses bottom up and top down processes which he refers to as the direction of processing. They are often used to mark a distinction between information from perceptual sources and information derived from contextualized ones. "This statement explicitly states that students actually spend most of their time translating what they heard before actually giving it a meaning.

Second language is a very touchy subject in the classroom presently and lecturers handle it by encouraging students to never make use of their home language/mother tongue but to rather speak as much isiZulu as possible. This has its perks but according to Cummins(2000) conceptual knowledge developed in one language helps to make input in the other language comprehensible. This is how to go about teaching learners the skills they require in a second language. He believes that promoting a second language does not mean discontinuation of the students first language, instead we should use the learners language skills in their first language in order to help their acquisition of the second language. So, if student knows the meaning and the concept of the word in their home language, all they will be required to do is to find the label for this word in the isizulu language. This is the theory all Conversational IsiZulu lecturers should put into practice when dealing with second language IsiZulu learning students.

It has shown that dedication, effort and enthusiasm on the lecturer's side can make the project a success and I have no doubt it will successfully motivate students to excel in their studies and improve their spelling and vocabulary. From the classroom observation, it is seen that the lecturers make good use of questioning techniques which allows the student to interact and also give their own opinions. Their questioning was also used in scaffolding the students from the known to the unknown.

In another extended writing lesson, while the students were still restricted in terms of the length of the dialogue, they were free to write about any topic of their choice. The instruction was "You are going to write your own dialogue. The dialogue must not be more than ten lines and it must not be less than five lines." Contrary to other learning activities I observed, in this lesson the lecturer had given the students models of a dialogue: three pieces she had generated herself and another piece from the course pack. 
I observed that all the dialogues had few exchanges between the characters and tended to focus on a particular language structure. For example, the dialogue in the course pack followed the same structure: a question and answer structure with the first character asking a question and the second character providing an answer, with most of the answers starting with either a "yebo" meaning "yes' or "cha" meaning "no". Furthermore, although the dialogue was about the topics to which the students could relate, such as buying a favourite chocolate, preparing supper, and doing shopping; the structures of the sentences were controlled. This seemed to have affected the natural flow of the dialogue and may have undermined the content. In fact, the fact that the teacher did not encourage the students to talk about the content of any of the model dialogues may have conveyed the message that content is not important, a view that may also have been unintentionally conveyed by the substantial amount of time the lecturer spent teaching the dialogue structure, using the model dialogues.

In sum, the discussion on writing in this class shows that in large part writing was a controlled activity, which was intended to teach specific skills. Writing was not about exploring ideas, expressing cultural identities, and/or discussing knowledge about a particular topic (Calkins, 1994; Franklin, 1999; Hendricks, 2009). In all the lectures I observed this lecturer spent half of the time in each lesson drilling the students on how to combine syllables with vowels to form words. This culminated into the spelling test illustrated below:

Lecturer: [talking to one group] Ngicela abantu baka p-. (May I have a p-sound group). [A group of students went forward]. Ngizonibizela umsindo ka-p-esiwufunde ngesonto eledlule. (I am going to give you a spelling test about the sound p- we learned last week).

Lecturer: [addressing the whole class] Ngibizela abantu baka p-; abanye bayabhala. (I am giving a spelling test to the $p$-group, the rest of you should be writing your work.)

Lecturer: [talking to the $p$-sound group] Nangu umsindo $k a$ - $p$ - (Here is the $p$-sound). [Writing the sound $p$ - on the board and combining it with the vowels: $p a, p e, p i, p o, p u]$.

Lecturer: Asibhaleni-ke. (Let us start writing).

Lecturer: [giving the students the first word] Ipasi (a pass) [She repeated this word 4 times. As the other students were writing this word, one of the girls stood up, went to the board and looked closely at the syllables $p a, p e, p i, p o, p u$. Seemingly, she was looking for the sound $p a$. As she was doing so, she was sounding out the syllable $p a$.] 
Lecturer: Okay. Number 2, Izipopolo. [She repeated this word 4 times as well. Again, as the other students were writing this word, two male students stood up, went to the board and looked closely at the syllables $p a, p e, p i, p o, p u$. One of them kept on sounding out the syllable $p o$.] In an interview I had with the lecturer, she indicated: Ingane kufanele iwazi amaletters; ikwazi ukubhala amasyllables nokuwahlanganisa ukwakha amagama. Ingane engakwazi lokho iba nenkinga yokukopisha ebhodini noma usuthi uyayisiza kuba nzinyana. (Students should know the letters).

One of the lecturer said the students should know the syllables and how to combines them to form words. She said students who do not know these things have a problem. They cannot copy work from the board, and sometimes it becomes difficult to help them copy from the board). The fact that the lecturer believed in the development of sub-word and word skills was also evidenced by the writing exercises she assigned to the students. I observed that since it is the 8th month of the academic year, most of the students' writing exercises were mainly syllables, words, and only a few exercises were sentences. I noticed from the students' books that there was no writing that was generated by the students regardless of how it looked like. In brief, I think the lecturers was concerned about getting things right; there was no room for writing that allowed the students to use inventive spelling to show what they knew about sounds.

Evidently, the lecturers seemed to believe that developing students' oral language fluency and reading fluency should be the main components of teaching isiZulu. Through the recitation, repetition of grammatical structures, and repeated correction of the students' oral reading when they read the texts aloud, the lecturer supported the students' oral language fluency and reading fluency. This skills-based instructional approach extended to writing: the lecturer used writing as a tool to reinforce the language and literacy knowledge the students had learned. The students did not engage in activities where they explored their ideas and identities nor did they write to discuss knowledge about a topic. In addition, the discussion showed that the lecturers incorporated IsiZulu, the students' L2, to make the input accessible and comprehensible to the students. Along with IsiZulu, the lecturer also employed other strategies, including gestures, demonstrations, students' background knowledge and experiences, albeit to varying degrees. 
Furthermore, this discussion showed that the lecturers' instructional practices did not occur in a vacuum but occurred within a nested context of the larger sociocultural context of the school. In some cases, the lecturer shared similar instructional practices and beliefs about language and literacy learning with the foundation phase lecturers, and in other cases she did not do so. The consistencies and inconsistencies among the lecturers demonstrate that participants across the school contexts interact with one another in dialectical and contradictory ways. In the next section, I turn to the students' interview, still showing how contexts shape and influence language learning in complex and dynamic ways such as in this study.

\subsection{Findings and Discussion}

There were essentially three questions that this study sought to answer. These research questions were motivated by my interest in wanting to understand how isiZulu was being perceived in the university contexts. Data was gathered by means of classroom observations of students in the conversational isiZulu classes, and through semi-structured interview and focus group interviews of the students. I intentionally chose the Indian students doing this module because they are learning isiZulu as a second. This is considered a very important shift in research because it is the first time it is happening. The motivation for this sample was discussed in chapter four. As a qualitative researcher, I seek to understand the phenomenon as it occurs in broader context. In

the case of this study, The school of Education, Conversational isiZulu students were purposely selected because it is where the researcher has been a student for the past three years. I attempted to conclude the research by breaking down the results according to the researcher's questions.

\subsubsection{Results}

Results show that all the sampled students speak English at home. Concerning language spoken with friends at home and at play, all the students indicated that English was the only language they used for communication.

The results show that the majority of students understood when IsiZulu little when used as the medium of instruction in the class. Hence, students' responses to the interview concerning their language preference in reading, speaking and writing showed that: 
- That the majority of students interviewed enjoyed learning conversational isizulu, but when it came to speaking, they mainly speak English to their peers.

- More respondents indicated that students preferred and enjoyed to learn conversational isiZulu

- The greater percentage of those who responded indicated that parents also wanted their children to learn the module.

- Various reasons were given by students for the language preferred as their home language.

Perceptions and attitudes of students in Conversational isiZulu classes were assessed on the basis of their language preferences in reading, speaking and writing. The general mentality among the participants was that students were enjoying learning an additional language at the university, while they mainly liked to speak in IsiZulu.

However, on a more positive note towards L1, the study found that students liked to speak an additional language because of the linguistic landscape of South Africa. One first-year student, Sinead van Niekerk (not real name) told the researcher that the Zulu module was enjoyable. "It was hard but I adjusted. I did Zulu for a year in primary and it made me want to learn more," said van Niekerk.

These correspond with what the literatures pointed out according to Genesee (1989) that "The most proficient bilinguals mix the most and in the most sophisticated ways without violating the rules of either language. It is normal for children growing up in these communities to mix their languages extensively because they are simply learning the patterns of communication that are common in their community. It can be difficult and unnatural, if not impossible, to keep the languages completely separate. If most people in the children's wider community use only one language, the children will eventual learn the monolingual patterns."

It was surprising that the facts emanating from the data shows an overwhelming acceptance of this module by the students who were interviewed. All the students interviewed agreed that it was enjoyable and interesting to learn the module and the felt in it the right decision for the University to make it compulsory for them because it is so important for them to speak the language spoken by majority of South Africans since they will end up becoming teachers in the 
classrooms and this will definitely come into play to help them in teaching learners who may not be able to understand English language.

\subsection{Conclusion}

This chapter has presented and analyzed the responses from the participants in order to obtain a better understanding of the learners' responses towards the teaching of isiZulu at an independent school. In here, participants viewed isiZulu as not being seen as having the same status as English. IsiZulu was seen as having a low status; hence it was not seen as a language of value in society. However, most the participant agreed that they enjoyed learning the module and admit that they wish they can do it to final year of their study. 


\section{CHAPTER SIX}

\section{SUMMARY, CONCLUSIONS AND RECOMMENDATIONS}

\subsection{Summary}

The purpose of this study is to assess the students' perception of the introduction of conversational isiZulu as a compulsory module in a South African university. It can be said that the learning of conversational isiZulu is effective and successful according to the participants because of the support giving to the participants in the university. For the purpose of the study, I was interested in finding out what were the ten focal students' perceptions of being taught in and assessed in IsiZulu. It is also important to ponder what we can learn from their perceptions. In addition, I sought to understand the impact of the home language and language policy implication of the university on the ten focal students, and also establish if there were any tensions between the policy and the second language they are learning at school, and most importantly, the meanings of the tensions for the students' language learning at school. Throughout the study, I tried to show how the socio-political and cultural factors and the university language policy shaped the students' learning of the new language in the university.

The study found that the participants wanted the integration of indigenous languages to take place at the school; however they indicated that for the integration to be effective changes in policy, curriculum and the school environment had to change. The study found that the participants felt that the language policy was not fully meeting their needs because though isiZulu was a subject at the school, it was however not promoted. The study found that the policy to a certain degree did not adhere to the principles as stated in the Constitution that:

Indigenous languages 'shall be the official South African languages at national level, and conditions shall be created for their development and promotion of their equal use and enjoyment'.

The study found that indigenous languages were not equally used and promoted at the school. Baker (2001) argues that in South Africa, our history is riddled with issues of power, prejudice, discrimination, marginalization and subordination. Baker (2001) further argues that in order to 
build a better South Africa, the past inequalities must be addressed and effectively dealt with. In dealing with the past therefore, there is a need for the education system to effectively deal with past issues in order to make way for the integration of indigenous languages in South African schools.

In this research, I was guided by Cummins second language acquisition theories. Using data collected from the participants at the university, I found that while the home context limited the development of students' bilingualism, the university context offered a better context for the students to enhance their bilingual skills. At the home, the students were exposed to limited texts and limited opportunities to engage with the texts and use their languages in meaningful ways. On the other hand, the students' lecture rooms seemed to provide the students with diverse texts that encouraged them to use languages in flexible ways as they made sense of the language learning. These findings raise questions about what lecturers and researchers can do in order to ensure that bilingual students in South Africa and in similar contexts receive literacy instruction that addresses their needs and sustains bi/multilingualism in these contexts.

\subsection{Recommendations}

After reflecting on my findings, I offer the following recommendations which are based on the findings of this study that I hope may help:

a. Learners noted that there is not much done at the school to promote isiZulu. It is therefore recommended that the school establish isiZulu committees that will be responsible for establishing programs that will promote the use of isiZulu at the school. The school can do this by having open communication with the students and the parents in order to establish what the needs are and try to accommodate these needs in the established isiZulu programs.

b. Learners raised concerns about the time allocated for the teaching of isiZulu and the classrooms not accommodating enough. It is recommended that isiZulu timetable be revised by school timetable boards at the school and changes be made to prioritise the time allocated for the teaching of isiZulu. 
c. The use of isizulu at the school should not only be confined to the classroom but students should be offered an opportunity to speak isiZulu as this can also give students of different races an opportunity to learn the language as well. It is recommended that schools should consider the impact that their policies have on the students' impression about language. It is also recommended that the school should be more sensitive towards the matters relating to language.

d. There was a strong sense from the students that isiZulu is not given any value in society. Students noted that isiZulu is not viewed as a language that can offer one better employment opportunities. It is recommended isiZulu must be made as a requirement in the job market, this way educational institutions will ensure that isiZulu gets space and increased time in the curriculum.

e. students are cognizant of the dominance of English and are aware of how English influences their lives both at school, at home as well as socially. These findings present a challenge in that they show how students have come to view the boundaries created by the dominance of English as natural. The findings indicate that some students view the dominance of English as normal hence isiZulu is not perceived as normal because it will not, as Deizao noted "open opportunities globally".

These findings support Bourdieu's argument that languages are valued or devalued according to the power vested in their users (Bourdieu, 1993, p.7). It is recommended therefore that, for the language of isiZulu to be accepted, it has to be seen as an appropriate language that has value by those in power.

Currently, the African Languages Research Institute (ALRI) is making great strides (Chimhundu, 2003; Magwa, 2007) to promote indigenous languages standards through sub-projects which involve making monolingual mother tongue dictionaries. Unless there is attitude change at all levels of society, and strong government intervention, the work done by ALRI might be a futile exercise.

There is a need for further research on how to solve the current problem on implementing a mother tongue policy at the Higher education in South Africa. And it seems there is no imminent solution in sight, because twenty years after independence, some institutions still have negative attitudes towards learning in the L1, despite benefits offered by mother tongue instruction. 
Furthermore, this research is necessary because it contributes on how South Africa as a nation can take advantage of additive bilingualism rather than viewing it as a subtractive bilingualism which undermines learning at the L1 level. Hence, the scope of this research should also extended to how skills can be enhanced between the L1 level and the L2 level, considering that some studies show that the transfer is not automatic (McLaughlin, 1987; Roller, 1988).

Finally egalitarian multiculturalism captures fully the spirit behind the universal declaration of human rights of the persons belonging to national, ethnic, religious, and linguistic minorities and of linguistic rights. It is this culture of democracy and the theory of egalitarian multilingualism that South Africa tries to build on and to promote. I believe that Egalitarian multilingualism will adequately cater for the existence of official languages in a polity. It now calls for the proper handling of South Africa multilingual society.

\subsection{Need for Further Research}

After the review of this study and the facilitated research, recommendations for a future study exist. This research has just briefly touched upon the vastness of the learning of an indigenous language in higher education being used as tools for student retention rates, student success rates, student completion rates, and student learning outcomes

From the literature review and the results of this study it is recommended the future research should focus on because during the course of the study, the researcher realized that there are many aspects that were not covered in the research. Some of it is the link that shows that learning conversational isiZulu contributes to students' success and it would be impossible to include them all in this study because the study was focused on students' perception of the introduction of IsiZulu as a compulsory in the university.

\subsection{Conclusion}

The review of literature provides ample answers and examples to the research questions. The review of literature indicates there are many factors that need to be present to have an effective use of indigenous language in instructions, for example, choosing the right model, selecting appropriate instructors, campaigns, creating the right synergy of structure, learning, and funding, 
etc. Keeping all these factors in mind, the researcher attempted to use the relevant data from the study to answer the research questions.

I would argue after going through the data made available to me through interview and observation that there is a high degree of acceptance by students who are learning conversation IsiZulu at Edgewood campus of University of KwaZulu-Natal irrespective of their culture, ethnicity and identity. In short, the majority of respondents in this study indicated that they favoured learning conversational isizulu as a compulsory module in the university and as the language of instruction. 


\section{REFERENCES}

Adegbija, E. E., (1994). Language Attitudes in Sub-Saharan Africa: A Sociolinguistic Overview. Clavedon, Philadelphia: Multilingual Matters.

Alexander. N. (2005). Language, Class and Power in Post-Apartheid South Africa. Harold Wolpe memorial lecture.

Altarriba, J. \& Soltano, E. G. (1996). Repetition, Blindness and Bilingual Memory: Token Individuation for Translation Equivalents. Memory and Cognition.

Asfaha, Y. M., Beckman, D., Kurvers, J., \& Kroon, S. (2009). L2 reading in multilingual Eritrea: The influences of L1 reading and English proficiency. Journal of Research in Reading, 32(4), $351-365$.

Babbie, E.R. (2004). The Practice of Social Research $10^{\text {th }}$ Edition.USA: Wadsworth.

Baker, C. (1988). Key Issues in Bilingualism and Bilingual Education Clevedon: Multilingual Matters.

Bamgbose, A. (1991). Language and the Nation. The Language Question in Sub-Saharan Africa.

Barkhuizen, P. (2005). Language-in-education policy: students' perceptions of the status and role of Xhosa and English. System 30 (2002) 499-515. Department of Applied Language Studies and Linguistics, University of Auckland, Private Bag 92019, Auckland, New Zealand.

Bassey, M (1999). Case study research in educational settings. Berkshire: Open University Press.

Best, J. W. and Kahn, J. V. (1993). Research in Education. Boston, Allyn and Bacon.

Bialystok, E. (2001). Bilingualism in development: Language, literacy, and cognition. New York: Cambridge University Press.

Bialystok, E., McBride-Chang, C., \& Luk, G. (2005). Bilingualism, language proficiency, and learning to read in two writing systems. Journal of Educational Psychology, 97(4), 580-590.

Blanche, T.M \& Durrheim, K. (1999). Research in practice. Cape Town: UCT Press.

Bloomfield, L. (1933). Language. New York: Holt. 
Borich, G.D. and Tombari, M.L. (1997). Educational Psychology: A Contemporary Approach. New York, Longman.

Břenková. R. (2007). Teacher's Usage of the Mother Tongue versus English at the Level of Young Learners Thesis. Masaryk University in Brno, Faculty of Education, Department of English Language and Literature.

Brock-Utne, B. (2012). Language policy and science: Could some African countries learn from some Asian countries? International review of education. 58: 481-503.

Buck, M., Lambert, W. E. \& Tucker, G. R. (1976). Cognitive and Attitudinal Consequences of Bilingual Schooling: The Saint Lambert Project through Grade Six. International Journal of Psycholinguistics.

Calkins, L. M. (1994). The art of teaching writing. Portsmouth, NH: Heinemann

Carroll, J. B. (1981). Twenty-Five Years of Research on Foreign Language Aptitude. Individual Differences and Universals in Language Learning Aptitude. Rowley, MA: Newbury House

Chaudron, C. (1998). Second Language Classrooms. Research on Teaching and Learning. Cambridge, Cambridge University Press.

Chick, K., \& McKay, S. (2001). Positioning learners in post-apartheid South African schools: A case study of selected multicultural Durban schools. Linguistics in Education, 12(4), 393-408.

Chimhundu, H. (ed) (2003). African Languages Research Institute (ALRI) Report on the Retreat to Review the Allex Project. Harare, University of Zimbabwe.

Cleghorn, A. (1992). Primary Level Science in Kenya. Contributing meaning through English and Indigenous Languages. Qualitative Analysis Studies. Vol 14 p. 311

Cohen, L., Manion, L. \& Morrison, K. (2011). Research Methods in Education. (7 $7^{\text {th }}$ ed.) London: Routledge.

Collier, V. (1987). How long? A synthesis of research on academic achievement in a second language. TESOL Quarterly, 23. 
Conduah. N. A. (2003). Introducing an African Language for Teaching and Learning at the University of Witwatersrand. University of Witwatersrand, South Africa. Nordic Journal of African Studies 12(3): 245-264 (2003)

Constitution of the Republic of South Africa. (1996). Retrieved from http://www.info.gov.za/documents/constitution/1996.

Creswell, John (2009). Research Design; Qualitative and Quantitative and Mixed Methods Approaches. London: Sage. ISBN 978-1-4522-2609-5.

Cummins, J. (1979). Linguistic interdependence and the educational development of bilingual children. Review of Educational Research, 49(2), 222-251.

Cummins, J. (1981). The role of primary language development in promoting educational success for language minority students. In C. F. Leyba (Ed.), Schooling and language minority students (pp. 3-49). Sacramento. CA: California Department of Education.

Cummins, J. (1984). Bilingual Education and Special Education: Issues in Assessment and Pedagogy San Diego: College Hill.

Cummins, J. (1994). The Acquisition of English as a Second Language, in SpangenbergUrbschat, K. and Pritchard, R. (eds) Reading Instruction for ESL Students Delaware: International Reading Association.

Cummins, J. (1996). Negotiating identities: Education for empowerment in a diverse society. Ontario, CA: California Association of Bilingual Education.

Cummins, J. (2000). Language, Power and Pedagogy: Bilingual Children in the Crossfire. Clevedon: Multilingual Matters.

Cummins, J. and McNeely, S. (1987). Language Development, Academic Learning, and Empowering Minority Students. In Tikunoff, K. Bilingual Education and Bilingual Special Education: A Guide for Administrators Boston: College Hill.

Dawes, L. (1988). Bilingual Children with Special Educational Needs. London, Borough of Redbridge Language Support Service. 
De Klerk, V. (2002). Language issues in our schools: Whose voice counts? Part 1: the parents speak. Perspectives in Education. 20(1): 1-14.

De Wet.C, (2002). Factors influencing the choice of English as language of learning and teaching (LoLT)- a South African perspective, Department of Comparative Education and Education Management University of the Free state.

Denzin, N.K. (1978). The Research Act: A Theoretical Introduction to sociological methods, 2nd edition. New York: McGraw-Hill (1 ${ }^{\text {st }}$ edition London: Butterworth, 1970).

Department of Education (1997). Language in Education Policy. Retrieved from http://www.education.gov.za/Documents/policies/LanguageEducationPolicy1997. pdf

Department of Education (2002). Revised National Curriculum Statement R-9. Retrieved from http://www.education.gov.za/Curriculum/GET/doc/overview.pdf

Dörnyei, Z. (1990). Conceptualizing Motivation in Foreign Language Learning. Language Learning

Dulay, H., Burt, M. and Krashen, S. (1982). Language Two. Oxford, Oxford University Press.

Duminy, P. A. (1975). General Teaching Methods. Cape Town, Longman.

Duskova, L. (1969). On Sources of Errors in Foreign Language Learning. International Review of Applied Linguistics.

Dworin, J. E. (2003). Insights into biliteracy development: Toward a bidirectional theory of bilingual pedagogy. Journal of Hispanic Higher Education, 2(2), 171-186.

Dyanda, C. and Mateta, V. (2001). Developing Handwriting Skills in Children. International Edinburgh, Edinburgh University Press.

Eisterhold, J. (1990). Reading-Writing Connections: toward a description for second language learners. In Kroll, B. (ed) Second Language Writing: Research Insights for the Classroom Cambridge: CUP. 
Ellis, N. C. \& Beaton, A. (1993). Factors Affecting the Learning of Foreign Language Vocabulary: Imagery Keyword and Phonological Short-Term Memory. Quarterly Journal of Experimental Psychology.

Ellis, R. (1997). Second Language Acquisition. Oxford: Oxford University Press.

Fleisch, B. (2008). Primary education in crisis. Why South African schoolchildren in reading and mathematics. Cape Town: Juta.

Fradd, S. \& McGee, P. (1994). Instructional Assessment: an integrative approach to evaluating student performance Reading: Addison Wesley.

Franklin, E. (1999). The fiction writing of two Dakota boys. In E. Franklin (Ed.),

Reading and Writing in more than one language (pp. 955-113). Alexandria, VA: Teachers of English to Speakers of Other Languages, Inc.

Freire, P., \& Macedo, D. (1987). Literacy: Reading the word and the world. South

Hadley, MA: Bergin \& Garvey.

Fyle, C. (1976). The Use of the Mother Tongue in Education in Sierra Leone. In Bamgbose, A. Mother Tongue Education. The West African Experience. London, Hodder and Stoughton.

Garcia, O. (2009). Bilingual Education in the $21^{\text {st }}$ Century: A Global Perspective: London: Blackwell.

Gass, S.M. and Selinker, L. (1994). Second Language Acquisition: An Introductory Course. Hillsdale, NJ/ London: Lawrence Erlbaum.

Gatawa, B.S.M. (1998). Quality-Quantity Dilemma in Education. The Zimbabwean experience. Harare, College Press Publishers.

Genesee, E. (1977). Discussion and Summary. In Hornby, P.A. (1977) Bilingualism. Psychological, Social and Educational Implications. New York, Academic Press.

Goodman, S \& Graddol, D. (1996). Introduction: Redesigning English: New texts, New Identities. Goodman, S \& Graddol, D. London: Routledge. 
Granville, S.; Janks, H.; Joseph, M.; Mpahlele, M.; Ramani, E.; Reed, Y. and Watson, P.(1998) English without guilt: A position paper on language in Education policy for South Africa. In Language in Education. 12 (4) p 254-272.

Gregory, E., Long, S., \& Volk, D. (Eds.). (2004). Many pathways to literacy: Young children learning with siblings, grandparents, peers, and communities. London: RoutedgeFalmer.

Grosjean, F. (1989). The bilingual as a competent but specific speakers-hearer. Journal of Mulitilingual and Multicultural Development, 6(6), 467-477.

Gudhlanga, E. S. (2005). Promoting the Use and Teaching of African Languages in Zimbabwe. Zimbabwe Journal of Educational Research. Vol 17(1) p54-68.

Gutierrez, K., Rymes, B., \& Larson, J. (1995). Script, counterscript, and underlife in the classroom: James Brown versus "Brown vs. Board of Education". Harvard Educational Review, $65,445-471$.

Harley, T. A. (2008). The Psychology of Language: From Data to Theory (3rded).UK: Ashford Colour Press Ltd.

Harmer, J. (2001). The Practice of English Language Teaching. Third Edition. Longman. www.longman.com

Hawes, H. (1979). Curriculum and Reality in African Primary Schools. Essex, Longman.

Heuges, K. (1999). Languages, development and reconstructing education in South Africa. Int. J. of Educational Development 19 (1999) 301-313. PRAESA, University of Cape Town, 6.06 Education Building, Private Bag, Rondebosch, 7700 South Africa.

Heuges, K. (2008). Language Policy and Education in Southern Africa. In May, S. \& Hornberger, N. Volume 1: Language Policy and Political Issues in Education.

Heugh, K (1995). "From Unequal Education to the Real Thing." In K.Heugh, A.P. Siegruhn, \& P. Pluddermann (eds.). Multilingual Education for South Africa, Heinemann, Johannesburg, pp. $42-52$.

Hendricks, M. (2009). Grade-appropriate literacy and South African grade seven learners' classroom writing in English. Early Child Development and Care, 179(3), 271-284. 
Hornberger, H. N. (2010). Language and education: A Limpopo lens. In N. H. Hornberger \& S. Lee McKay (Eds.), Sociolinguistics and language education (pp. 549-564). Bristol:Multilingual Matters.

Hornberger, N, H. (1998) Language Policy, Language Education, Language Rights: Indigenous, Immigrant and International Perspectives. Language in society 27:439-458.

Hornberger, N. H., \& Skilton-Sylvester, E. (2000). Revisiting the continua of biliteracy: International and critical perspectives. Language and Education, 14(2), 96-122.

Hornby, P. A. (1977). Bilingualism. Psychological, Social and Educational Implications. New York, Academic Press.

Howie, S.J. (2008). A historical overview of the IEA's language - related studies leading to the implementation of the Project in International Reading Literacy Studies. In Howie, S.J. \& T Plomp (eds.), Reading achievement: International perspective from IEA's Progress in International Reading Literacy Studies. Paris: Education Research and Evaluation.

Hugo, A. J. (2008). Primary school teachers' opinions of their ESL learners' language abilities. Journal of Language Learning, 42(2), 63-76.

Janks, H. (1992). Language, power and pedagogy. In N. H. Hornberger \& S. Lee McKay (Eds.), Sociolinguistics and language education (pp. 40-61). Bristol: Multilingual Matters.

Jefferies, A. (1996). "Linguistics and Development". A paper presented at University of Zimbabwe Faculty of Education's International Conference on Education and Development: Strategies for the 21st Century. 26-29 September. Harare International Conference Centre.

Kamwendo G.H (2010). Denigrating the local, glorifying the foreign: Malawian language policies in the era of African Renaissance, International Journal of African Renaissance Studies Multi-, Inter- and Transdisciplinary, 5:2,270-282.

Kamwendo G.H, et al (2013). Current Issues in Language planning: On medium of instruction and African scholarship: the case of IsiZulu at the University of KwaZulu-Natal in South Africa, Current Issues in Language Planning,DOI:10.1080/14664208.2013.858014

Kersten, A. W. \& Earles, J, L. (2001). Less Really is More for Adults Learning a Miniature Artificial Language. Journal of Memory and Language. 
Krashen, S (1982). Principles and Practice in Second Language Acquisition. Oxford: Pergamon Press.

Krashen, S. D. (1981). Principles and Practice in Second Language Acquisition. English Language Teaching series. London: Prentice-Hall International (UK) Ltd.

Krashen, S. D. (1985). The input hypothesis: Issues and implications. New York: Longman.

Krashen, S. D. (1988). Second Language Acquisition and Second Language Learning. HemelHempstead: Prentice Hall.

Kroll, B. (1990) Second Language Writing Research. Insights for the Classroom. Cambridge, Cambridge University Press.

Lambert, W. E. (1977). The effects of bilingualism on the individual: Cognitive and SocioculturalConsequences. In Hornby, P. A. Bilingualism. Psychological, Social and Educational Implications. New York, Academic Press.

Lamnek.S (2005). Qualitative Sozialforschung. Lehrbuch. 4. Auflage. Beltz Verlag. Weihnhein, Basel.

Langa, M. and Setati, M. (2006). "Students' views on the use of home language for learning." Paper presented at the 14th Annual SAARMSTE Conference, University of Pretoria.

Lapan, S.D., Quartaroli, M.T., \& Riemer, F.J., (editors). (2012). Qualitative Research: An introduction to methods and designs. San Francisco: Jossey-Bass.

Leedy, P.D., \& Ormrod, J.E., (2005). Practical Research: planning and design. ( $8^{\text {th }}$ ed.). New Jersey: Pearson.

Lemlech, J. K. (1994) Curriculum and Instruction Methods for the Elementary and Middle School. New York, Macmillan.

Lincoln, Y., \& Guba, E. (1985). Naturalistic enquiry. Thousand Oaks, CA: SAGE.

Mackay, R. (1991) Embarrassment and hygiene in the classroom ELT Journal 47/1 Oxford: OUP 
Magwa, W. (2007). Kusimudzira Mutauro neTsika dzeVaShona muZimbabwe. Monograph Series No. 73. The Centre for Advanced Studies of African Society (CASAS) Cape Town, SED Printing Solutions.

Marree, K. (Ed.) (2012). First Step in Research. Pretoria: Van Schalk Publishers.

Mavhunga, P.J. (2008). Africanising the School Curriculum: A case for Zimbabwe. Zimbabwe

Mazrui, A. A. \& Mazrui, A.M., (1995). Swahili state and society: political economy of an African language.

London/Nairobi: James Currey; East African Educational Publishers.

McLaughlin, B. \& Heredia, R. (1996). Information-Processing Approaches to Research on Second Language Acquisition and Use. London: Academic Press

Mclaughlin, B. (1987). Theories of Second Language Learning. New York: Routledge, Chapman and Hall, Inc.

McMillan, J.H. \& Schumacher, S. (2006). Research in education: Evidence-Based Inquiry. (6th Ed.). Boston: Pearson Education.

Merriam, S.B. (1998). Qualitative research and case study applications in education: a conceptual introduction. San Francisco: Jossey-Bass.

Mesthrie, R \& Hromnik, J, (2011). Eish but is it English? Celebrating the South African variety; Cape Town; Zebra press.

Mesthrie, R, Pheiffer, R, Satyo, S \& Gowlett, D (1995). Languages and Social History, studies in South African Sociolinguistics: Cape Town, David Philip Publishers

Mitchell, R. and Myles, F. (1998). Second Language Learning Theories London: Edward Arnold

Mitchell, R. and Myles, F. (2004). Second Language Learning Theories (2nded).London: Edward Arnold.

Miti, M. (1995). The Problem of establishing initial literacy in an L2: The case of Zambia. Education for Africa. 1(1) p3 
Mqgwashu, EM. (2007). "Language and the Postcolonial Condition". University Of Kwa-Zulu Natal. Vol 13. No.1

Murry, J. and Smith, F. (1988). Language Arts and the Learner. Melbourne, Mcmillan.

Muthwii, M. J. (2004). Language of instruction: A qualitative analysis of the perceptions of parents, pupils, and teachers among the Kalenjin in Kenya. Language, Culture, and Curriculum, 17(1), 15-32.

Mwamwenda, T.S. (1996). Educational Psychology. An African Perspective. Durban, Butterworths.

Ndamba, G. T. (1999). Discrepancy between the official language policy and implementation at infant level. M. Ed Dissertation. Unpublished. University of Zimbabwe.

Nel, N. (2004). Second language difficulties in a South Africa context. In Elandsbery, D. Kruger and N. Nel (eds) Addressing barriers to learning: a South African perspective Pretoria Van Schalk.

Newmar, L. (1966). How Not to Interfere with Language Learning. Cognitive Science

Ngara, E.A. (1982) .Bilingualism, Language Contact and Language Planning. Proposal for Language Use and Language Teaching in Zimbabwe. Gweru, Mambo Press.

Ngugi wa Thiong'o (1986.) Decolonising the Mind. The Politics of Language in African Literature. Harare, Zimbabwe Publishing House.

Ngwenya, T. (2012). The North-West University language policy: A glimmer of hope and flashes of red light. Language matters, 43 (2): 221-239.

Nkosi,Z.P (2014): Postgraduate students' experiences and attitudes towards isiZulu as a medium of instruction at the University of KwaZulu-Natal, Current Issues in Language Planning, DOI: $10.1080 / 14664208.2014 .915456$

Nondo, S. J. (1996). The main problems faced by students whose mother tongue are other Zimbabwean African languages in learning Ndebele. University of Zimbabwe, Unpublished. 
Norton B, (2007). Critical literacy and international development.-Critical Literacy: Theories and practices volume $1:(1), 6$

Obanya, P. (1985). Teaching Methods Across the Curriculum. London, Billing and Sons Ltd.

Obondo, M. A. (2007). Tensions between English and mother tongue in post-colonial Africa. In J. Cummins \& C. Davidson (Eds.), International handbook of English language teaching (pp. 37-50). New York: Springer

Otto, D. (1997). First Language Maintenance in a Second Language Context. Paper presented at the Regional Conference on Early Childhood Education in Higher Education: The way forward. Kadoma, Zimbabwe.

Papagno, C., Valentine, T. \& Baddeley, A. (1991). Phonological Short-Term Memory and Foreign Language Vocabulary Learning. Journal of Memory and Language

Reddy. S. P.(2012). Importance of English and Different Methods of Teaching English .Journal of Business Management \& Social Sciences Research (JBM\&SSR) ISSN No: 2319-5614 Volume 1, No.3, December 2012

Republic of South Africa (RSA) 1996(a). Constitution of the Republic of South Africa Act No. 108 of 1996. Government Gazette Vol. 378, No 17678. Pretoria. Office of the President.

Republic of South Africa (RSA) 1996(b). South African Schools Act. Act No. 84 of 1996. Government Gazette, Vol. 377, No. 17579. Cape Town: Office of the President (No. 1867).

Reyes, M. L. (2001). Unleashing possibilities: Biliteracy in the primary grades. In J. J. Halcon \& M. L. Reyes (Eds.), The best of our children: Critical perspectives on literacy for Latino students (pp. 96-121). New York: Teachers College Press.

Robinson, C. (2007). Issues of multilingualism in adult literacy. In Report of the International Workshop on Mass Literacy Campaign as a strategy for achieving the EFA and MDGs on education in Nigeria (pp. 59-73). Abuja: UNESCO.

Robinson, C.D.E. (1996). Language use in Rural Development. An African Perspective. New

Robinson, P. (2001). Individual Differences, Cognitive Abilities and Aptitude Complexes. Second Language Research 
Roller, C. (1988). Transfer of Cognitive Competence and L2 Reading in a Rural Zimbabwean Primary School. TOSEL Quarterly. 22 p. 303-319.

Roy-Campbell, Z.M. (1996). "A Neglected Pillar of African Education: The Language of Schooling." Paper presented at the First Annual Conference of the Zimbabwe Languages Association. 10-12 December. Harare.

Rwambiwa, J.P. (1996). "Indigenous Languages: An Answer towards economic independenceA Simpler case for Zimbabwe. Towards Capacity Building in Science and Technology." Paper presented to the 5th Symposium of the Research Council of Zimbabwe. 24-26 September in Harare.

Sailors,M.,Hoffman,J.V \& Matthee,B. (2007). South African schools that promote literacy learning with students from low-income communities. Reading Research Quarterly, 42(3), 364387.

Saville-Troike, M. (1982). Languages in Society. The Ethnography of Communication. An Introduction. Oxford, Basil Blackwell Ltd.

Saville-Troike, M. (2006). Introducing Second Language Acquisition. Cambridge: Cambridge University Press.

Setati, M. (2005). "Access to Mathematics versus access to the language of power: The struggle in multi-lingual mathematics classrooms" Paper presented at the 4th International Conference on Mathematics Education and Society. Australia, July.

Sharma, S. R. (1994). Methods of Educational Research. New Dehli, Annol.

Sharpe, K. (1992). Communication, Culture, Context, Confidence: The Four Cs of Primary Modern Language Teaching. Language Learning Journal.

Silverman, D. (2005).Doing qualitative research. $\left(2^{\text {nd }}\right.$ ed.)Thousand Oaks, CA: Sage Publications.

Simons, H. (2009). Case study Research in Practice. London: Sage Publications. 
Smith. M. (2010). The language challenge: The Language Challenge in the classroom: serious shift in thinking and action is needed. Home-Language Project

Sprosty, L. (1995). Teaching the Language Arts in the Primary School. Gweru, Mambo Press.

Thomas, G (2001). How to do your Case Study (Thousand Oaks: Sage, 2011).

Thomas, G (2011). A typology for the case studies in social science following a review of definition, discourse and structure. Qualitative Inquiry, 17, 6, 511-521

Thompkins, G.E. and Hoskisson, K. (1995). Language Arts. Content and Teaching Strategies. London, Prentice-Hall, Inc.

Tibategeza, E \& Du Plessis (2012). Language in education policy development in Tanzania: An overview. Language matters, 43 (2): 184-201

Travers, J.F., Elliott, S.N. \& Kratochwill, T.R. (1993) Educational Psychology. Effective Teaching. Effective Learning. Oxford, Brown and Benchamark.

UNESCO (1953). The use of vernacular language in education. Monographs on Fundamental Education.

Van der Walt, C. (2004). The Challenge of Multilinguism: in response to the language policy for higher education South African Journal of Higher Education 18(1): 140-152.

Wallwork, J. F. (1985). Language and Linguistics. An Introduction to the Study of Language. Oxford, Heinemann.

Webb, V (2012). Managing multilingualism in higher education in post 1994 South Africa Language matters, 43 (2): 202-220.

White, L. (2003). Second Language Acquisition and Universal Grammar. Cambridge: Cambridge University Press

Whitehead, M. R. (1997). Language and Literacy in the Early Years. London, Paul Chapman.

Yin, R.K (2009). Case study Research: Design and Methods (fourth edition).thousand Oaks, C.A: Sage.York, Mouton de Gruyter. 
York-Barr, J. \& Duke, K. (2004). What do we know about teacher leadership? Findings from two decades of scholarship. Review of Educational Research, 74(3), 255-316. 


\section{APPENDIX 1}

\section{Informed consent letter}

Dear student

Education Faculty

College of Humanities,

University of KwaZulu-Natal

Edgewood Campus

10 Oct, 2014

\section{INFORMED CONSENT LETTER}

My name is Chinekpebi Anyanwu and I am a M.Ed. candidate studying at the University of KwaZuluNatal, Edgewood campus, South Africa. I am conducting a study Assessing student's reception of conversational isiZulu as a compulsory module in a South African university.

To gather the information, I am interested in having a conversation with you, making references to your experiences in this module.

I am kindly requesting you to be participant in this study by answering all the questions in an interview schedule

This interview is to gather information on the level of students' reception of compulsory IsiZulu in this university. Your participation in this study will help in providing useful information which may inform the university about what to modify in the module if need be. Information provided will be treated with confidentiality and pseudonyms will be used. Your personal information is not required so that confidentiality can be assured. Participation in this study is voluntary and you will have a choice to withdraw from the study for any reason, anytime if you so wish without penalties

Should you encounter any problems during this research project, please feel free to contact my supervisor using the following details: Prof Ayub Sheik at 0312603138

In addition, should you have any queries please feel free to contact me using the following contact details: Email: chinadeca@yahoo.com Cell: 0730131225 
If you agree to take part in this project, please complete, sign and return the declaration form below back to me

\section{DECLARATION}

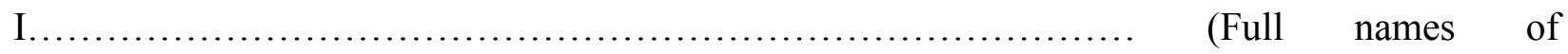
participant) hereby confirm that I understand the contents of this document and the nature of the research project, and I consent to participating in the research project.

I understand that I am at liberty to withdraw from the project at any time, should I so desire.

SIGNATURE OF PARTICIPANT

DATE 


\title{
APPENDIX II
}

\section{Gate keeper note}

\author{
Education Faculty \\ College of Humanities, \\ University of KwaZulu-Natal \\ Edgewood Campus.
}

Hi

\section{Dear Professor Kamwendo}

I hereby request your permission to conduct a research study located in the School of Education at UKZN. This research will be for my M.Ed. study. My research topic is: Assessing student's reception of conversational isiZulu as a compulsory module in a South African university. My finalised research proposal, completed under the supervision of Prof. Ayub Sheik, is hereby attached, as are the templates for informed consent.

In the course of this study I will be examining students' receptions of conversational isiZulu as a compulsory module. While I will not name the University of KwaZulu-Natal in my study, it could be inferred by prospective readers who know about this module at this institution.

In my data generation, I will have audiotaped conversations with students' school of education at UKZN. Formal consent will be obtained from these colleagues and they will not be identified by name in the study.

Thank you

Chinekpebi Anyanwu 


\section{$\underline{\text { Declaration }}$}

"Assessing students' perception of conversational isiZulu as a compulsory module in a South African University".

\section{I. .}

....(full names) hereby declare that I have read and understood the contents of this document and the research project, and I give consent to Mr Anyanwu in using lecturers, tutors and students that are concerned in the Conversational IsiZulu for Undergraduate Students module as participants in his study.

I also understand that the participants are given liberty to withdraw from the project at any time without any penalty should the need be. 


\section{APPENDIX III}

\section{Sample of interview schedule questions for conversational isiZulu students}

1. What is your Name?

2. How old are you?

3. What is your gender?

4. How do you linguistically identify yourself, and why?

5. What level of study are you in this university?

6. Do you think it is a good idea to introduce conversational isiZulu in Edgewood campus

7. What are the challenges you are facing learning conversational IsiZulu as a a nonnative speaker?

8. Are there any other problems you are experiencing if any in learning of conversational isiZulu?

9. Do you think that the teaching and learning resources are adequate and interesting in learning this module?

10. What more do you think could be done to facilitate the learning of isizulu in the campus

11. What are your general experiences of learning conversational isizulu, Give an explanation

12. Was it too difficult or easy?

13. Was enough time allotted?

14. Are necessary language and conceptual background skills taught?

15. Do you have anything to add with regard to Conversational isiZulu?

16. Is there any benefit in learning an additional language? 


\section{APPENDIX IV}

\section{Turnitin Originality Report}

Topic: Assessing the Students Reception of Conversational IsiZulu as a compulsory module in a South African University. By Anyanwu Chinekpebi

From Master's thesis - (Med)

- $\quad$ Processed on 23-Jan-2015 10:14 AM CAT

- ID: 348526460

- Word Count: 39,605

Similarity Index

$7 \%$

Similarity by Source

Internet Sources:

$3 \%$

Publications:

$2 \%$

Student Papers:

$2 \%$ 
cif copywriting \& editing services

witing, proofreading and editing

P.O. Box 86

SEAPOINT

1620

Email: colleenfigg@gmail.com

0769450185

To whom it may concern

Date:

25:12:14

Doc No: chinaThesiscert1

This serves to certify that I, Colleen Figg, of CJF Copywriting \& Editing Services, have proofread and checked the following chapters of the Master's Thesis in Language and Media Studies Education. Titled: Assessing students' Perceptions of conversational isiZulu as a compulsory module in a south African university. By chinekpebi Ngozi Anyanwu

Chapter 1

Chapter 2

Chapter 3

Chapter 5

Chapter 6

Colleen Figg

Proofreader and Copy Editor

South Africa

$$
\text { thank you for using my services }
$$




\section{YAKWAZULU-NATALI}

6 August 2014

Mir Chinekpebi Ngozi Anyanwu 212558676

School of Education

Edgewood Campus

\section{Dear Mr Anyanwu}

Protocol reference number: HSS/0885/014M

Project title; Assessing Students' Reception of Conversational Isizulu as a Compulsory Module in a South African University

Full Approval - Expedited Application In response to your application dated 20 July 2014, the Humanities \& Social Sciences Research Ethics Committee has considered the abovementioned application and the protocol have been granted FULL. APPROVAL.

Any alteration/s to the approved research protocol i.e, Questionnaire/Interview Schedule, Informed Consent form, Title of the Project, Location of the Study, Research Approach and Methods must be reviewed and approved through the amendment/modification prior to its implementation. In case you have:further queries, please quote the above reference number.

PLEASE NOTE: Research data should be securely stored in the discipline/department for a period of 5 years.

The ethical clearance certificate is only valld for a period of 3 years from the date of issue. Thereafter Recertification must be applied for on an annual basis.

I take this opportunity of wishing you everything of the best with your study.

Yours faithfully

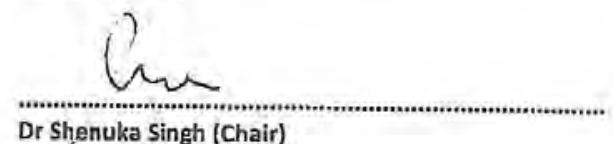

Dr Shenuka Singh (Chair)

$/ \mathrm{pm}$

Cc Supervisor: Prof A Sheik

Cc Academic Leader Research: Professor P Morojele

Cc School Administrator: Mr Thoba Mthembu

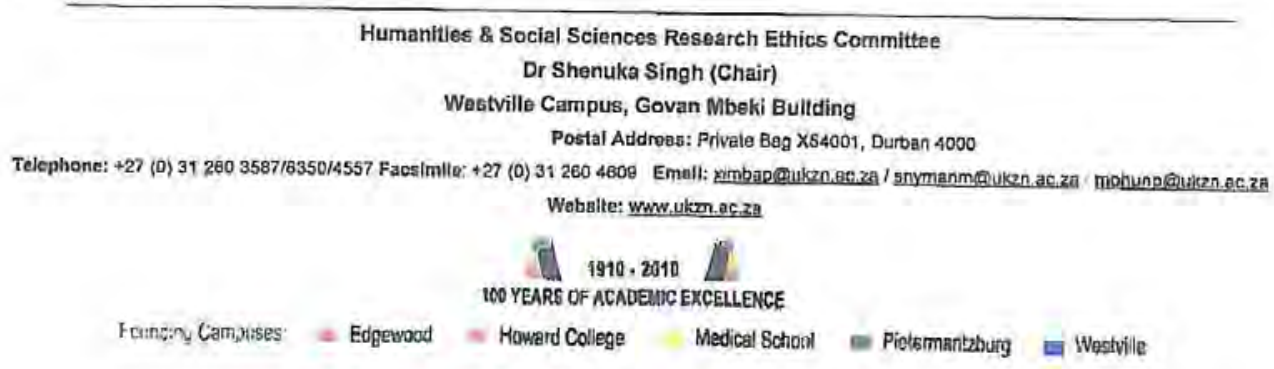

